Edmir Cavalcanti Gurgel Pini NADER

\title{
Avaliação da estrutura familiar com crianças e adolescentes portadores de transtorno bipolar
}

Dissertação apresentada à Faculdade de Medicina da Universidade de São Paulo para a obtenção do título de Mestre em Ciências

Programa de: Psiquiatria

Orientadora: Dra. Sheila Cavalcante Caetano

São Paulo

2012 
Dados Internacionais de Catalogação na Publicação (CIP)

Preparada pela Biblioteca da

Faculdade de Medicina da Universidade de São Paulo

Creprodução autorizada pelo autor

Nader, Edmir Cavalcanti Gurgel Pini

Avaliação da estrutura familiar com crianças e adolescentes portadores de transtorno bipolar / Edmir Cavalcanti Gurgel Pini Nader. -- São Paulo, 2012.

Dissertação(mestrado)--Faculdade de Medicina da Universidade de São Paulo. Programa de Psiquiatria.

Orientadora: Sheila Cavalcante Caetano.

Descritores: 1.Transtorno bipolar 2.Criança 3.Adolescente 4.Família 5.Relações familiares 6.Pais

USP/FM/DBD-187/12 
DEDICATÓRIA 
A meus pais, José Geraldo e Frésia, que me ensinaram a valorizar os laços familiares.

A meu marido, Daniel, pelo amor e insubstituível apoio às minhas decisões.

A meus irmãos, Dominique e Brenno, meus sobrinhos queridos, Felipe, Giovanna, Victor, Helena, Gustavo, meu sobrinho(a) que está a caminho e demais familiares, pelo afeto. A meus amigos, pelo companheirismo. 
AGRADECIMENTOS 
A todas as famílias das crianças e dos adolescentes que participaram desta pesquisa, por confiarem a mim informações muito importantes sobre suas vidas tornando-as as principais motivadoras desta Dissertação.

Às famílias das crianças e adolescentes, sem qualquer doença, que aceitaram participar apenas pelo desejo de ajudar e por entenderem a importância de suas contribuições.

À Dra. Sheila Caetano, orientadora deste estudo, pela confiança, muitas vezes acreditando mais em mim do que eu mesma e não me deixando nunca desacreditar. Ela me deu oportunidade para aprofundar conhecimentos sobre o transtorno do humor bipolar e possibilitou meu aprofundamento tanto na parte clínica quanto na pesquisa, tornando a elaboração deste trabalho muito prazerosa e profícua, devido à sua grande capacidade profissional, generosidade e disponibilidade.

A minha querida amiga e colega do PROMAN e PROTHUIA, Dra. Ana Kleinman, minha gratidão pela confiança e por acreditar tanto em mim como em meu trabalho, estando sempre a meu lado, com palavras de afeto e incentivo.

A Bernardo Gomes, por suas valiosas contribuições, ajuda, suporte, paciência, generosidade e objetividade sempre oportunos.

A todos os colegas do PROTHUIA (Programa de transtorno de humor Bipolar da Infância e Adolescência), Alessandra Bizeli, Ana Maria Teixeira, Carolina Moreira, Guilherme Ferreira, Julio Renó Sawada, Silvia Letícia dos Santos pelas contribuições e apoio ao longo dessa jornada.

Ao Prof. Dr. Beny Lafer, por sua disponibilidade e contribuição tão relevante. A todos os colegas do PROMAN (Programa de transtorno de humor Bipolar), do Instituto de Psiquiatria do HC - FMUSP pelo apoio, suporte, orientações e disponibilidade notáveis. 
A Bernardo dos Santos, por sua colaboração e parceria com seus conhecimentos e suporte, em estatística, muito valiosos.

À Dra. Cristiana Rocca, por sua paciência em me ajudar com dados importantes para o estudo, sendo sempre disponível, acolhedora e incentivadora. Deixo aqui também meu agradecimento pela ajuda de todos os neuropsicólogos envolvidos nesta pesquisa, especialmente Ana Paola Gurgel, Camila Folquitto, Camila Luisi Rodrigues e Everton Duarte.

A Gabriela Zanim e Taís Albuquerque, pelo suporte e pela atenção.

A Eliza Fukushima e Isabel Ataide, pela disponibilidade e precisão nas informações sobre o regimento da pós-graduação.

A Erika H. Hayashi, Maria Umbelina Santos e Tayna Rios, da Biblioteca Dr. Paul Janssen- Instituto de Psiquiatria - HCFMUSP, pela ajuda e presteza.

À querida Profa. Dra. Claudia Bruscagin, da Pontifícia Universidade Cátólica, por sua maneira de ensinar, pela transmissão de seus conhecimentos, por sua presença ao longo de todo o trabalho, sem deixar de me apoiar. A todas as professoras do curso de especialização em Terapia Familiar e de Casal, do Núcleo de Família e Comunidade da Pontifícia Universidade Católica de São Paulo, pelos ensinamentos fundamentais para a vida profissional e para este trabalho.

A meu marido, Daniel, meu agradecimento muito especial por ter sido a pessoa mais próxima a mim durante o desenvolvimento desta Dissertação, muitas vezes me ajudando e sendo o melhor ouvinte e amigo que eu poderia ter. Agradeço seu apoio, paciência e sabedoria em lidar com as dificuldades de maneira sábia e otimista, fazendo tudo parecer muito mais simples.

A meu pai, José Geraldo e minha mãe, Frésia, que me ensinaram os valores tão preciosos que me acompanham vida afora, como pessoa e profissional. Pelo apoio incondicional em todas as minhas decisões e pelo incentivo em meus estudos e minha profissão. À minha querida irmã Dominique e ao querido irmão Brenno, por sempre me apoiarem e estarem ao meu lado, acreditando e me incentivando. 
À família Cavalcanti e Gurgel (ao cunhado Carlos Eduardo, avós, tios, tias, primos e primas), por fazerem a família ser sempre importante e darem grande suporte em muitos momentos.

A Mazé, Lucimar e Seu Marcos, por todos esses anos fazendo parte da nossa família e sempre presentes nos momentos importantes.

A toda a família Pini e Nader (aos cunhados: Luís, Fabio, Rodrigo e Rafael; às cunhadas: Mônica, Fernanda, Bruna e Mariana, tios, tias, primos e primas), por me acolherem desde o começo e estarem sempre interessados em meu trabalho. A D. Izabel Nader, por me motivar com suas histórias, sua sabedoria e seu carinho.

A meus sogros Celina e Charles Nader, por serem pessoas maravilhosas e generosas, sempre me apoiando e vibrando com minhas conquistas.

A minha grande amiga Thais Lapp, pelo incentivo, há três anos, e o constante apoio.

A minhas amigas Camyla Azevedo, Fabiana Alves e Izabella Strenger pela paciência, pelas palavras carinhosas e amigas, pelos auxílios práticos e essenciais ao trabalho.

A Tânia Maria Ramos Fernandes, por ter me introduzido à Terapia Sistêmica e a todo o suporte e ampliação de horizontes que me proporcionou ao longo de tantos anos.

A Maria Emilia Macedo e Marlies Wiest, pela aprendizagem no último ano e pelas tantas ajudas.

A Aileen Daphne Morrell, por ser sempre solícita e ágil em momentos tão importantes. 
Esta dissertação está de acordo com as seguintes normas, em vigor no momento desta publicação:

Referências: adaptado de International Committee of Medical Journals Editors (Vancouver).

Universidade de São Paulo. Faculdade de Medicina. Serviço de Biblioteca e Documentação. Guia de apresentação de dissertações, teses e monografias. Elaborado por Anneliese Carneiro da Cunha, Maria Julia de A. L. Freddi, Maria F. Crestana, Marinalva de Souza Aragão, Suely Campos Cardoso, Valéria Vilhena. 3a ed. São Paulo: Serviço de Biblioteca e Documentação; 2011.

Abreviaturas dos títulos dos periódicos de acordo com List of Journals Indexed in Index Medicus. 
SUMÁRIO 
Dedicatória

Agradecimentos

Lista de tabelas e gráficos

Lista de abreviaturas e siglas

Resumo

Summary

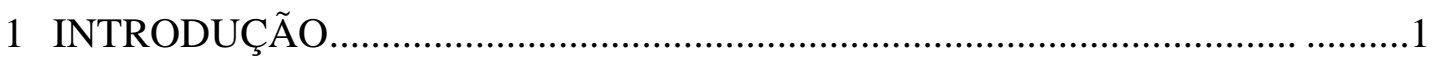

1.1 Transtorno do Humor Bipolar na Infância e Adolescência.............................. 3

1.2 Família com membro com THB ............................................................... 5

1.3 A família compreendida como um sistema ............................................... 8

2 ESCALAS UTILIZADAS EM FAMÍLIAS COM CRIANÇAS E ADOLESCENTES PORTADORES DE THB NA INFÂNCIA E

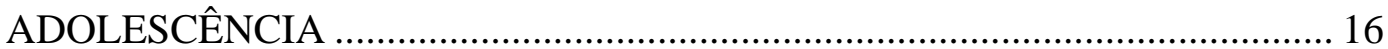

2.1 Inventário de Adjetivos de Emoção Expressa.............................................. 18

2.2 Escala Psicossocial para Crianças em Idade Escolar - Revisada................... 21

2.3 FES - Escala de Ambiente Familiar ............................................................. 23

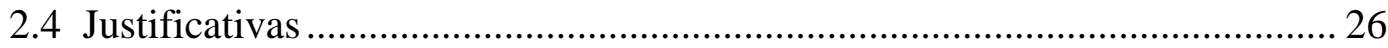

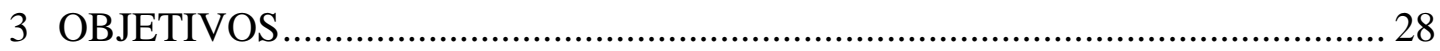

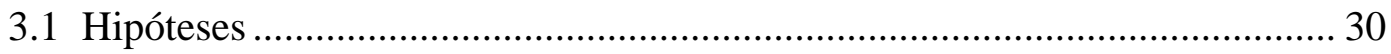

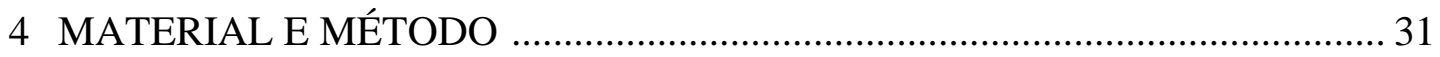

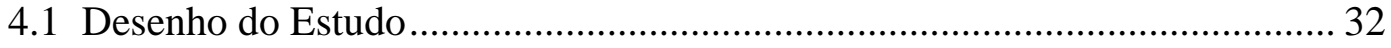

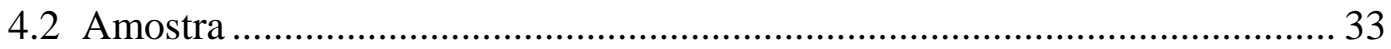

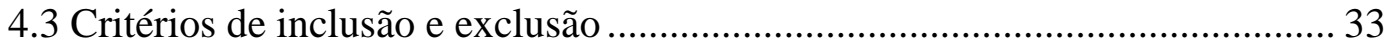

4.3.1 Critérios de Inclusão para todas as crianças e adolescentes ................ 33

4.3.2 Critérios de Inclusão THB............................................................... 34

4.3.3 Critérios de Inclusão Controles ......................................................... 34

4.3.4 Critérios de Exclusão para todas as crianças e adolescentes .............. 34

4.4 Avaliação Clínica ............................................................................................. 34 
4.4.1 Entrevista Psiquiátrica.....

4.4.1.1 Entrevista Psiquiátrica para crianças e adolescentes.

4.4.1.2 Entrevista para Transtornos Afetivos e Esquizofrenia para Crianças em Idade Escolar - Versão Atual e ao Longo da Vida 35

4.4.2 Escalas de Avaliação Clínica. 35

4.4.2.1 Escala de Funcionamento Global da Criança (C-GAS) ...... 35

4.4.2.2 Escala para avaliação de Depressão em CriançasRevisada 36

4.4.2.3 Escala de Mania de Young.................................................... 36

4.4.2.4 Escala de Impressão Global ............................................... 37

4.4.2.5 Escala de Desenvolvimento Pubertal de Petersen ............... 37

4.4.2.6 Escala Socioeconômica e Demográfica das Classes Associação Brasileira dos Institutos de Pesquisas de

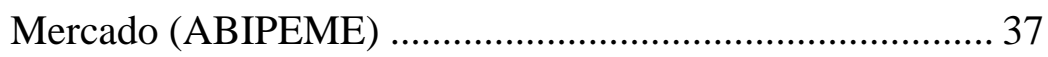

4.4.2.7 WASI - Escala Abreviada de Inteligência de Wechsler ...... 38

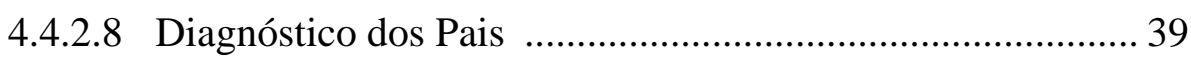

4.4.3 Escalas para Avaliação de Família ..................................................... 39

4.4.3.1 Inventário de Adjetivos de Emoção Expressa........................ 39

4.4.3.2 Escala Psicossocial para Crianças em Idade Escolar Revisada ..... 41

4.4.3.3 FES - Escala de Ambiente Familiar.... 43

4.5 Análise Estatística 44

5 RESULTADOS 46

5.1 Características sócio-demográficas da amostra. 47

5.2 Características clínicas da amostra..... 50

5.3 Avaliação da família. 53

5.3.1 Inventário de Adjetivos de Emoção Expressa ................................... 53

5.3.2 Escala Psicossocial para Crianças em Idade Escolar - Revisada....... 56

5.3.3 FES - Escala de Ambiente Familiar................................................. 70

5.3.4 Análise Discriminante .................................................................... 73 


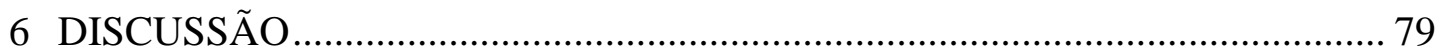

6.1 Características sócio-demográficas e clínicas ................................................. 80

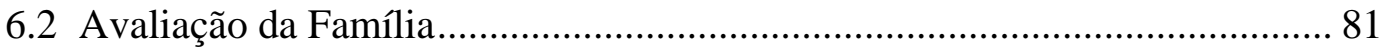

6.2.1 Inventário de Adjetivos de Emoção Expressa .................................... 81

6.2.2 Escala Psicossocial para Crianças em Idade Escolar - Revisada....... 84

6.2.3 FES - Escala de Ambiente Familiar................................................ 87

6.3 A família compreendida como um sistema .............................................. 94

6.3.1 Tratamento: Terapia de Família......................................................... 95

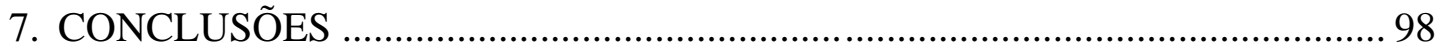

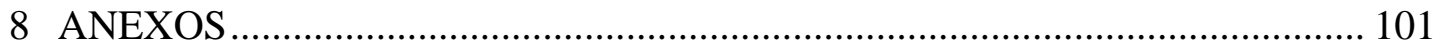

Anexo I - Inventário de Adjetivos de Emoção Expressa.................................... 102

Anexo II - FES - Escala de Ambiente Familiar .................................................. 103

Anexo III - Termo de Consentimento Livre e Esclarecido .................................. 105

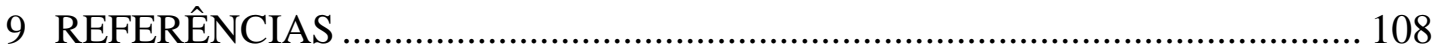




\section{LISTAS}




\section{LISTA DE TABELAS E GRÁFICOS}

Tabela 1 - Dados Sócio-Demográficos do grupo de crianças e adolescentes com THB e crianças e adolescentes sem transtornos psiquiátricos e a análise estatística

Tabela 2 - Variáveis clínicas em crianças e adolescentes com THB 52

Tabela 3- Emoção Expressa (EE) entre parentes de famílias com filhos com THB versus famílias com filhos sem transtornos psiquiátricos com variáveis de controle 55

Tabela 4 - Associação entre nível socioeconômico e Inventário de Adjetivos de Emoção Expressa medido pelo modelo de ANCOVA 55

Tabela 5 - Comparação da Escala Psicossocial para Crianças em Idade Escolar - Revisada com variáveis de controle entre famílias com filhos com THB e famílias com filhos sem transtornos psiquiátricos

Tabela 6 - Comparação da FES pelas variáveis de controle (Média e desvio-padrão) entre famílias com filhos com THB versus famílias com filhos sem transtornos psiquiátricos

Tabela 7 - $\quad$ Associação entre nível socioeconômico e FES medido pelo modelo de ANCOVA 72

Tabela 8 - Pesos padronizados dos preditores para classificação de famílias com crianças e adolescentes com THB obtidos pela análise discriminante

Tabela 9- $\quad$ Parâmetros da Curva ROC Receiver Operating Characteristic

- Característica Operativa do Receptor. 76 
Gráfico 1- Curva ROC para variáveis em que o THB está acima do ponto

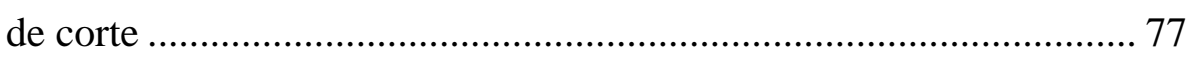

Gráfico 2- Curva ROC para Variáveis em que o THB está abaixo do ponto de corte ......................................................................... 77 


\section{LISTA DE ABREVIATURAS E SIGLAS}

\begin{tabular}{|c|c|}
\hline ABIPEME & $\begin{array}{l}\text { Escala Socioeconômica e Demográfica das Classes - Associação } \\
\text { Brasileira dos Institutos de Pesquisas de Mercado }\end{array}$ \\
\hline ANEP & Associação Nacional de Empresas de Pesquisa \\
\hline CDRS-R & $\begin{array}{l}\text { Children’s Depression Rating Scale - Revised - Escala para } \\
\text { Avaliação de Depressão em Crianças - Revisada }\end{array}$ \\
\hline CFI & $\begin{array}{l}\text { Camberwell Family Interview - Esquema de Entrevista Familiar de } \\
\text { Camberwell }\end{array}$ \\
\hline C-GAS & $\begin{array}{l}\text { Children's Global Assessment Scale - Escala de Funcionamento } \\
\text { Global da Criança }\end{array}$ \\
\hline $\mathrm{CP}$ & Correlação de Pearson \\
\hline CGI & Clinical Global Impression Scale - Escala de Impressão Global \\
\hline Curva ROC & $\begin{array}{l}\text { Receiver Operating Characteristic - Característica Operativa do } \\
\text { Receptor }\end{array}$ \\
\hline \pm D.P. & Desvio Padrão \\
\hline DSM-IV & $\begin{array}{l}\text { Manual Diagnóstico e Estatístico para Transtornos Mentais, } 4^{\mathrm{a}} \\
\text { edição }\end{array}$ \\
\hline EE & Emoção Expressa \\
\hline EUA & Estados Unidos da América \\
\hline FACES - II & $\begin{array}{l}\text { Family Adaptability and Cohesion Evaluation Scale - II- Escala } \\
\text { para Avaliação de Adaptação e Coesão Familiar - II }\end{array}$ \\
\hline $\mathrm{AD}$ & Family Assessment Device - Inventário de Avaliação Familiar \\
\hline
\end{tabular}


FAS

FES

FMSS

IBGE

K-SADS-PL Schedule for Affective Disorders and Schizophrenia for SchoolAge Children - Present and Lifetime Version - Entrevista para Transtornos Afetivos e Esquizofrenia para Crianças em Idade Escolar - Versão Atual e ao Longo da Vida

PSS

PSS-R

QI

SOE

TC

TDAH

TDM

THB

TOC

TOD

WASI

YMRS

Family Attitude Scale - Escala de Atitude Familiar

Family Environment Scale - Escala de Ambiente Familiar

Five Minute Speech Sample - Modelo de Discurso de Cinco Minutos

Instituto Brasileiro de Geografia e Estatística

Psychosocial Schedule for School-Age Children - Escala Psicossocial para Crianças em Idade Escolar

Psychosocial Schedule for School Age Children-Revised

Quociente de Inteligência

Sem Outra Especificação

Transtornos de Conduta

Transtorno de Déficit de Atenção e Hiperatividade

Transtorno Depressivo Maior

Transtorno do Humor Bipolar

Transtorno Obsessivo-Compulsivo

Transtorno Opositor Desafiador

Wechsler Abbreviated Scale of Intelligence - Escala Abreviada de Inteligência de Wechsler

Young Mania Rating Scale - Escala de Mania 
RESUMO 
Nader ECGP. Avaliação da estrutura familiar com crianças e adolescentes portadores de transtorno bipolar [dissertação]. São Paulo: Faculdade de Medicina, Universidade de São Paulo; 2012. 127p.

Em estudos conduzidos nos EUA, o ambiente familiar de crianças com Transtorno do Humor Bipolar (THB) apresentou-se desorganizado, com alta emoção expressa (EE), baixo acolhimento materno, com baixa coesão entre os membros familiares, altos níveis de conflitos, em parentes de crianças e adolescentes com THB comparadas a famílias com crianças e adolescentes sem transtornos psiquiátricos. Propomos avaliar simultaneamente características da comunicação, das relações entre membros e estrutura familiar de crianças e adolescentes com THB em comparação a famílias de crianças e adolescentes sem transtornos psiquiátricos para encontrar qual a variável que melhor diferencia os dois grupos. Foram utilizadas três escalas para esta finalidade: Inventário de Adjetivos de Emoção Expressa (Adjective Checklist) Escala Psicossocial em Idade Escolar - Revisada (Psychosocial Schedule for School Age Children-Revised) e a Escala de Ambiente Familiar (Family Environment Scale - FES). Hipóteses: Famílias de crianças e adolescentes com THB comparadas às famílias de crianças e adolescentes sem transtornos psiquiátricos apresentariam: alto nível de emoção expressa negativa nos familiares de pacientes com THB, de acordo com o Inventário de Adjetivos de Emoção Expressa, menor acolhimento materno segundo a Escala Psicossocial em Idade Escolar - Revisada, menor nível de coesão e maior nível de conflito de acordo com a FES. Coesão seria a variável que melhor diferenciaria os dois grupos. Métodos: Trinta e três (33) famílias foram selecionadas ao preencherem os critérios de inclusão: a) presença de um filho (a) com mais de 6 anos de idade e menos de 18 anos que apresentasse diagnóstico de THB, segundo critérios do DSM-IV. b) Vinte e nove (29) famílias-controle com crianças, adolescentes e parentes de primeiro grau sem transtornos psiquiátricos. Todas as crianças e adolescentes participantes foram excluídas se QI $<70$. Resultados: Famílias com crianças e adolescentes com THB, quando comparadas às famílias de crianças e adolescentes sem transtornos, apresentaram maiores níveis de EE negativa no comportamento do filho (a) em relação à mãe/pai ( $F=98,27, p<$ 0,001) e no comportamento da mãe/pai em relação ao filho (a) ( $F=31,72, p$ < 0,001), menores níveis de EE positiva no comportamento do filho (a) em relação à 
mãe/pai ( $F=51,57, \mathrm{p}<0,001)$ e no comportamento da mãe/pai com relação ao filho (a) $(\mathrm{F}=18,38, \mathrm{p}<0,001)$ segundo o Inventário de Adjetivos de Emoção Expressa. Famílias com crianças e adolescentes com THB apresentaram, comparadas às famílias de crianças e adolescentes sem transtornos psiquiátricos, maiores níveis para tensão materna ( $\mathrm{p}<0,001)$ e paterna (Wald $=8,551, \mathrm{p}=0,003)$ e família não intacta (Wald $=6,999, \mathrm{p}=0,008$ ), segundo a Escala Psicossocial em Idade Escolar Revisada; menores níveis de coesão $(F=10,99, p=0,002)$ e organização $(F=9,37$, $\mathrm{p}=0,003)$ e maiores níveis de conflito $(\mathrm{F}=14,66, \mathrm{p}<0,001)$ e controle $(\mathrm{F}=13,02$, $\mathrm{p}$ = 0,001), segundo a FES. Na Análise Discriminante, EE negativa do comportamento do filho em relação à mãe $(0,798)$, veio em primeiro lugar, depois, EE positiva do comportamento do filho em relação a mãe $(-0,599)$, em terceiro EE negativa do comportamento da mãe em relação ao filho $(0,449)$, em quarto lugar tensão materna da Escala Psicossocial para Crianças em Idade Escolar - Revisada (0,381) e em quinto lugar EE positiva do comportamento da mãe em relação ao filho (-0,362). Também realizamos uma Curva ROC para encontrar pontos de corte nas escalas classificando as famílias como controle ou THB, segundo os níveis de sensibilidade e especificidade. Encontramos os seguintes resultados: em primeiro lugar, temos EE negativa do comportamento do filho em relação à mãe (0,956), depois EE positiva do comportamento do filho em relação à mãe $(0,914)$, em seguida, EE negativa do comportamento da mãe em relação ao filho $(0,869)$, em quarto lugar, EE positiva do comportamento da mãe em relação ao filho $(0,813)$ e em quinto lugar conflito da FES (0,792). Alto nível de EE foi a característica da família que melhor discriminou a estrutura familiar das crianças/ adolescentes com THB das famílias dos controles. As estruturas familiares de crianças e adolescentes com THB apresentaram padrões alterados relacionadas com comunicação, tensão e acolhimento materno/paterno, coesão e conflitos. De acordo com nossos resultados de maior nível de EE nas famílias de crianças e adolescentes com THB, a psicoterapia familiar deve incluir estratégias para melhorar a comunicação.

Descritores: 1. Transtorno bipolar, 2. Criança, 3. Adolescente, 4. Família, 5. Relações Familiares, 6. Pais. 
SUMMARY 
Nader ECGP. Study on the family structure of BD children and adolescents [dissertation]. São Paulo: "Faculdade de Medicina, Universidade de São Paulo"; 2012. 127p.

Studies conducted in the USA have demonstrated that family environments of children with Bipolar Disorder (BD) were disorganized, presenting higher Expressed Emotion (EE), lower maternal warmth, lower cohesion among family members and higher level of conflict compared to families of children and adolescents who had no psychiatric disorder. We proposed to evaluate simultaneously the communication, relationship among members and family structure of BD children and adolescents in comparison with families of children and adolescents who have no psychiatric disorder in order to find the variable that would better differentiate the two groups. Three combined scales were used for this purpose: the Inventory of Expressed Emotion Adjectives - the Adjective Checklist, Psychosocial Schedule for School Age Children-Revised - PSS-R, and the Family Environment Scale - FES. Hypotheses: Families of bipolar disorder children and adolescents compared to families of children and adolescents with no psychiatric disorder would present: higher levels of negative expressed emotion in $\mathrm{BD}$ patients' relatives, according to the Adjectives Checklist; lower maternal warmth according to the Psychosocial Schedule for School Age Children-Revised, and lower level of cohesion and higher level of conflict according to the FES. Cohesion would be the variable which better differentiates the two groups. Methods: Thirty three (33) families were selected as they met the inclusion criteria: a) presence of a child who was between 6 and 18 years old, and had a DSM-IV BD diagnosis. Twenty nine (29) control families composed of children, adolescents and direct relatives with no psychiatric disorder were also included. Children and adolescents who had a $\mathrm{QI}<70$ were excluded. Results: Families of BD children and adolescents, compared to families of children and adolescents with no psychiatric disorder, presented higher negative EE levels regarding the child's behavior towards parents $(F=98.27, p<0.001)$ and the behavior of parents towards their child ( $\mathrm{F}=31.72, \mathrm{p}<0.001)$, and lower levels of positive EE regarding the child's behavior towards his/her parents ( $F=51.57, \mathrm{p}<$ 0.001 ) and parents' behavior towards their child ( $\mathrm{F}=18.38, \mathrm{p}<0.001)$, according to the Adjective Checklist; and higher levels of maternal ( $\mathrm{p}<0.001)$ and paternal (Wald 
$=8.551, \mathrm{p}=0.003$ ) tension and a non intact family (Wald $=6.999, \mathrm{p}=0.008$ ), according to the Psychosocial Schedule for School Age Children-Revised; lower levels of cohesion $(F=10.99, p=0.002)$ and organization $(F=9.37, p=0.003)$ and higher levels of conflict $(F=14.66, p<0.001)$ and control $(F=13.02, p=0.001)$, according to the FES. In the Discriminant Analysis, child's negative EE behavior towards his/her mother (0.798) came first, secondly came the child's positive EE behavior towards his/her mother (-0.599), third, the mother's negative EE behavior towards her child (0.449), fourth, maternal tension according PSS-R (0.381) and, fifth, the mother's positive EE behavior towards her child (-0.362). We also carried out a ROC Curve to identify scale cut-off values, classifying the families as controls or bipolar (BDs), considering the levels of sensitivity and specificity, and we achieved the following results: firstly, we found negative EE behavior of the child towards his/her mother (0.956), then positive EE behavior of the child towards his/her mother (0.914), third, negative EE behavior of the mother towards her child (0.869), fourth, positive behavior of the mother towards her child (0.813) and, at last, conflict measured by FES (0.792). Higher levels of EE were the family characteristic that better discriminate family structures of BD children/adolescents and control families. Family structures of BD children and adolescents present abnormal patterns related to communication, parents' tension and warmth, cohesion and conflicts. According to our results of higher EE in families of BD children and adolescents, family psychotherapy should include strategies to improve communication.

Descriptors: 1. Bipolar disorder, 2. Child, 3. Adolescent, 4. Family, 5. Family Relations, 6. Parents 
1 INTRODUÇÃO 
Os transtornos psiquiátricos são, atualmente, uma área de interesse tanto na medicina quanto na psicologia, dado o grande número de indivíduos que apresentam diagnósticos graves e crônicos, com significativa repercussão em seu meio familiar. Estudos sobre transtornos psiquiátricos na população brasileira ainda são escassos, se comparados com a vasta literatura estrangeira. Constata-se grande dificuldade em encontrar dados na literatura em geral e, especificamente, dados realizados com a população brasileira sobre a família com crianças e adolescentes portadores de transtorno do humor bipolar (THB).

O trabalho a seguir é um estudo utilizando 3 escalas para avaliar nas famílias com crianças e adolescentes com THB, comparadas a famílias com membros sem transtornos psiquiátricos emoção expressa, acolhimento materno e paterno, tensão materna e paterna, coesão e conflito.

Foram escolhidas as escalas mais utilizadas na literatura com o intuito de verificar quais, dentre as suas variáveis, melhor diferenciam os dois grupos (crianças e adolescentes com THB e crianças e adolescentes sem transtornos psiquiátricos). No futuro, essas variáveis poderão ser priorizadas e usadas como medidas de desfecho de novas intervenções psicossocias adequadas às necessidades da população brasileira.

O THB é uma doença grave e crônica caracterizada pela ocorrência de pelo menos 2 episódios do humor, sendo um obrigatoriamente de mania ou misto, mas também é frequente a presença de um ou mais Episódios Depressivos Maiores (DSM-IV, 1994). O Manual Diagnóstico e Estatístico para Transtornos Mentais, $4^{\mathrm{a}}$ 
edição (Diagnostic and Statistical Manual of Mental Disorders - DSM IV), estabelece os tipos de THB: tipo I (pelo menos um episódio de mania ou estado misto), tipo II (episódios de hipomania alternando com episódios de depressão) e sem outras especificações (SOE) (DSM-IV, 1994).

Cerca de 1 a 4,4\% dos adultos são acometidos pelo THB, nos Estados Unidos (EUA); no Brasil essa prevalência é de 0,9 a 2,1\% (Merikangas et al., 2011). Cinquenta a sessenta por cento dos pacientes adultos com THB relataram início dos sintomas de alteração do humor com 19 anos ou menos (Lish et al., 1994; Chengappa et al., 2003). Nos EUA estima-se uma prevalência de THB de 1\% em adolescentes (Lewinsohn et al., 1995). No Brasil ainda não temos estudos específicos sobre a prevalência de THB em crianças e adolescentes (Fleitlich-Bilyk e Goodman, 2004).

\subsection{Transtorno do Humor Bipolar na Infância e Adolescência}

O THB com início na infância e adolescência está associado a um curso crônico com oscilações diárias (Tillman; Geller, 2003), e importantes prejuízos funcionais, tais como dificuldades nas relações interpessoais, escolares, problemas legais e múltiplas hospitalizações (Carlson; Kelly, 1998; Geller et al., 2002a; Chang et al., 2003). Nessa faixa etária, as taxas de prevalência de comorbidades são altas. Em amostras ambulatoriais de adolescentes com THB: 59 a $71 \%$ apresentavam comorbidade com Transtorno de Déficit de Atenção e Hiperatividade (TDAH); 38 a 71\% com Transtorno Opositor Desafiador (TOD), 7 a 35\% com Transtornos de Conduta (TC), 17 a 59\% com Transtornos Ansiosos, 38\% com Transtorno 
Obsessivo-Compulsivo (TOC) e 2 a 35\% com abuso de substâncias (Faraone et al., 1997; Kowatch et al., 2000; Caetano et al., 2006). Lewinsohn et al. (1995, 2003) encontraram também taxas altas no que se refere a comorbidades em uma amostra na comunidade com transtorno do espectro bipolar: $11 \%$ de TDAH, $22 \%$ por abuso de substâncias e transtornos disruptivos e 33\% com ansiedade. A presença de sintomas psicóticos também é frequente (de $35 \%$ a 39,5\%); assim como, de tentativa de suicídio (de 33 a 47\%) (Bhangoo et al., 2003; Goldstein et al., 2005; Caetano et al., 2006).

Para o diagnóstico de THB na infância e adolescência são usados os mesmos critérios diagnósticos do DSM-IV do adulto. Portanto, para o episódio de mania estabelece-se a presença de elação, grandiosidade e/ou irritabilidade, associados respectivamente a 3 ou 4 dos seguintes sintomas: auto-estima inflada ou grandiosidade; necessidade de sono diminuída; mais loquacidade do que o habitual ou pressão por falar; fuga de ideias ou experiência subjetiva de aceleração do pensamento; distratibilidade; aumento da atividade dirigida a objetivos ou agitação psicomotora; envolvimento excessivo em atividades prazerosas com um alto potencial para consequências dolorosas. No entanto, observou-se que os casos encontrados na infância não eram descritos adequadamente por esses critérios. Atualmente, pesquisadores estão propondo novos critérios que considerem as peculiaridades dessa faixa etária.

O grupo de pesquisa da Dra. Barbara Geller, da Washington University School of Medicine, afirma que a presença de sintomas cardinais de mania, elação do humor e/ou grandiosidade é mandatória para o diagnóstico de THB. Irritabilidade é 
excluída como sintoma principal, pois apresenta baixa especificidade na psiquiatria infantil (Geller et al., 2000a, 2002a,b,c, 2004, 2008).

O grupo de pesquisa da Dra. Ellen Leibenluft do NIMH considera 4 grupos distintos para abranger as diferentes apresentações clínicas das crianças com THB:

Fenótipo restrito: critérios do DSM-IV, incluindo duração e sintomas cardinais; Dois fenótipos intermediários: b) Um com hipomania ou mania, porém sem preencher os critérios de duração (entre 1 e 3 dias); c) O segundo sem hipomania ou mania, e sim irritabilidade; d) Fenótipo amplo chamado de Desregulação Grave do Humor (Leibenluft et al., 2003).

O grupo de pesquisa do Massachussetts General Hospital, Harvard Medical School, chefiado por Joseph Biederman, segue os critérios do DSM-IV sem modificações (Biederman, 2004a,b). Boris Birmaher, da University of Pittsburgh Medical Center, utiliza os critérios do DSM-IV com uma modificação em relação ao número de sintomas: na presença de elação são necessários apenas 2 sintomas do item B do DSM-IV e, na irritabilidade, apenas 3 dos sintomas descritos no item B. A duração dos sintomas foi modificada para o mínimo de 4 horas por dia durante 4 dias, não necessariamente consecutivos (Birmaher et al., 2006; Birmaher, 2007).

\subsection{Família com membro com THB}

A associação entre transtornos do humor e os sintomas do ambiente familiar, como dificuldades de comunicação e conflitos (Fristad, 2006 Belardinelli et al., 
2008) é bidirecional, pois a família é afetada pelos sintomas do THB assim como o paciente com THB é afetado pela família (Miklowitz; Goldstein, 1997).

Os familiares de pacientes com THB frequentemente apresentam dificuldades em entender os sintomas das doenças psiquiátricas e a importância das medicações; com isto, as habilidades de resolver os problemas e de comunicação ficam prejudicadas (Fristad, 2006). De fato, crianças e adolescentes com THB, foram caracterizados por baixo grau de acolhimento, afeto, intimidade e altos níveis de brigas e punição na relação entre pais e filhos, quando comparados ao grupo controle (Schenkel et al., 2008). Ressalta-se que a recuperação do paciente demanda reajustes de todos os familiares para se reorientarem nos relacionamentos e padrões de vida (Walsh, 2005).

O ambiente familiar disfuncional ou desorganizado está associado ao desencadeamento, recorrência/recaída para diversos transtornos psiquiátricos (Minuchin, et al., 1978; Miklowitz; Goldstein, 1997; Walsh, 2005). O ambiente familiar pode gerar níveis elevados de estresse que, por sua vez, tendem a exercer um importante papel na precipitação do THB e em suas recorrências (Miklowitz; Goldstein, 1997). Nesse sentido, o suporte familiar pode ser um fator muito significativo nos momentos de crise do familiar acometido. Por exemplo, a família intacta (quando os dois pais moram juntos) está associada a maiores chances de remissão do episódio de mania (Schenkel et al., 2008; Geller et al., 2002a), indicando que um ambiente familiar minimamente organizado tende a melhorar $o$ funcionamento da criança e o prognóstico da doença. Dessa forma, entendemos que fatores ambientais, não apenas fatores genéticos, são fatores de risco para o THB. 
Crianças e adolescentes, em particular, dependem da adesão dos pais/responsáveis para que possam receber o tratamento adequado, pois ainda não têm autonomia (financeira e emocional) para tanto. Em muitos casos, essas crianças são filhos de pais com THB ou com outros transtornos psiquiátricos, que estão impossibilitados pelas próprias dificuldades de seu estado clínico de exercerem seus papéis parentais.

Pais de crianças com THB tipo I têm 4 vezes mais chances de apresentarem o THB (Wozniak et al., 2010). Por outro lado, filhos de pais com THB estão propensos a um maior risco de desenvolver o THB, quando comparados a filhos de pais controles: 10,6\% x 0,8\% respectivamente (Birmaher et al., 2009). Filhos de pais com THB tipo I apresentaram 14 vezes mais chance de desenvolver o THB que filhos de pais sem THB (Birmaher et al., 2009).

As psicoterapias familiares têm papel fundamental no tratamento de crianças e adolescentes com THB. Através de intervenções apropriadas nas famílias, é possível melhorar muito a interação entre os familiares e assim ajudar o paciente a gerenciar melhor seus momentos de crise, como descrito na psicoterapia psicoeducacional realizada em grupos de pais e pacientes de Fristad (2006). Outra intervenção com bons resultados é o RAINBOW (Pavuluri et al., 2004), uma alusão às cores do arco-íris, ao espectro de emoções que podem ser simbolizadas por cores como raiva em infra-vermelho ou tristeza em ultra-violeta, e o objetivo de ficar na cor verde que simboliza o equilíbrio. Nessa terapia familiar são abordados temas como rotina, regulação do humor, equilíbio do estilo de vida dos pais, resolução de problemas, com o objetivo de organizar a família de uma maneira mais funcional. 
Por fim, entender que o membro portador de um transtorno psiquiátrico faz parte de um ambiente familiar que influencia e é influenciado por ele é compreender a família como um sistema.

\subsection{A família compreendida como um sistema}

A família, ao longo dos anos, passou por muitas transformações e ainda hoje não é possível caracterizá-la de uma única maneira (Haley, 1979 ${ }^{1}$; Poster, $1979^{2}$; Figueira, $1987^{3}$; Da Matta, 19894) apud Cerveny (1994). É possível estudar famílias por meio de diferentes abordagens. A abordagem proposta para o presente trabalho é a sistêmica, cujo foco se encontra no contexto e nas relações entre os membros da família, ao longo de suas diferentes fases de desenvolvimento (Cerveny, 1994).

A partir dos estudos com pacientes com esquizofrenia e de suas famílias, profissionais de diferentes áreas (Bateson, 1951 ${ }^{5}$; Lidz; 19576 Wynne, $1958^{7}$ ) apud Cerveny (1994) (Watzlawick et al., 1973) começaram a observar que a família não é apenas um conjunto de indivíduos, mas uma totalidade que interage entre si (Cerveny, 1994). A ideia de abordar os grupos sociais como organismos, como

\footnotetext{
Haley J. Psicoterapia familiar. Belo Horizonte, MG: Interlivros; 1979.

Poster M. Teoria crítica da família. Rio de Janeiro: Zahar; 1979.

3 Figueira S.A. Uma nova família?. Rio de Janeiro: Jorge Zahar Editor Ltda.; 1987.

4 Da Matta R. A família como valor: considerações não-familiares sobre a família à brasileira. Pensando a família no Brasil. Rio de Janeiro: Espaço e Tempo / Editora da UFRJ; 1989.

5 Bateson G. The convergence of science and psychiatry. In: Ruesch J, Bateson G. Communication: the social matrix of psychiatry. New York: W. W. Norton; 1951.

6 Lidz T, Cornelison AR, Fleck S, Terry D. The intrafamilial environment of schizophrenic patients: II. Marital schism and marital skew. Am J Psychiatry. 1957;114(3):241-248.

7 Wynne LC, Ryckoff IM, Day J, Hirsch SI. Pseudo-mutuality in the family relations of schizophrenics. Psychiatry. 1958;21(2):205-20.
} 
sistemas abertos em intercâmbio com o ambiente, surgiu a partir de Bertalanffy que desenvolveu a teoria geral dos sistemas em 1937 (Bruscagin, 2010). Nessa teoria, os elementos da família são vistos como interdependentes e influenciando-se mutuamente (Vasconcellos, 2002).

Pensar sistemicamente é buscar as semelhanças e as diferenças, é poder observar uma situação sob diferentes aspectos, buscando compreender como as partes e o todo se relacionam, interagem e se mantêm (Bruscagin, 2010). Segundo Bruscagin (2010), a família pode ser vista como um grupo de pessoas íntimas que dividem crenças, defesas, pontos de vista, histórias e mitos em comum. Os membros familiares não são iguais entre si, não pensam da mesma forma e nem se relacionam necessariamente de forma democrática. Desse modo, a família, sendo compreendida como um todo, como um sistema complexo e multi-individual, permite que os profissionais atuem em diferentes níveis dela, buscando atuar nas relações disfuncionais para que se tornem mais saudáveis (Minuchin; Fishman, 1990).

A unidade familiar é composta por pessoas que podem ser consideradas sistemas por si só. Essa unidade familiar está inserida numa comunidade e esta, numa sociedade. Um subsistema é composto por pessoas em relação, agrupadas em suas semelhanças ou diferenças de papel, geração, gênero, interesses, função e poder (Piszezman, 2006). Cada membro familiar exerce múltiplos papéis em vários subgrupos. Por exemplo: uma pessoa pode fazer parte do subsistema conjugal exercendo o papel de marido, subsistema parental - exercendo o papel de pai, etc... (Piszezman, 2006; Minuchin, 1974).

Segundo Minuchin (1974), a família observada como um sistema aberto é formada por subsistemas, com um limite semipermeável, que é um conjunto de 
regras que estabelece quem está incluído dentro daquele subsistema e de que maneira eles interagem com quem está fora dele. Em todas as sociedades, a família promove a formação da identidade a partir de dois elementos: o sentido de pertencimento e o sentido de ser separado. Dessa forma, cada sistema familiar deve desenvolver características que promovam esse pertencimento sem prejudicar a independência de seus membros.

A repetição de certos comportamentos ao longo de um período vai caracterizar os padrões da família. Padrão sendo considerado como um conjunto de regras veladas que dirigem as transações dentro da família e desta com seu ambiente, e que frequentemente são resistentes a mudanças. Esse padrão é influenciado por questões culturais e específicas a cada indivíduo em seu contexto (Minuchin, 1974).

A fronteira vai delimitar os tipos de relacionamentos entre os subsistemas. A fronteira determina quem e como participa dos sistemas. Essas fronteiras podem ser nítida, rígida (ou desligada) e difusa (emaranhada).

O bom funcionamento familiar demanda fronteiras nítidas, ou seja, permite variações na relação entre os indivíduos ou subsistemas, o que possibilita o crescimento e a independência de seus membros. As fronteiras rígidas são explicitamente restritivas e possibilitam pouco contato entre os subsistemas externos, resultando em distanciamento e isolamento dos membros. Nessas famílias, a coesão entre os membros é bastante diminuída e a comunicação prejudicada, por isso são chamadas de famílias desligadas (Piszezman, 2006). As fronteiras difusas ocorrem à custa da independência e da autonomia. Esse tipo de funcionamento tende a levar a uma dependência (diminuição da distância entre os membros) e a problemas com outras pessoas fora da família. Essas famílias recebem o nome de aglutinadas ou 
emaranhadas e apresentam altíssimo grau de coesão entre os membros (Piszezman, 2006). Nas famílias aglutinadas ou emaranhadas os comportamentos entre seus membros negam a função dos papéis familiares, a diferenciação é prejudicada e a comunicação familiar reforça isso (Piszezman, 2006).

Algumas características comuns parecem fazer parte das famílias que apresentam um bom funcionamento familiar. Bom funcionamento é conceitualizado como a interação que apóia a integração e manutenção da unidade familiar e a sua habilidade para o cumprimento das tarefas essenciais para o crescimento e bem-estar de seus membros mais vulneráveis (Walsh, 2003).

Walsh (2003) aponta o processo de comunicação como um aspecto fundamental nesse sentido. Alguns aspectos que favorecem a boa comunicação são: clareza, esclarecimento da situação vivida pela família, expressão emocional aberta, compartilhamento empático das emoções, tolerância amorosa para as diferenças e emoções negativas e estimulação de interações positivas (Walsh, 2005).

A resolução cooperativa dos problemas, em que as decisões são tomadas de forma compartilhada, negociadas e assumidos compromissos entre os membros da família, também é sugerida como uma característica de famílias funcionais. Os conflitos também existem nessas famílias, porém a resolução acontece de forma equilibrada, sem sacrificar a empatia e a riqueza dos vínculos.

O desenvolvimento da família deve ocorrer em um processo com períodos de equilíbrio e adaptação, mas também ocorrem períodos de desequilíbrio (Minuchin, 1974). Os padrões organizacionais da família formam a estrutura familiar e, se essa estrutura não for flexível, incorporando a execução das tarefas e atitudes pertinentes a cada etapa da vida familiar, essa família não terá um relacionamento saudável. 
Walsh (2005) também aponta, nas famílias com funcionamento saudável, a capacidade de mudança que decorre do equilíbrio entre a flexibilidade e a estabilidade; a capacidade de conexão entre seus membros ("vínculo emocional entre os membros da família, marcada pelo equilíbrio entre apoio mútuo e colaboração com a separação e a autonomia do indivíduo") (Walsh, 2003; p.7). A capacidade da família em manter o equilíbrio entre a unidade e a separação entre seus membros permite que possam recorrer uns aos outros, resguardando a autonomia quando necessária, o que gera o sentimento de segurança e apoio entre seus membros. Os limites interpessoais, diferenciação individual e autonomia, promovem o funcionamento individual, tendo como consequência o respeito por limites claros e capacidade de aceitar as diferenças.

A possibilidade de acesso a recursos sociais e econômicos é outra característica importante nas famílias com funcionamento saudável. Os recursos sociais são caracterizados pelas redes de apoio, sejam elas institucionais, familiares, informais (amigos), religiosa, dentre outras. A segurança financeira favorece a autonomia, tornando os parentes responsáveis pelos próprios destinos, e assim desconectando as famílias de ações assistencialistas que pouco colaboram para a independência da mesma.

Vários autores da terapia sistêmica descrevem características do que possa ser um bom funcionamento familiar (Minuchin, 1974; Sluzki, 1983; Pipher, 1997; Walsh, 2003). Essas características foram avaliadas em escalas utilizadas com crianças e adolescentes portadoras de THB.

O pensamento sistêmico é determinado como pensamento de processo. A mudança em uma das partes do sistema causa mudanças nas outras partes do sistema 
(Capra, 1982). Assim sendo, quando em uma família há um membro com algum transtorno psiquiátrico, entendemos que a família como um todo vive uma mudança intensa em seu equilíbrio, e os comportamentos e atitudes de uns em relação aos outros serão afetados mutuamente. Assim, é quase impossível falarmos em THB sem mencionarmos a família. Walsh (2003) aponta que não há uma associação simples e direta entre o indivíduo e a saúde ou funcionalidade de sua família. Uma criança com transtorno não é produto somente de uma família disfuncional; vulnerabilidades genéticas ou biológicas e influências do meio social mais amplo também devem ser consideradas.

Os problemas na funcionalidade da família podem estar relacionados a dificuldades na comunicação entre seus membros. Por exemplo, problemas na expressão de sentimentos e desejos, uma frequência exagerada de críticas e pouco reconhecimento das atitudes e características positivas dos membros da família. Isso é demonstrado nas famílias de pacientes com THB através dos relatos de seus parentes que apresentam altos níveis de emoção expressa (EE) (Honig et al., 1995; 1997; Fristad et al., 1998a, 1998b; 2003; Simoneau et al., 1998; Miklowitz et al., 1988, 2000, 2009; Mino et al., 2001; Kim; Miklowitz, 2004; Fristad, 2006; Coville et al., 2008; Sullivan; Miklowitz, 2010). Em nosso estudo, EE é considerada uma característica dos membros da família e não dos pacientes (Hooley; Gotlib, 2000). Para melhor compreender a EE nos parentes de pacientes com crianças e adolescentes com THB, optamos pelo Inventário de Adjetivos de EE.

Problemas no funcionamento do sistema familiar também podem ser devido à relação entre seus membros. A relação entre mãe/ pai e filho (a) é composta, segundo Puig-Antich et al. (1986), pelas atividades conjuntas, o carinho, o estabelecimento de 
limites, a quantidade e profundidade de comunicação entre mãe/pai e filho(a), tensão, hostilidade, violência e castigo corporal. O alto acolhimento materno e paterno é definido como preocupação um com o outro, relação carinhosa; e o baixo acolhimento materno e paterno, como sem cuidado adequado entre mãe, pai e filho (a), relação fria e indiferente, sem afeto (Puig-Antich et al., 1986). Para caracterizar as relações entre os membros da família e por consequência os tipos de família (desligada ou emaranhada) (Minuchin; Fishman, 1990), escolhemos a entrevista Escala Psicossocial para Crianças em Idade Escolar - Revisada (Puig-Antich et al., 1986). Essa entrevista obtém escores individuais e globais de funcionamento da criança em sua estrutura familiar (relação mãe e filho (a), relação pai e filho (a), relação entre os irmãos), na escola e com os colegas, bem como indicações gerais de organização familiar e do funcionamento conjugal. Em destaque estão o acolhimento e a tensão maternos e paternos e o funcionamento da criança em sua estrutura familiar.

É frequente observamos, em famílias com membros com THB, baixa coesão (Chang et al., 2001; Romero et al., 2005; Belardinelli et al., 2008), sendo coesão definida como ajuda e suporte entre os membros da família (Moos; Moos, 2002; Vianna et al., 2007). Problemas no funcionamento do sistema familiar podem também decorrer de níveis inadequados de coesão, expressividade, conflito, independência, assertividade, interesses culturais, lazer, religião, organização e controle (Moos; Moos, 2002; Vianna et al., 2007). Escolhemos a Escala de Ambiente Familiar - FES (Moos; Moos, 2002) para avaliar essas características entre os membros familiares de crianças e adolescentes com THB versus famílias de crianças e adolescentes sem transtornos psiquiátricos. 
O Inventário de Adjetivos de EE avalia a comunicação verbal entre mãe/pai e filho, o que representa o subsistema de pai/mãe e filho. A Escala Psicossocial para Crianças em Idade Escolar - Revisada avalia as relações e as comunicações verbais e não verbais, focando nos subsistemas de mãe-filho, pai-filho, amigos, irmãos e casal. A FES, por sua vez, avalia a estrutura da família como um todo, portanto, o sistema familiar. 
2 ESCALAS UTILIZADAS EM FAMÍLIAS COM CRIANÇAS E ADOLESCENTES PORTADORES DE THB NA INFÂNCIA E ADOLESCÊNCIA 
Dentre as escalas utilizadas para avaliar famílias com crianças, adolescentes e adultos com transtornos psiquiátricos, as mais usadas são:

- Camberwell Family Interview Schedule (C.F.I.S.) - Esquema de Entrevista Familiar de Camberwell elaborada por Brown e Rutter (1966), sendo utilizada para a avaliação de EE a sua versão abreviada, a Camberwell Family Interview (CFI) - Escala Familiar de Camberwell (Vaughn; Leff, 1976), traduzida para o português por Montagna (1981) em estudo envolvendo adultos;

- Five Minute Speech Sample (FMSS) - Modelo de Discurso de Cinco Minutos (Magaña et al., 1986);

- Family Adaptability and Cohesion Evaluation Scale - II (FACES - II) - Escala para Avaliação de Adaptação e Coesão Familiar - II (Olson et al., 1983; Olson; Tiesel, 1991);

- Family Assesment Device (FAD) - Inventário de Avaliação Familiar (Epstein et al., 1983);

- Family Attitude Scale (FAS) - Escala de Atitude Familiar (Kavanagh et al., 1997);

- Adjective Checklist - Inventário de Adjetivos de Emoção Expressa;

- Psychosocial Schedule for School Age Children - Revised - Escala Psicossocial para Crianças em Idade Escolar - Revisada;

- Family Environment Scale - Escala de Ambiente Familiar (FES).

As três últimas escalas são as selecionadas em nosso estudo, por terem sido as mais utilizadas em estudos que envolveram crianças e adolescentes com THB. 


\subsection{Inventário de Adjetivos de Emoção Expressa - Adjective Checklist}

A Escala de Emoções Expressas é um inventário auto-preenchível pelo pai ou mãe (Anexo I), que contém dez adjetivos positivos e dez adjetivos negativos (Friedmann; Goldstein, 1993), e que tem sido aplicada como uma medida para avaliar o ambiente familiar.

A EE não é uma medida de expressão emocional, mas da extensão do relato de um membro da família de um paciente psiquiátrico sobre aquele paciente, de uma forma crítica ou hostil ou que indique preocupação ou envolvimento emocional exagerados. A EE é uma característica dos membros da família e não dos pacientes (Hooley; Gotlib, 2000).

Os primeiros estudos de EE foram realizados em familiares de pacientes com esquizofrenia e demonstraram alta EE em familiares de pacientes com Esquizofrenia (Leff et al., 1987; 1989; Tarrier et al., 1988; Weisman et al., 1998; 2000; Hooley; Phil, 1998; Arthur; Nursing Research Group, 2002). Parentes de pacientes com esquizofrenia com alta EE são mais propensos, comparados aos com baixa EE, a visualizar os problemas ou comportamentos inadequados dos pacientes como sendo único ou pessoal do paciente (em vez de comum a todos os pacientes que têm o transtorno) e também, como algo controlável pelo paciente (Brewin et al., 1991; Weisman et al., 1993; Barrowclough et al., 1994). 
A EE é um robusto preditivo de recaída psiquiátrica em uma série de condições psicopatológicas e diagnósticos (Hooley; Phil, 1998), especialmente em esquizofrenia (Butzlaff e Hooley, 1998; Leff; Vaughn, 1981; Tarrier et al., 1988; Marom et al., 2005).

Butzlaff e Hooley (1998) demonstraram, em sua meta análise que, apesar do construto da EE estar mais associado com pesquisas em esquizofrenia, o tamanho médio do efeito para a EE, tanto em transtornos do humor como no transtorno alimentar, foram significantemente mais altos do que em esquizofrenia.

Em adolescentes e adultos com THB, usando a CFI para avaliar EE (Honig et al., 1995, 1997; Yan et al., 2004; Wendel et al., 2000), foi constatado que pais com alta EE descreveram suas famílias com baixa coesão e adaptabilidade e com mais conflito, comparados a pais com baixa EE (Miklowitz et al., 2009; Sullivan; Miklowitz, 2010). Pacientes com parentes com alta EE, comparados aos pacientes com parentes com baixa EE, apresentaram mais recaídas, especialmente de depressão (Yan et al., 2004; Kim; Miklowitz, 2004) e internações hospitalares (Honig et al., 1995, 1997; Mino et al., 2001). Uma análise das várias dimensões da EE (comentários críticos e superenvolvimento emocional) indicou que uma maior frequência de comentários críticos previam maior gravidade de mania e depressão no seguimento (Kim; Miklowitz, 2004). Contudo, níveis de EE somente foram considerados preditivos de recaída em pacientes que tinham estreita relação com os pais (Miklowitz et al., 2000). Pacientes de famílias com alta EE tratadas com FamilyFocused Psychoeducational Treatment (FFT - Tratamento Psicoeducacional Focado na Família) obtiveram uma melhora significativa dos sintomas (Miklowitz et al., 2000). 
No Inventário de Adjetivos de EE foi observada alta EE nos pais de crianças e adolescentes com THB- Essa parece ter uma boa resposta a intervenções psicoterápicas. A seguir descreveremos estudos usando essa escala em crianças e adolescentes com THB e outros transtornos do humor.

Pais de 20 criancas e adolescentes com transtorno do humor (média de idade \pm D.P. $=14,3 \pm 2,3$ anos; $45 \%$ com transtorno depressivo maior (TDM), $30 \%$ com transtorno distímico e $25 \%$ com THB) relataram aumento de emoções positivas e diminuição de emoções negativas, após seguimento de 4 meses de uma intervenção psicoeducacional de 90 minutos (Fristad et al., 1998a).

Em outro estudo, pais relataram aumento nas atitudes e comportamentos positivos e diminuição nas atitudes e nos comportamentos negativos em relação aos filhos, após participarem do programa não randomizado Multi-Family Psychoeducation Groups (MFPG - Psicoeducacional Multifamiliar em Grupo) de 6 sessões. Foram avaliadas 9 famílias de 3 crianças com THB e 6 adolescentes com outros transtornos do humor (Fristad et al., 1998b).

Em estudo seguinte, de comparação entre intervenções, Fristad et al. (2003) ofereceram randomicamente para 35 crianças e 47 pais MFPG imediata $(n=18)$ ou 6 meses de lista de espera mais o tratamento habitual $(n=17)$. Os participantes apresentavam média de idade \pm D.P. $=10,1 \pm 1,2$ anos, sendo $54 \%$ com TDM e 46\% com espectro THB. No sexto mês de seguimento, famílias envolvidas no MFPG relataram aumento das interações familiares positivas, mas não houve diminuição das interações familiares negativas (Fristad et al., 2003).

Fristad, em 2006, também realizou uma intervenção Psicoeducacional Familiar Individual, em que participaram famílias de 20 crianças com THB, com 
idades entre 8 a 11 anos. Os familiares de crianças do Individual Family Psychoeducation - Randomized Clinical Trial (IFP - RCT - Psicoeducacional Familiar Individual - Ensaio Clínico Randomizado), comparadaos aos familiares de crianças do grupo controle de lista de espera, apresentaram melhor clima familiar.

\subsection{Escala Psicossocial para Crianças em Idade Escolar - Revisada - Psychosocial Schedule for School Age Children - Revised}

A Escala Psicossocial para Crianças em Idade Escolar - Revisada é uma entrevista direta com a mãe ou o pai e a criança. É um instrumento utilizado para registrar dados demográficos, eventos de vida, funcionamento social e familiar. A entrevista tem como principal objetivo obter escores individuais e globais de funcionamento da criança em sua estrutura familiar, na escola e com os colegas, bem como obter indicações gerais de organização familiar e do funcionamento conjugal (Puig-Antich et al., 1986).

Geller et al. (2000b) avaliaram funcionamento psicossocial em 93 crianças e adolescentes com THB tipo I, com e sem comorbidade de transtorno de déficit de atenção e hiperatividade (TDAH), comparados a 81 crianças e adolescentes com TDAH e 94 crianças e adolescentes controles. A média de idade \pm D.P. das crianças e adolescentes com THB era de 10,9 $\pm 2,7$ anos. Crianças e adolescentes com THB comparados a portadores de TDAH e controles apresentaram comprometimentos significativamente maiores quanto a acolhimento materno, tensão materna e paterna. 
No estudo prospectivo longitudinal de 2 anos, a amostra inicial era de 89 indivíduos com THB tipo I, com média \pm D.P. de idade de $10,9 \pm 2,7$ anos. A proporção de indivíduos que se recuperaram de mania e que recaíram após a recuperação foi de $65,2 \%$ e $55,2 \%$, respectivamente. Baixo nível de acolhimento materno (em 55,1\% da amostra), medido pela Escala Psicossocial para Crianças em Idade Escolar - Revisada, aumentou em 4,1 vezes a chance de apresentar recaídas. Os indivíduos que viviam com suas famílias biológicas intactas apresentaram 2,2 vezes mais chances de se recuperar. Nenhuma outra característica de base como medicações e psicoterapias foi preditora de recaída (Geller et al., 2002a).

No estudo longitudinal de 4 anos, foram avaliados 86 indivíduos com THB tipo I (média de idade \pm D.P. de 10,8 $\pm 2,7$ anos). A estimativa da taxa de recuperação foi de $87,2 \%$ e a de recaída de 70,2\%. A estimativa de recaída nos 32 sujeitos com alto acolhimento materno foi de 50,3\%, e nos 43 sujeitos com baixo acolhimento foi de $85,9 \%$, mantendo o baixo acolhimento materno como um preditor de recaída. Os sintomas psicóticos foram preditivos de um maior número de semanas doentes em episódios de mania ou hipomania (Geller et al., 2004).

No estudo longitudinal de 8 anos, participaram 115 crianças e adolescentes com THB tipo I (média de idade \pm D.P. de 11,1 $\pm 2,6$ anos). Durante o seguimento, $101(87,8 \%)$ dos indivíduos com THB tipo I recuperaram-se e $74(73,3 \%)$ desses tiveram recaídas. Ter baixo acolhimento materno e ser mais novo, no início do estudo, foram preditores de mais semanas doente, em episódio maníaco ou misto (Geller et al., 2008).

Kim e Miklowitz (2004) relataram que o papel da alta EE no curso do THB tipo I, na vida adulta, era semelhante ao baixo acolhimento materno como preditor de 
recaída em sujeitos com THB tipo I, na infância. Porém, o efeito da alta EE no curso do THB tipo I, na vida adulta, não foi confirmado por todos (Yan et al., 2004).

\subsection{FES - Escala de Ambiente Familiar - Family Environment Scale}

A Escala de Ambiente Familiar (Family Environment Scale - FES) (Moos; Moos, 2002) é auto-preenchível, validada para o português (Vianna et al., 2007), composta por 10 subescalas com três dimensões (Anexo II). Segundo Moos e Moos (1974, 1994, 2002 e 2009), as subescalas foram definidas da seguinte maneira:

Dimensão de Relacionamento Interpessoal:

1. Coesão: ajuda e suporte entre os membros da família.

2. Expressividade: expressão de sentimentos.

3. Conflito: expresso abertamente na família.

Dimensão de Crescimento Pessoal:

4. Independência: capacidade de decisão.

5. Assertividade: atividades orientadas para um objetivo.

6. Interesses culturais: atividades políticas, intelectuais e culturais.

7. Lazer: atividades sociais e recreacionais.

8. Religião: questões éticas e valores religiosos.

Dimensão de Manutenção do Sistema:

9. Organização: no planejamento de atividades familiares. 
10. Controle: presença de regras e procedimentos na vida familiar cotidiana (Moos; Moos, 2002; Vianna et al., 2007).

O funcionamento interno familiar é refletido pelas dimensões de Relacionamento Interpessoal e Manutenção do Sistema, já a dimensão de Crescimento Pessoal reflete as ligações entre a família e o contexto social mais amplo (Romero et al., 2005).

Chang et al. (2001) compararam as diferenças entre 36 famílias com ao menos um pai biológico com THB tipo I ou II e os dados normativos da FES da população dos Estados Unidos (Moos; Moos, 1994). Foram coletados dados dos pais de 56 crianças com idades entre 6 a 18 anos, sendo 9 bipolares e 47 não bipolares. Os principais resultados indicaram que famílias com um dos pais com THB diferem da média das famílias americanas, apresentando menos coesão e organização e mais conflitos. Não houve diferença na comparação de famílias do grupo bilineal (um pai com THB e outro pai com transtorno depressivo maior ou THB) com grupo unilineal (famílias com apenas um dos pais com THB), ou de famílias com crianças com ou sem THB.

Romero et al. (2005) compararam 24 famílias, com pelo menos um dos pais com THB tipo I, e 27 famílias com pais saudáveis (famílias saudáveis) com filhos entre 8 a 12 anos, utilizando-se a FES (Moos; Moos, 2002). Das famílias com THB, $45 \%$ eram bilineal e $71 \%$ apresentavam pelo menos um filho com transtorno do humor (THB, Transtorno depressivo maior (TDM), transtorno ciclotímico ou transtorno distímico). Uma família (3,7\%), das 27 famílias saudáveis, apresentava um filho com transtorno distímico. As famílias com THB apresentaram menores escores de coesão e expressividade, quando comparadas às famílias saudáveis e 
apresentaram menores escores de coesão e independência, e maiores escores de conflitos, interesses culturais, religião e controle, quando comparadas aos dados normativos da população dos EUA. Na comparação entre famílias unilineal e famílias bilineal, estas apresentaram maiores escores de coesão que as primeiras; o que pode indicar que famílias bilineal sejam mais tolerantes aos sintomas.

Belardinelli et al. (2008) relataram menores níveis de coesão familiar, expressividade, lazer, interesses culturais e maiores níveis de conflito em 36 famílias com crianças e adolescentes com THB I, II ou SOE (média de idade \pm D.P. de 12,9 $\pm 3,6$ anos) comparadas a 29 famílias com crianças e adolescentes saudáveis (média de idade \pm D.P. $=12,6$ e \pm 3,8 anos), utilizando a FES (Moos; Moos, 2002). As famílias, em que um ou ambos os pais também tiveram diagnóstico de qualquer transtorno do humor, apresentaram menores níveis de organização e coesão quando comparadas às famílias em que os pais não tinham transtornos do humor.

Hua et al. (2011) relataram que famílias de 75 crianças e adolescentes com THB I e II com sintomas psicóticos (faixa etária: 4 a 18 anos) apresentaram diminuição da coesão familiar quando comparadas a famílias de 151 crianças e adolescentes com THB sem sintomas psicóticos, usando a FES (Moos; Moos, 1974).

A FES (Moos; Moos, 2002) também foi usada em crianças e adolescentes com transtorno depressivo maior (TDM). Ogburn et al. (2010) mostraram que famílias com crianças e adolescentes com TDM ( $\mathrm{n}=31$, faixa etária: 8 a 17 anos) tiveram maiores níveis de conflito e menores níveis de coesão, expressividade e lazer, quando comparadas a 34 famílias de crianças e adolescentes sem transtornos psiquiátricos do eixo I do DSM-IV. 
Em suma, esses instrumentos demonstraram que as famílias com membros com THB, quando comparadas a famílias com crianças sem transtornos psiquiátricos, apresentaram:

- Alto nível de emoção expressa em parentes de adultos, crianças e adolesentes com THB pelo Inventário de Adjetivos de Emoção Expressa.

- Baixo acolhimento materno pela Escala Psicossocial para Criança em Idade Escolar - Revisada.

- Baixo nível de coesão e altos níveis de conflitos pela FES - Escala de Ambiente Familiar.

Todos esses instrumentos foram estudados em famílias com crianças acometidas por THB, no entanto, nenhum estudo foi realizado no Brasil. Até o presente momento, nenhum estudo - que esteja publicado e seja de nosso conhecimento - avaliou simultaneamente a estrutura de família utilizando todas as escalas citadas acima para investigar qual variável melhor diferencia as famílias com crianças e adolescentes com THB das saudáveis.

\subsection{Justificativas}

A família influencia o desenvolvimento da criança e do adolescente. Nesse sentido, é essencial o seu papel na apresentação, evolução e prognóstico dos transtornos psiquiátricos na infância e adolescência.

O envolvimento dos pais no tratamento do filho é fundamental, pois sem tal engajamento a adesão ao tratamento está, em muitos casos, fadada ao fracasso, visto 
que a criança ou o adolescente não possui autonomia, nem muitas vezes discernimento, para entender a importância de um tratamento, principalmente a longo prazo, no caso de doenças crônicas.

Baixo acolhimento materno e altos níveis de EE são preditores de mau prognóstico em crianças e adolescentes com THB (Geller et al., 2000b; 2002a; 2004; 2008; Coville et al., 2008; Miklowitz et al., 2009; Sullivan; Miklowitz, 2010); em especial, com alto nível de EE foi preditivo de recaída (Leff; Vaughn, 1981; Tarrier et al., 1988; Honig et al., 1995, 1997; Marom et al., 2005).

Diante dessas constatações, e não havendo, no Brasil, estudos que analisem estas características nas famílias brasileiras com crianças e adolescentes portadores de THB, justifica-se nosso trabalho, cuja intenção final é, fundamentando-nos nos estudos já realizados e referidos aqui, propor intervenções mais precisas e específicas para o tratamento de THB no Brasil.

A utilização simultânea de 3 escalas para o estudo da estrutura familiar permitirá avaliar concomitantemente a comunicação e as relações entre seus membros, assim como o ambiente familiar de crianças e adolescentes portadores de THB, e analisar qual variável melhor distingue famílias com membros com THB de famílias saudáveis. 
3 OBJETIVOS 


\section{Objetivo Geral}

Avaliar a estrutura da família com crianças e adolescentes portadores de transtorno do humor bipolar.

\section{Objetivo Específico 1:}

Avaliar se a estrutura de família de crianças e adolescentes com THB comparada à estrutura de famílias de crianças e adolescentes sem transtornos psiquiátricos apresentarão:

- Maior nível de EE negativa nos familiares de crianças e adolescentes com THB de acordo com o Inventário de Adjetivos de Emoção Expressa.

- Menor acolhimento materno segundo a Escala Psicossocial em Idade Escolar - Revisada.

- Menor nível de coesão e maior nível de conflito de acordo com a Escala de Ambiente Familiar (FES).

\section{Objetivo Específico 2:}

Avaliar qual a variável que melhor diferencia os dois grupos (crianças e adolescentes com THB e crianças e adolescentes sem transtornos psiquiátricos). 


\subsection{Hipóteses}

Famílias de crianças e adolescentes com THB comparadas às famílias de crianças e adolescentes sem transtornos psiquiátricos apresentarão:

- Maior nível de EE negativa nos familiares de pacientes com THB de acordo com o Inventário de Adjetivos de Emoção Expressa.

- Menor acolhimento materno segundo a Escala Psicossocial em Idade Escolar - Revisada.

- Menor nível de coesão e maior nível de conflito, de acordo com a FES.

Coesão será a variável que melhor diferenciará os dois grupos (crianças e adolescentes com THB e crianças e adolescentes sem transtornos psiquiátricos). 
4 MATERIAL E MÉTODO 
Este projeto foi aprovado pela Comissão de Ética para Análise de Projetos de Pesquisa (CAPPesq, protocolo $n^{\circ}$ 0459/09) do Hospital das Clínicas da Faculdade de Medicina da Universidade de São Paulo (HC-FMUSP)(Anexo III).

A pesquisa foi desenvolvida no Instituto de Psiquiatria do Hospital das Clínicas da Faculdade de Medicina da Universidade de São Paulo (IPq HC FMUSP), inserida nas atividades do PROMAN (Programa de Transtorno Bipolar), coordenado pelo Prof. Dr. Beny Lafer; especificamente no nosso ambulatório no Serviço de Psiquiatria Infantil (SEPIA) IPq HC FMUSP.

\subsection{Desenho do Estudo}

Este estudo prospectivo transversal consiste em uma avaliação quantitativa da estrutura familiar com crianças e adolescentes portadores de THB, com a utilização de três diferentes escalas, simultaneamente: Escala de Ambiente Familiar (FES), Escala Psicossocial em Idade Escolar - Revisada e Inventário de Adjetivos de Emoção Expressa. 


\subsection{Amostra}

Os participantes do grupo de crianças e adolescentes com THB foram selecionados no nosso ambulatório no SEPIA IPq HC FMUSP, coordenado pela Dra. Sheila C. Caetano. Também foram selecionados pacientes novos, inicialmente triados pela autora deste trabalho e por mais duas colegas do ambulatório, Ana Maria Teixeira e Carolina Moreira, sendo todas treinadas na avaliação de pacientes com sintomas de THB na infância e adolescência. Os pacientes (crianças e adolescentes) que apresentaram diagnóstico provável de THB foram encaminhados às triagens com as psiquiatras Dra. Sheila Caetano e Dra.Ana Kleinman.

Crianças e adolescentes sem transtornos psiquiátricos foram convidados por anúncios na comunidade, por meio de programas de rádio, televisão e imprensa escrita.

Para participar do estudo, os sujeitos tiveram que preencher os seguintes critérios de inclusão:

\subsection{Critérios de inclusão e exclusão}

\subsubsection{Critérios de Inclusão para todas as crianças e adolescentes}

Mais de 6 anos e menos de 18 anos de idade.

QI>70. 


\subsubsection{Critérios de Inclusão THB}

Diagnóstico de THB tipo I, II ou SOE segundo critérios do DSM-IV.

\subsubsection{Critérios de Inclusão Controles}

Ausência de transtornos psiquiátricos do eixo I do DSM-IV

Ausência de transtornos psiquiátricos do eixo I do DSM-IV em seus parentes de primeiro grau.

\subsubsection{Critérios de Exclusão para todas as crianças e adolescentes}

Doenças clínicas com repercussão no sistema nervoso central, incluindo doenças neurológicas.

\subsection{Avaliação Clínica}

\subsubsection{Entrevista Psiquiátrica}

\subsubsection{Entrevista Psiquiátrica para crianças e adolescentes}




\subsubsection{Entrevista para Transtornos Afetivos e Esquizofrenia para Crianças em Idade Escolar - Versão Atual e ao Longo da Vida - Schedule for Affective Disorders and Schizophrenia for School- Age Children - Present and Lifetime version}

O diagnóstico de THB e de outros transtornos psiquiátricos da infância e adolescência do eixo I do DSM-IV foram estabelecidos pela entrevista "Schedule for Affective Disorders and Schizophrenia for School-Age Children - Present and Lifetime version" (K-SADS-PL) (Kaufman et al., 1997) adaptada por Brasil (2003). Essa é uma entrevista semi-estruturada, em que pais ou responsáveis e crianças respondem questões que serão usadas para formular os diagnósticos psiquiátricos do eixo I da infância e adolescência (episódios atuais e passados) de acordo com os critérios do DSM-IV. A entrevista é realizada com a criança ou o adolescente e, separadamente, com um familiar ou responsável legal que melhor conheça o sujeito (Caetano et al., 2006). Essas entrevistas foram realizadas por toda a equipe, inclusive a autora desta dissertação, após treinamento, e o diagnóstico final foi supervisionado pelas psiquiatras Dras. Sheila Caetano e Ana Kleinman.

\subsubsection{Escalas de Avaliação Clínica}

\subsubsection{Escala de Funcionamento Global da Criança (C-GAS) - Children's Global Assessment Scale}

Essa escala possui pontuação de 0 a 100 (excelente funcionamento), é específica para crianças e adolescentes, e está incluída no K-SADS. Seu resultado é relatado como o eixo V do DSM-VI (Shaffer et al., 1983). 


\subsubsection{Escala para Avaliação de Depressão em Crianças - Revisada - Children's Depression Rating Scale Revised}

A “Children's Depression Rating Scale, Revised (CDRS-R)” foi estruturada para avaliar a gravidade da depressão em crianças e adolescentes. Seus escores totais variam de 17 a 113 (grave) (Poznanski et al., 1985), adaptada por Barbosa et al. (1997). Os 17 itens que compõem a escala avaliam: desempenho na escola, prazer nas atividades, sociabilização, sono, apetite, nível de energia, sintomas físicos, irritabilidade, culpa, auto-estima, humor, ideação mórbida e suicida, choro, expressão facial, velocidade da fala e psicomotricidade. Os itens recebem escores de 1 (sem alteração) a 7, com exceção de sono, apetite e velocidade da fala que podem variar de 1 a 5. Os escores são somados e, a partir do escore total, é realizada correlação com escores T. O ponto de corte da escala é 39.

\subsubsection{Escala de Mania de Young - Young Mania Rating Scale}

A Escala de Young para Mania (Young Mania Rating Scale, YMRS) (Young et al., 1978), adaptada por Vilela e Loureiro (1999), foi utilizada para a avaliação de presença e intensidade de sintomas maníacos nos sete dias precedentes. Os itens que compõem a escala são: humor e afeto elevados, atividade motora, interesse sexual, sono, irritabilidade, fala (velocidade e quantidade), linguagem (forma do pensamento), conteúdo das ideias, comportamento agressivo, aparência e insight. O ponto de corte da escala para eutimia foi $\geq 7$, de acordo com a recomendação da International Society of Bipolar Disorder para definição de remissão sintomática de mania (Tohen et al., 2009). 


\subsubsection{Escala de Impressão Global - Clinical Global Impression Scale}

A Escala de Impressão Global (Clinical Global Impression Scale - CGI) de gravidade (Guy, 1976) também foi utilizada para avaliar a gravidade clínica. A escala varia de 1 (normal) a 7 (entre os sujeitos mais graves).

\subsubsection{Escala de Desenvolvimento Pubertal de Petersen - Petersen Rating Scale Puberty}

Escala de Desenvolvimento Pubertal de Petersen é uma escala de autoavaliação para crianças e adolescentes que consiste em questões sobre alteração de voz, pelos faciais e pubianos para os meninos, e questões sobre menarca, desenvolvimento dos seios e pelos pubianos para as meninas. Essa escala produz uma classificação em 5 categorias: pré-puberdade, início da puberdade, meio da puberdade, puberdade avançada e pós-puberdade. As 3 primeiras categorias referemse ao período pré-púbere e as 2 últimas, ao período pós-púbere (Petersen et al., 1988). A escala foi traduzida e retro-traduzida pelo nosso grupo ${ }^{8}$.

\subsubsection{Escala Socioeconômica e Demográfica das Classes - Associação Brasileira dos Institutos de Pesquisas de Mercado (ABIPEME)}

O sistema de classificação ABIPEME foi originalmente desenvolvido para a construção de uma escala de estratificação socioeconômica que pudesse ser utilizada nos diversos mercados regionais do Brasil (Jannuzzi; Baeninger, 1996). A classificação socioeconômica da população é apresentada por meio de cinco classes, denominadas A, B, C, D e E correspondendo, respectivamente, a uma pontuação

8 A tradução dessa escala foi realizada pela Dra. Sheila C. Caetano; e a retro-tradução por uma professora de inglês. 
determinada. Os limites de classificação ficaram definidos da seguinte maneira: A89 ou mais; B - 59/88; C - 35/58; D - 20/34; E - 0/19.

\subsubsection{WASI - Escala Abreviada de Inteligência de Wechsler - Wechsler Abbreviated Scale of Intelligence}

A escala foi utilizada para excluir retardo mental (Wechsler, 1999) e gerar o Quociente de Inteligência (QI) - recurso psicométrico que avalia o funcionamento intelectual - das amostras estudadas. A Escala Wechsler de Inteligência Abreviada é composta por quatro tarefas padronizadas que apresentam forte associação com o fator geral de inteligência: "Vocabulário", "Semelhanças", "Cubos" e "Raciocínio Matricial". O QI estimado pode ser obtido a partir da aplicação de duas provas apenas: "Vocabulário" ${ }^{9}$ e "Raciocínio Matricial". Kaufman e Reynolds $(1983)^{10}$ e Wechsler (1981) ${ }^{11}$ apud Cunha (2002) apresentaram uma classificação descritiva para os diferentes níveis de QI. A classificação foi definida da seguinte maneira: QI $\geq 69$ é considerado uma deficiência mental; QI entre 70 a 79 desempenho limítrofe; 80 a 89 desempenho médio inferior; QI de 90 a 109 dentro da média; 110 a 119, faixa média superior; 120 a 129 desempenho superior e $\mathrm{QI} \leq 130$ desempenho considerado muito superior se comparado a pares de mesma idade. Para a obtenção do resultado do QI foi necessário utilizar as normas americanas do teste,pois, até o presente, esse instrumento ainda não foi padronizado para a população brasileira.

\footnotetext{
9 A tradução das palavras de vocabulário (WASI) foi realizada pela Dra. Cândida Helena Pires de Camargo, neuropsicóloga, ex-Diretora do Serviço de Psicologia e Neuropsicologia do IPqHCFMUSP, para pesquisa.

10 Kaufman AS, Reynolds CR. Clinical evaluation of intellectual function. 1983.

11 Wechsler D. Wechsler Adult Intelligence Scale. San Antonio: The Psychological Corporation / Harcourt Brace \& Company; 1981.
} 


\subsubsection{Diagnóstico dos pais}

O diagnóstico dos pais foi obtido através da entrevista de anamnese.

\subsubsection{Escalas para Avaliação de Família}

\subsubsection{Inventário de Adjetivos de Emoção Expressa - Adjective Checklist}

No início dos anos 50, na Grã-Bretanha, a modificação de ênfase do tratamento psiquiátrico do modelo hospitalar para o modelo de atenção comunitária motivou uma série de indagações sobre a influência de fatores psicossociais no curso da esquizofrenia (Scazufca, 1998). No primeiro estudo realizado por George Brown (1959), foi observado que pacientes do sexo masculino com histórico de pelo menos 2 anos de internação apresentavam pior evolução quando passavam a viver com os pais ou cônjuges do que aqueles que passavam a viver sozinhos (Brown, 1959). Essa diferença na evolução da doença poderia estar refletindo as atitudes dos membros familiares em relação aos pacientes, segundo Brown, e não foi atribuído ao fato de que os pacientes que apresentavam pior estágio clínico estariam voltando a viver com cônjuges ou pais (Brown, 1959). Brown et al. (1972) adotaram a expressão "alta emoção expressa" (EE) para apontar características dos familiares que se mostraram preditoras de recaída sintomática dos pacientes. EE indicava a presença de hostilidade e o grau de envolvimento emocional do familiar em relação ao paciente pelo número de comentários críticos feitos sobre o paciente durante a entrevista (Jenkins; Karno, 1992). A EE foi posteriormente confirmada como manifestação 
comportamental da interação familiar no cotidiano (Kuipers, 1979; Miklowitz et al., 1989).

Níveis de EE são ligados aos traços de personalidade dos próprios parentes, ao nível da psicopatologia do paciente e do parente ou a uma combinação desses fatores.

Foram identificados quatro fatores que diferenciam parentes com EE alta contra os com baixa EE: 1) respeito pelas necessidades de relacionamento dos pacientes, 2) atitudes em relação à legitimidade do transtorno, 3) nível de expectativas com relação à funcionalidade do paciente e 4) reações emocionais com relação ao transtorno do paciente (Vaughn,1986). Esses quatro domínios são úteis quanto às variações observadas na reação da família e constituem um passo importante no desenvolvimento de um modelo conceitual mais amplo de EE (Jenkins; Karno, 1992).

Para medir os níveis de EE escolhemos o Inventário de Adjetivos de Emoção Expressa. Essa escala é preenchida pelo pai ou mãe ou cuidador circulando a melhor resposta que descreve o comportamento de filho (a), nos últimos três meses, em relação ao cuidador que realiza o preenchimento. Em seguida, o pai ou mãe circulam a melhor resposta que descreve o próprio comportamento em relação ao fillho (a) nos últimos três meses. O inventário varia de pontuações de 1 (nunca) a 8 (sempre) tendo nesse intervalo pontuações que variam de 2 a 7 (vide Anexo I). Conceitualmente os adjetivos negativos representam o componente de criticismo e o superenvolvimento emocional aos adjetivos positivos (Friedmann; Goldstein, 1993). A tradução do inventário foi realizada pelo Programa de Crianças e Adolescentes com Transtorno 
Bipolar (PROCAB) da Universidade Federal do Rio Grande do Sul ${ }^{12}$. O inventário não tem validação nem padronização para o português.

Os adjetivos positivos incluem: aceitante/receptivo, ativo, claro, considerável, cooperativo, leal, fácil de se relacionar, amistoso, bem intencionado/humorado e amoroso. Os adjetivos negativos são: bravo, entediado, contrário, mentiroso, hostil, irresponsável, irritável, preguiçoso, mau e rude.

\subsubsection{Escala Psicossocial para Crianças em Idade Escolar - Revisada -}

\section{Psychosocial Schedule for School Age Children - Revised}

A Psychosocial Schedule for School-Age Children - "PSS" - Escala Psicossocial para Criança em Idade Escolar (Puig-Antich; Lukens, 1978) é uma entrevista semiestruturada em que foram reunidos e modificados vários instrumentos: (1) Children's Symptom History, 1973 - Histórico de Sintomas Infantis, (2) Children's Personal Data Inventory, 1973 - Inventário de Dados Pessoais Infantis, e (3) o protocolo de entrevistas para medidas da vida familiar e relacionamentos desenvolvido e usado por D. Shaffer, F. Brown, M. Rutter, e G. Brown (Brown; Rutter, 1966; Rutter; Brown, 1966). As entrevistas The Hollingshead Four Factor Index of Social Status (Hollingshead, 1976) - Quatro Fatores de Status Social para estabelecer o status socioeconômico da família; e the Coddington scales for "Preschool Age Children" and for "Elementary School Age Children" - Escala Coddington para Crianças em Idade Pré-escolar e Crianças em Idade de Escola

12 A tradução dessa escala foi realizada pelo grupo do PROCAB chefiado pelo Dr. Luis Augusto Rohde do Serviço de Psiquiatria do Hospital de Clínicas da Universidade Federal do Rio Grande do Sul -UFRGS. 
Fundamental são usadas em forma não modificada para coletar dados sobre eventos de vida (Coddington, 1972a, 1972b).

Essa escala foi revisada para registrar dados em relação às medidas demográficas, eventos de vida, funcionamento social (na escola e com os colegas) e familiar (acolhimento materno e paterno, tensão materna e paterna) e escores de família intacta / não intacta (família intacta refere-se a filhos morando com ambos os pais) e indicações gerais de organização familiar e do funcionamento conjugal (PuigAntich et al., 1986). Para adaptar-se ao grande número de crianças que vivem com dois grupos parentais distintos, a pontuação permite o registro de dados para duas famílias (ou domicílios) diferentes. O escore final é dado pelo entrevistador que usa seu julgamento clínico baseado em informações colhidas ao longo de cada seção; com a exceção de acolhimento, tensão (materna, paterna e entre o casal), escore geral da relação com os amigos e irmãos. Para esses últimos--o escore final refere-se à pior nota dada pela mãe e criança/adolescente somada ao escore dado pelo entrevistador (julgamento clínico) divido por dois.

A Escala Psicossocial para Crianças em Idade Escolar - Revisada foi traduzida e retrotraduzida pelo nosso grupo, sendo nossa retrotradução revisada pelo grupo da Dra. Barbara Geller. A escala não tem validação e padronização para o português. O tempo médio de aplicação é de uma hora e meia para crianças e adolescentes com THB e de uma hora para crianças e adolescentes sem transtornos psiquiátricos.

A psiquiatra infantil Ana Kleinman foi treinada pelo grupo da Dra. Barbara Geller, com quem se tornou confiável. Por sua vez, Ana Kleinman treinou a autora desta Dissertação e seu colega Bernardo C. Gomes. O coeficiente de correlação de 
Kendall foi calculado para Escala Psicossocial para Crianças em Idade Escolar Revisada e em $80 \%$ dos casos, a medida foi acima de 0,7 , indicando uma boa confiabilidade intra-avaliadores.

\subsubsection{FES - Escala de Ambiente Familiar - Family Environment Scale}

Para avaliar o ambiente social das famílias, os autores da FES conduziram entrevistas estruturadas com membros de diferentes tipos de famílias; e usaram também a Social Climate Scales - Escalas de Clima Social (Moos, 2003; Moos; Moos, 1974, 1994, 2002 e 2009). Foram avaliados mais de 1.000 indivíduos em 285 famílias provenientes de três paróquias religiosas, anúncios em jornais e estudantes do ensino secundário. Também foi obtida uma amostra de famílias de minorias raciais com afro-americanos e latinos e um grupo de 42 famílias em tratamento de transtornos (Moos; Moos, 1974, 1994, 2002 e 2009). Para maiores considerações sobre os aspectos psicométricos e conceituais envolvidos na construção da FES, vide Moos, 1990; Moos; Moos, 1974, 1994, 2002 e 2009.

Em nosso estudo, utilizamos a versão da FES de Moos e Moos (2009), traduzida e validada no Brasil por Vianna et al. (2007), mas ainda não padronizada para a cultura brasileira. É uma escala auto-preenchível, respondida pela mãe ou pai ou responsável, composta por 90 itens sobre a família agrupados em 10 subescalas com três dimensões (vide Anexo II). A dimensão do Relacionamento Interpessoal abrange as subescalas de coesão, expressividade e conflito. A dimensão de Crescimento Pessoal compreende subescalas de independência, assertividade, interesses culturais, lazer e religião. A dimensão de Manutenção do Sistema abarca as subescalas de organização e controle. O funcionamento interno familiar é refletido 
pelas dimensões de Relacionamento Interpessoal e Manutenção do Sistema e a dimensão de Crescimento Pessoal reflete as ligações entre a família e o contexto social mais amplo (Romero et al., 2005).

Segundo Roosa e Beals (1990) é importante incluir apenas um dos pais (como feito em nosso estudo) para que não ocorra dupla observação.

Em nosso estudo, a pontuação foi realizada pelos valores padronizados (s/s) e foi escolhida a forma $\mathrm{R}$ (real), que mede a percepção do indivíduo no ambiente familiar atual (Moos; Moos, 1974, 1994, 2002 e 2009). As outras duas formas da escala são utilizadas para avaliação pré e pós intervenção.

\subsection{Análise Estatística}

A análise estatística foi realizada no programa estatístico SPSS, versão 14 (SPSS, Inc., Chicago, IL), usando nível de significância de 5\%. Todas as variáveis foram sujeitas ao teste de Kolmogorov-Smirnov, para verificar a suposição de normalidade. O teste de Mann-Whitney foi usado para comparar a idade. O teste exato de Fisher foi utilizado para avaliar sexo, etnia, nível socioeconômico do pais, escolaridade das crianças e adolescentes e puberdade entre os dois grupos. O teste $\mathrm{t}$ foi empregado para comparação de médias entre os grupos em relação ao QI. Modelos de ANCOVA foram ajustados também para avaliar diferenças entre os grupos nas variáveis EE positiva e negativa (pelo Inventário de Adjetivos de EE) e para os fatores da escala FES. Para avaliar a Escala Psicossocial para Crianças em Idade Escolar - Revisada entre os dois grupos foi utilizado um modelo de regressão 
logística e o teste exato de Fisher. Foi aplicado o método de correção Bonferroni para correção para múltiplas análises nos Modelos de ANCOVA e Regressão Logística.

Para medir a associação linear de C-GAS, CDRS-R, YOUNG e CGI, no grupo de crianças e adolescentes com THB, foi realizada uma Correlação de Pearson.

Foi feita uma Análise Discriminante utilizando-se o método linear de Fisher para avaliar quais das variáveis são maiores preditoras de famílias com crianças e adolescentes com THB, porém só foram incluídas na análise as variáveis que diferenciaram os grupos na ANCOVA e Regressão Logística.

Por fim, curvas ROC Receiver Operating Characteristic - Característica Operativa do Receptor foram ajustadas para encontrar pontos de corte nas escalas classificando as famílias como controle ou THB, segundo os níveis de sensibilidade e especificidade. Na curva ROC, só foram incluídas na análise as variáveis que diferenciaram os grupos no ANCOVA. Especificamente para a escala Psicossocial para Crianças em Idade Escolar - Revisada não foi realizada Curva ROC para essas variáveis que foram dicotômicas. 
5 RESULTADOS 


\subsection{Características sócio-demográficas da amostra}

Foram avaliados 33 crianças e adolescentes com THB e 29 crianças e adolescentes sem transtornos psiquiátricos. A faixa etária foi de 6 a 17 anos, sendo a média de idade \pm D.P. das crianças e adolescentes com THB de 13,1 $\pm 3,1$ anos e, das crianças e adolescentes sem transtornos psiquiátricos, de 13,7 $\pm 3,5$ anos. No grupo de crianças e adolescentes com THB, treze eram do sexo feminino $(39,4 \%)$, enquanto no grupo controle dezessete eram do sexo feminino $(58,6 \%)$. Os grupos não apresentaram diferença estatisticamente significativa quanto à idade e sexo (ver Tabela 1). Das crianças e adolescentes com THB, 22 (66,7\%) eram caucasóides; enquanto das crianças e adolescentes sem transtorno psiquiátricos $15(51,7 \%)$ eram caucasóides. A média do nível intelectual \pm D.P. das crianças e adolescentes com THB foi de 97,24 $\pm 16,48$ e das crianças e adolescentes sem transtornos psiquiátricos de $102,93 \pm 11,85$, indicando que ambos os grupos apresentaram nível intelectual médio.

Segundo a Escala Sócio-econômica e Demográfica das Classes ABIPEME, não houve diferenças estatisticamente significantes entre os grupos de famílias com filhos com THB versus famílias com filhos sem transtornos psiquiátricos, sendo o nível social B o prevalente $(54,5 \%$ e $58,6 \%$, respectivamente).

O nível educacional das crianças e adolescentes com THB estava distribuído em $24,2 \%$ no ensino fundamental I, 36,4\% no ensino fundamental II e 39,4\% no ensino médio. Das crianças e adolescentes sem transtornos psiquiátricos, 20,7\% 
estavam no ensino fundamental I, 24,1\%, no ensino fundamental II e 55,2\%, no ensino médio.

Das crianças e adolescentes com THB, 5 (15,2\%) encontravam-se no período pré-puberdade, $6(18,2 \%)$, no início da puberdade, 9 (27,3\%), no meio da puberdade, $8(24,2 \%)$, na puberdade avançada e $5(15,2 \%)$, no período pós-puberdade. Das crianças e adolescentes sem transtornos psiquiátricos, 5 (17,2\%) encontravam-se na pré-puberdade, $5(17,2 \%)$, no início da puberdade, $2(6,9 \%)$ no meio da puberdade, $14(48,3 \%)$ na puberdade avançada e $3(10,3 \%)$ na pós-puberdade.

Não houve diferenças estatisticamente significantes entre os grupos com relação à idade $(U=423,00$ e $p=0,427)$, sexo $(p=0,203)$, etnia $(p=0,323), Q I(t=$ $1,541, \mathrm{p}=0,129)$, nível socioeconômico dos pais $(\mathrm{p}=0,781)$, escolaridade dos filhos $(p=0,484)$ e nível de puberdade $(p=0,165)($ Tabela 1$)$. 
Tabela 1- Dados Sócio-Demográficos do grupo de crianças e adolescentes com THB e crianças e adolescentes sem transtornos psiquiátricos e a análise estatística

\begin{tabular}{|c|c|c|c|c|c|c|}
\hline & \multicolumn{2}{|l|}{$\begin{array}{c}\text { THB } \\
(\mathrm{n}=33)\end{array}$} & \multicolumn{2}{|c|}{$\begin{array}{c}\text { Controle } \\
(\mathrm{n}=29)\end{array}$} & Teste & Valor-p \\
\hline $\begin{array}{l}\text { Idade Média (Desvio- } \\
\text { Padrão) }\end{array}$ & $\begin{array}{l}13,1 \\
(3,1)\end{array}$ & & $\begin{array}{l}13,7 \\
(3,5)\end{array}$ & & $* \mathrm{U}=423,00$ & 0,427 \\
\hline Sexo \% (Feminino) & 39,4 & & 58,6 & & $* *$ & 0,203 \\
\hline Etnia & $\mathrm{n}$ & $(\%)$ & $\mathrm{n}$ & $(\%)$ & $* *$ & 0,323 \\
\hline Caucasóide & 22 & 66,7 & 15 & 51,7 & & \\
\hline Africano & 2 & 6,1 & 4 & 13,8 & & \\
\hline Pardo & 9 & 27,3 & 8 & 27,6 & & \\
\hline Asiático & 0 & 0,0 & 2 & 6,9 & & \\
\hline QI Média (Desvio-Padrão) & $\begin{array}{c}97,24 \\
(16,48)\end{array}$ & & $\begin{array}{l}102,93 \\
(11,85)\end{array}$ & & $* * * \mathrm{t}=1,541$ & 0,129 \\
\hline Nível Socioeconômico & $\mathrm{n}$ & $(\%)$ & $\mathrm{n}$ & $(\%)$ & $* *$ & 0,781 \\
\hline A -89 ou mais & 3 & 9,1 & 2 & 6,9 & & \\
\hline B -59 a 88 & 18 & 54,5 & 17 & 58,6 & & \\
\hline$C-35$ a 58 & 10 & 30,3 & 10 & 34,5 & & \\
\hline$D-20$ a 34 & 2 & 6,1 & 0 & 0,0 & & \\
\hline Escolaridade filhos & & & & & $* *$ & 0,484 \\
\hline Fundamental I & 8 & 24,2 & 6 & 20,7 & & \\
\hline Fundamental II & 12 & 36,4 & 7 & 24,1 & & \\
\hline Médio & 13 & 39,4 & 16 & 55,2 & & \\
\hline Puberdade & $\mathrm{n}$ & $(\%)$ & $\mathrm{n}$ & $(\%)$ & $* *$ & 0,165 \\
\hline Pré-Puberdade & 5 & 15,2 & 5 & 17,2 & & \\
\hline Início da Puberdade & 6 & 18,2 & 5 & 17,2 & & \\
\hline Meio da Puberdade & 9 & 27,3 & 2 & 6,9 & & \\
\hline Puberdade Avançada & 8 & 24,2 & 14 & 48,3 & & \\
\hline Pós-Puberdade & 5 & 15,2 & 3 & 10,3 & & \\
\hline
\end{tabular}




\subsection{Características clínicas da amostra}

Em média, as crianças e adolescentes receberam o diagnóstico de THB aos 12,2 \pm 3,2 anos e tomaram a primeira medicação psiquiátrica (estimulante, antidepressivo, antipsicótico ou estabilizador do humor) em seguida, aos 12,3 $\pm 3,2$ anos.

Das 33 crianças e adolescentes com THB, 48,5\% eram do tipo I; 3,0\%, do tipo II e 48,5\%, do tipo SOE. Dentre essas crianças, apenas 2 estavam sem medicação e 31 estavam medicadas: 29 (93,5,\%), com estabilizadores do humor, 20 (64,5\%) antipsicóticos atípicos, 3 (9,7\%) estimulantes, 2 (6,5\%) antidepressivos e 2 $(6,5 \%)$ ansiolíticos.

O tratamento mais frequente, após o medicamentoso, foi psicoterapia individual, presente em $69,7 \%$ dos casos. Histórico de hospitalização psiquiátrica ocorreu em $6,1 \%$ das crianças e adolescentes com THB.

Na Escala de Mania (YMRS), a média de escores \pm D.P. foi de 9,73 $\pm 7,76$ considerada como presença de sintomas hipomaníacos; e, pela Escala de Gravidade de Depressão-Revisada (CDRS-R), de 29,21 \pm 12,10 pontos, abaixo do escore mínimo para depressão. A gravidade avaliada pela Escala de Impressão Global (CGI) indicou média de escore 3,85 $\pm 1,12$ (moderadamente doente). Na Escala de Funcionamento Global da Criança (C-GAS) atual as crianças e adolescentes apresentaram média \pm D.P. de 51,94 \pm 9,66.

As 33 crianças e adolescentes apresentaram os seguintes episódios do humor: $3(9,1 \%)$ em depressão, $7(21,2 \%)$ em hipomania, $3(9,1 \%)$ em estado misto, 11 $(33,3 \%)$ em mania e $9(27,3 \%)$ estavam em eutimia. 
Comorbidade estava presente em $75,8 \%$ das crianças e adolescentes com THB, sendo 51,5\% com TDAH (17,6\% do tipo desatento, 5,9\% do tipo hiperativo e $76,5 \%$ do tipo combinado), 27,3\% Transtorno Opositor Desafiador, 27,3\% Transtorno de Ansiedade Generalizada, 12,1\% Transtorno de Conduta (50\% com início na infância) e 9,1\% com Fobia Simples. As características clínicas da amostra estão descritas na Tabela 2. 
Tabela 2 - Variáveis clínicas em crianças e adolescentes com THB

\begin{tabular}{|c|c|c|}
\hline Variáveis clínicas & \multicolumn{2}{|c|}{ THB $(n=33)$} \\
\hline THB & $\mathrm{N}$ & $(\%)$ \\
\hline THB - I & 16 & 48,5 \\
\hline THB - II & 1 & 3,0 \\
\hline $\mathrm{THB}-\mathrm{SOE}$ & 16 & 48,5 \\
\hline Idade de início primeiro episódio de depressão (Média e Desvio-Padrão) & & $9,1(4,0)$ \\
\hline Idade de início de THB (Média e Desvio-Padrão) & & $8,8(4,0)$ \\
\hline Idade primeiro diagnóstico Depressão (Média e Desvio-Padrão) & & $11,7(2,9)$ \\
\hline Idade primeiro diagnóstico THB (Média e Desvio-Padrão) & & $12,2(3,2)$ \\
\hline Idade primeira medicação psiquiátrica (Média e Desvio-Padrão) & & $11,6(3,3)$ \\
\hline Idade primeiro Estabilizador de Humor (Média e Desvio-Padrão) & & $12,3(3,2)$ \\
\hline Hospitalização psiquiátrica n (\%) & 2 & 6,1 \\
\hline Psicose $n(\%)$ & 12 & 36,4 \\
\hline Tratamento Psicossocial & $\mathrm{N}$ & $(\%)$ \\
\hline Psicoterapia Individual & 23 & 69,7 \\
\hline Psicoterapia Familiar & 2 & 6,1 \\
\hline Atendimento Psicopedagógico & 5 & 15,2 \\
\hline Outros & 2 & 6,1 \\
\hline Estados do humor & $\mathrm{N}$ & $(\%)$ \\
\hline Depressão & 3 & 9,1 \\
\hline Hipomania & 7 & 21,2 \\
\hline Misto & 3 & 9,1 \\
\hline Mania & 11 & 33,3 \\
\hline Eutimia & 9 & 27,3 \\
\hline Escala de Mania (YMRS) (Média e Desvio-Padrão) & & $9,73(7,76)$ \\
\hline $\begin{array}{l}\text { Escala para Avaliação de Depressão em Crianças -Revisada (CDRS-R) } \\
\text { (Média e Desvio-Padrão) }\end{array}$ & & $29,21(12,10)$ \\
\hline Escala de Impressão Global (CGI) (Média e Desvio-Padrão) & & $3,85(1,12)$ \\
\hline C-GAS & & \\
\hline C- GAS atual (Média e Desvio-Padrão) & & $51,94(9,66)$ \\
\hline C-GAS melhor (Média e Desvio-Padrão) & & $58,61(9,82)$ \\
\hline C-GAS pior (Média e Desvio-Padrão) & & $42,88(8,04)$ \\
\hline Comorbidades & $\mathrm{N}$ & $(\%)$ \\
\hline Transtorno de Déficit de Atenção e Hiperatividade & 17 & 51,5 \\
\hline Transtorno Opositor Desafiador & 9 & 27,3 \\
\hline Transtorno de Ansiedade Generalizada & 9 & 27,3 \\
\hline Transtorno de Conduta & 4 & 12,1 \\
\hline Fobia Simples & 3 & 9,1 \\
\hline Fobia Social & 2 & 6,1 \\
\hline Pânico & 2 & 6,1 \\
\hline TOC & 2 & 6,1 \\
\hline Transtorno de Ansiedade de Separação & 1 & 3,0 \\
\hline Agorafobia & 1 & 3,0 \\
\hline Transtorno de Estresse Pós-Traumático & 1 & 3,0 \\
\hline Tourette & 1 & 3,0 \\
\hline Abuso de Substâncias & 1 & 3,0 \\
\hline
\end{tabular}




\subsection{Avaliação da família}

\subsubsection{Inventário de Adjetivos de Emoção Expressa}

Os familiares com filhos com THB apresentaram maior intensidade de EE negativa sobre o comportamento do filho (a) em relação à mãe/pai $(F=98,27, p<$ 0,001) e sobre o comportamento da mãe/pai em relação ao filho (a) $(F=31,72, p<$ 0,001) do que as famílias sem transtornos psiquiátricos. Em relação à EE positiva, as famílias com filhos com THB apresentaram baixa EE positiva referente ao comportamento do filho (a) em relação à mãe/pai $(\mathrm{F}=51,57$ e $\mathrm{p}<0,001)$ e do comportamento da mãe/pai em relação ao filho (a) $(\mathrm{F}=18,38$ e $\mathrm{p}<0,001)$ (Tabela 3). Com a correção para múltiplas análises nessa escala $(p=0,05 / 4)$, adotamos $p \leq$ 0,013 e os resultados permanecem significativos.

Quanto maior o nível socioeconômico dos pais menor a pontuação de EE negativa do comportamento do filho (a) em relação a mãe/pai $(F=8,58$ e $p=0,005)$ (Tabela 4).

Não foi, também, encontrado nenhum efeito significativo quando foi ajustado um modelo controlando pela idade, sexo, etnia, QI, grau de puberdade, psicose 2 grupos (psicose e não psicose), família não intacta, tipo de THB das crianças e adolescentes (I e II versus SOE), diagnóstico dos pais unilineal versus bilineal versus sem nenhum desses diagnósticos, comorbidades das crianças e adolescentes com THB (com comorbidades versus sem comorbidades, TDAH versus sem transtornos psiquiátricos; TOD + TC versus sem transtornos psiquiátricos), estados 
do humor mania + hipomania + misto versus depressão versus eutimia e idade do primeiro diagnóstico THB. 
Tabela 3 - Emoção Expressa (EE) entre parentes de famílias com filhos com THB versus famílias com filhos sem transtornos psiquiátricos com variáveis de controle

\begin{tabular}{|c|c|c|c|c|c|c|c|c|c|c|c|c|}
\hline & \multicolumn{3}{|c|}{ THB $(n=33)$} & \multicolumn{3}{|c|}{ Controle $(\mathrm{n}=29)$} & \multicolumn{6}{|c|}{ Comparação } \\
\hline & Média & D.P. & Min-Max & Média & D.P. & Min-Max & $F$ & Valor-p & Poder & TE & g.1. & Escore-z \\
\hline EE positiva $^{a}$ & 49,58 & 12,41 & $26-76$ & 71,72 & 10,14 & $41-80$ & 51,57 & $<0,001$ & 1,000 & 0,475 & $1 / 53$ & $-2,18$ \\
\hline EE negativa $^{a}$ & 48,94 & 10,22 & $26-74$ & 22,62 & 10,26 & $10-44$ & 98,27 & $<0,001$ & 1,000 & 0,633 & $1 / 53$ & 2,57 \\
\hline EE positiva $^{\mathbf{b}}$ & 61,21 & 9,70 & $44-79$ & 72,17 & 8,73 & $43-80$ & 18,38 & $<0,001$ & 0,988 & 0,244 & $1 / 53$ & $-1,26$ \\
\hline EE negativa $^{\mathbf{b}}$ & 34,73 & 9,00 & $19-55$ & 21,38 & 7,88 & $10-42$ & 31,72 & $<0,001$ & 1,000 & 0,358 & $1 / 53$ & 1,69 \\
\hline
\end{tabular}

a Comportamento do filho (a) com relação à mãe/pai, b Comportamento da mãe/pai com relação ao filho (a), D.P.: desvio-padrão, Min: mínimo, Max: máximo, F: estatística de teste, TE: tamanho de efeito (até 0,3: efeito pequeno, de 0,3 a 0,7: efeito médio, maior que 0,7: efeito grande), g.l.: graus de liberdade

Tabela 4 - Associação entre nível socioeconômico e Inventário de Adjetivos de Emoção Expressa medido pelo modelo de ANCOVA

\begin{tabular}{lccccccc}
\hline \hline Variável & Parâmetro & Coef. (B) & F & Valor-p & Poder & TE & g.1. \\
\hline EE negativa $^{a}$ & Nível Socioeconômico & $-0,219$ & 8,58 & 0,005 & 0,821 & 0,131 & $1 / 53$ \\
\hline \hline
\end{tabular}

a Comportamento do filho (a) com relação à mãe/pai, Coef.: coeficiente de regressão, F: estatística de teste, TE: tamanho de efeito (até 0,3: efeito pequeno, de 0,3 a 0,7: efeito médio, maior que 0,7: efeito grande), g.l.: graus de liberdade 


\subsubsection{Escala Psicossocial para Crianças em Idade Escolar - Revisada}

As famílias com crianças e adolescentes com THB apresentaram baixo acolhimento materno em relação às famílias com crianças sem transtornos psiquiátricos (Wald $=3,831$, $\mathrm{p}=0,050)$. Quando classificamos o acolhimento materno em alto e baixo, as famílias com filhos com THB apresentaram, em $84,4 \%$ dos casos, baixo acolhimento materno, enquanto as famílias com filhos sem transtornos psiquiátricos apresentaram apenas em 55,2\%. Isso resulta numa razão de chances de 3,83 , ou seja, as famílias com crianças e adolescentes com THB apresentaram aproximadamente 4 vezes mais chance de ter baixo acolhimento materno, comparado às famílias com filhos sem transtornos psiquiátricos (Tabela 5).

Quanto ao acolhimento paterno, as famílias com crianças e adolescentes com THB apresentaram, com maior freqüência, baixo grau em relação às famílias com crianças sem transtornos psiquiátricos (Wald $=3,979, \mathrm{p}=0,046)$. Quando classificamos o acolhimento paterno em alto e baixo, as famílias com filhos com THB apresentaram, em 86,7\% dos casos, baixo acolhimento paterno, enquanto as famílias com filhos sem transtornos psiquiátricos apresentaram apenas $65,4 \%$ de baixo acolhimento paterno (razão de chances $(\mathrm{RC})=4,83)($ Tabela 5).

Em relação à tensão materna, as famílias com crianças e adolescentes com THB apresentaram mais frequentemente alto grau, quando comparadas às famílias com crianças sem transtornos psiquiátricos $(\mathrm{p}<0,001)$. Classificando as famílias de acordo com o grau de tensão materna (alto e baixo), observamos que as famílias com filhos com THB se apresentaram, em 100\% dos casos, com alta tensão materna, enquanto 58,6\% das famílias com filhos sem transtornos psiquiátricos apresentaram alta tensão materna (Tabela 5). 
Nesse caso a razão de chances não pode ser definida, pois um dos grupos tem prevalência 1.

As famílias com crianças e adolescentes com THB apresentaram mais alta tensão paterna (Wald $=8,551, \mathrm{p}=0,003$ ), quando comparadas às famílias com crianças sem transtornos psiquiátricos. Alta tensão paterna ocorreu em $96,7 \%$ das famílias com filhos com THB, e em 57,7\% das famílias com filhos sem transtornos psiquiátricos [razão de chances $(\mathrm{RC})=51,43]($ Tabela 5$)$.

As famílias com filhos com THB apresentaram maior frequência de família não intacta $(60,6 \%)$ do que as famílias sem transtornos psiquiátricos $(20,7 \%)$ (Wald $=6,999, \mathrm{p}$ $=0,008)$. Isso resulta numa razão de chances 5,55 (Tabela 5).

O método de Bonferroni foi utilizado para corrigir comparações múltiplas. Nesse método, o valor de significância p 0,05 é dividido pelo número de comparações para proteger contra erros do tipo I. Os valores de probabilidade corrigidos e o número de comparações em cada domínio foram os seguintes: duas comparações e um $p \leq 0,025$, corrigido para boa saúde da mãe e do pai; oito comparações e um $p \leq 0,006$, corrigido para perinatal; quatro comparações e um $\mathrm{p} \leq 0,013$, corrigido para como seu filho (a) era quando criança (antes do primeiro ano de vida); cinco comparações e um $p \leq 0,010$, corrigido para como seu filho era antes da pré-escola; quatro comparações e um $p \leq 0,013$, corrigido para como seu filho (a) era na escola primária. Foram feitas uma comparação e um $\mathrm{p} \leq 0,050$ corrigido para excelente saúde física atual da criança/adolescente, oito comparações e um $\mathrm{p} \leq 0,006$, corrigido para tipo de doença crônica, vinte e quatro comparações e um $p \leq 0,002$, corrigido para escolaridade, duas comparações e um $p \leq$ 0,025, corrigido para funcionamento da criança na escola. Foram feitas uma comparação e um $\mathrm{p} \leq 0,050$ para família não intacta, uma comparação e um $\mathrm{p} \leq 0,050$ para relação pais - 
filho (a), dez comparações e um $p \leq 0,005$, corrigido para relação mãe - filho (a), dez comparações e um $p \leq 0,005$ corrigido para relação pai - filho (a), uma comparação e um p $\leq 0,050$ para indícios de abuso sexual, oito comparações e um $p \leq 0,006$, corrigido para relações com os colegas, duas comparações e um $\mathrm{p} \leq 0,025$, corrigido para relacionamento com irmãos, uma comparação e um $\mathrm{p} \leq 0,050$ corrigido para outros relacionamentos significativos, quatorze comparações e um $\mathrm{p} \leq 0,004$ corrigido para relação entre os pais ou o casal e duas comparações e um $\mathrm{p} \leq 0,025$ corrigido para exposição da criança à violência familiar no último ano.

Os resultados permanecem significativos exceto para: icterícia, problemas respiratórios e destrutivo. Em relação à escola primária: problemas de leitura e problemas de escrita. Em tipo de doença crônica: asma. Funcionamento na escola atualmente: sala regular com reforço. Na Relação mãe - filho (a): atividades conjuntas frequentes, sempre confia e baixo acolhimento materno. Na relação pai - filho (a): atividades conjuntas frequentes, sempre confia, ambiente consistente em relação aos limites impostos, hostilidade frequente e baixo acolhimento paterno. Nas relações com os colegas: tímido com os amigos e boas relações entre colegas. Na relação entre os pais ou o casal: ausência de reclamação e os assuntos de importância são plenamente discutidos/resolvidos.

Encontramos diferenças significativas para as seguintes variáveis: boa saúde da mãe; difícil de confortar; dificuldade para dormir; desajeitado, caia no chão bastante; tendência a sofrer acidentes; propenso a se envolver em situações de risco e sensívelsentimentos facilmente feridos, magoava-se facilmente. Em relação à escola primária: problemas com matemática. Excelente saúde física atual criança/adolescente. Escolaridade em algum período da vida: repetiu o ano sala; regular e sala regular com reforço; atualmente: sala regular. Funcionamento na escola: problemas de comportamento na escola 
e baixo desempenho acadêmico. Família não intacta. Na relação mãe e filho: conversas diárias, ambiente consistente em relação aos limites impostos; hostilidade frequente e alta tensão materna. Na relação pai e filho: conversas diárias e alta tensão paterna. Indícios de abuso sexual. Na relação com os amigos: Possui um amigo há dois anos ou mais e provocado frequentemente pelos colegas. No relacionamento com irmãos: relacionamento adequado com os irmãos e boa compreensão com os irmãos e cooperação mútua.

As variáveis utilizadas nas análises foram: idade, sexo, etnia, QI, grau de puberdade e nível socioeconômico dos pais (tabela 5). Porém apresentamos apenas o teste que compara os dois grupos, conforme realizado no estudo de Geller et al. (2000b). 
Tabela 5 - Comparação da Escala Psicossocial para Crianças em Idade Escolar - Revisada com variáveis de controle entre famílias com filhos com THB e famílias com filhos sem transtornos psiquiátricos

\begin{tabular}{|c|c|c|c|c|c|c|c|}
\hline & \multirow[b]{2}{*}{$\begin{array}{c}\text { THB } \\
(\mathrm{n}=33) \\
\%\end{array}$} & \multirow[b]{2}{*}{$\begin{array}{c}\text { Controle } \\
(\mathrm{n}=29) \\
\%\end{array}$} & \multicolumn{5}{|c|}{ Comparação } \\
\hline & & & Wald & Valor-p & g.l. & $\mathrm{RC}(\mathrm{THB})$ & $\begin{array}{l}\text { Limite da } \\
\text { correção de } \\
\text { Bonferroni } \\
\end{array}$ \\
\hline $\begin{array}{l}\text { Boa saúde do pai (Qualquer doença que resulte em comprometimento } \\
\text { funcional) }\end{array}$ & 46,7 & 69,2 & 3,098 & 0,078 & 1 & 0,27 & 0,025 \\
\hline $\begin{array}{l}\text { Boa saúde da mãe (Qualquer doença que resulte em comprometimento } \\
\text { funcional) }\end{array}$ & 34,4 & 69,0 & 6,363 & 0,012 & 1 & 0,19 & \\
\hline Perinatal: & - & - & - & - & - & - & 0,006 \\
\hline 1 Bebê foi prematuro? & 21,2 & 3,4 & 3,664 & 0,056 & 1 & 21,99 & - \\
\hline 2 Complicação ao nascimento? & 9,1 & 13,8 & 0,050 & 0,824 & 1 & 0,81 & - \\
\hline a. asfixia (sem oxigênio suficiente) * & 6,1 & 0,0 & - & 0,494 & - & - & - \\
\hline b. icterícia & 54,5 & 27,6 & 4,832 & 0,028 & 1 & 4,31 & - \\
\hline c. problemas respiratórios $*$ & 18,2 & 0,0 & - & 0,026 & - & - & - \\
\hline d. convulsões & 0,0 & 0,0 & - & - & - & - & - \\
\hline e. trauma de parto & 0,0 & 0,0 & - & - & - & - & - \\
\hline f. baixo açucar no sangue * & 3,0 & 0,0 & - & 1,000 & - & - & - \\
\hline
\end{tabular}


Tabela 5 - Comparação da Escala Psicossocial para Crianças em Idade Escolar - Revisada com variáveis de controle entre famílias com filhos com THB e famílias com filhos sem transtornos psiquiátricos

\begin{tabular}{|c|c|c|c|c|c|c|c|}
\hline & \multirow[b]{2}{*}{$\begin{array}{c}\text { THB } \\
(\mathrm{n}=33) \\
\%\end{array}$} & \multirow[b]{2}{*}{$\begin{array}{c}\text { Controle } \\
(\mathrm{n}=29) \\
\%\end{array}$} & \multicolumn{5}{|c|}{ Comparação } \\
\hline & & & Wald & Valor-p & g.l. & $\mathrm{RC}(\mathrm{THB})$ & $\begin{array}{c}\text { Limite da } \\
\text { correção de } \\
\text { Bonferroni }\end{array}$ \\
\hline Como seu filho (a) era quando criança (antes do primeiro ano de vida) & - & - & - & - & - & - & 0,013 \\
\hline Difícil de confortar? & 39,4 & 3,4 & 6,997 & 0,008 & 1 & 20,13 & - \\
\hline Dificuldade para dormir? & 42,4 & 13,8 & 6,317 & 0,012 & 1 & 7,02 & - \\
\hline $\begin{array}{l}\text { Cólicas (pelo menos } 2 \text { semanas de choro constante após alimentação? } \\
\text { Amamentação? nos primeiros } 2 \text { meses)? }\end{array}$ & 30,3 & 34,5 & 0,021 & 0,886 & 1 & 0,92 & - \\
\hline Gostava de carinho? * & 9,1 & 0,0 & - & 0,241 & - & - & - \\
\hline Como seu filho era antes da pré-escola & - & - & - & - & - & - & 0,010 \\
\hline Destrutivo? * & 21,2 & 0,0 & - & 0,012 & - & - & \\
\hline Desajeitado, caia no chão bastante? & 42,4 & 3,4 & 8,279 & 0,004 & 1 & 60,70 & - \\
\hline Tendência a sofrer acidentes?* & 30,3 & 0,0 & - & 0,001 & - & - & - \\
\hline $\begin{array}{l}\text { Propenso a se envolver em situações de risco independente do perigo } \\
\text { envolvido }\end{array}$ & 42,4 & 6,9 & 7,568 & 0,006 & 1 & 25,82 & - \\
\hline Sensível-sentimentos facilmente feridos, magoava-se facilmente? & 54,5 & 13,8 & 11,046 & 0,001 & 1 & 16,69 & - \\
\hline Como seu filho (a) era na escola primária & - & - & - & - & - & - & 0,013 \\
\hline Problemas de linguagem? & 24,2 & 6,9 & 1,296 & 0,255 & 1 & 2,88 & - \\
\hline Problemas de leitura? & 36,4 & 3,4 & 5,969 & 0,015 & 1 & 22,94 & - \\
\hline Problemas de escrita? & 39,4 & 13,8 & 5,876 & 0,015 & 1 & 7,31 & - \\
\hline Problemas com matemática? $*$ & 33,3 & 0,0 & - & $<0,001$ & - & - & - \\
\hline
\end{tabular}


Tabela 5 - Comparação da Escala Psicossocial para Crianças em Idade Escolar - Revisada com variáveis de controle entre famílias com filhos com THB e famílias com filhos sem transtornos psiquiátricos

\begin{tabular}{|c|c|c|c|c|c|c|c|}
\hline & \multirow{2}{*}{$\begin{array}{c}\text { THB } \\
(\mathrm{n}=33) \\
\%\end{array}$} & \multirow{2}{*}{$\begin{array}{c}\text { Controle } \\
(\mathrm{n}=29) \\
\%\end{array}$} & \multicolumn{5}{|c|}{ Comparação } \\
\hline & & & Wald & Valor-p & g.l. & $\mathrm{RC}(\mathrm{THB})$ & $\begin{array}{l}\text { Limite da } \\
\text { correção de } \\
\text { Bonferroni }\end{array}$ \\
\hline Excelente Saúde Física da criança/adolescente (atual): & 57,6 & 89,7 & 7,286 & 0,007 & 1 & 0,10 & 0,050 \\
\hline Tipo de doença crônica & - & - & - & - & - & - & 0,006 \\
\hline Epilepsia & 0,0 & 0,0 & - & - & - & - & - \\
\hline Asma * & 18,2 & 0,0 & - & 0,026 & - & - & - \\
\hline Problemas cardíacos & 0,0 & 0,0 & - & - & - & - & - \\
\hline Problemas renais * & 3,0 & 0,0 & - & 1,000 & - & - & - \\
\hline Problemas do trato gastro-intestinal & 18,2 & 6,9 & 0,000 & 0,999 & 1 & 3,73 & - \\
\hline Problemas de tiróide & 0,0 & 0,0 & 1,809 & 0,179 & 1 & - & - \\
\hline Problemas reumatológicos* & 3,0 & 0,0 & - & 1,000 & - & - & - \\
\hline Outros (especificar) & 51,5 & 55,2 & 0,084 & 0,772 & 1 & 0,84 & - \\
\hline
\end{tabular}


Tabela 5 - Comparação da Escala Psicossocial para Crianças em Idade Escolar - Revisada com variáveis de controle entre famílias com filhos com THB e famílias com filhos sem transtornos psiquiátricos

\begin{tabular}{|c|c|c|c|c|c|c|c|}
\hline & \multirow{2}{*}{$\begin{array}{c}\text { THB } \\
(\mathrm{n}=33) \\
\%\end{array}$} & \multirow{2}{*}{$\begin{array}{c}\text { Controle } \\
(\mathrm{n}=29) \\
\%\end{array}$} & \multicolumn{5}{|c|}{ Comparação } \\
\hline & & & Wald & Valor-p & g.l. & RC (THB) & $\begin{array}{l}\text { Limite da } \\
\text { correção de } \\
\text { Bonferroni } \\
\end{array}$ \\
\hline Escolaridade & & & & & & & 0,002 \\
\hline Tipo de Escola em algum período da vida & - & - & - & - & - & - & - \\
\hline 01 Repetiu o ano * & 30,3 & 0,0 & - & 0,001 & - & - & - \\
\hline 02 Sala regular $*$ & 48,5 & 100,0 & - & $<0,001$ & - & - & - \\
\hline 03 Sala regular com reforço $*$ & 27,3 & 0,0 & - & 0,002 & - & - & - \\
\hline 04 Sala especial & 0,0 & 0,0 & - & - & - & - & - \\
\hline 07 Escola especial & 0,0 & 0,0 & - & - & - & - & - \\
\hline 08 Parcialmente internado & 0,0 & 0,0 & - & - & - & - & - \\
\hline 09 Institucionalizado & 0,0 & 0,0 & - & - & - & - & - \\
\hline 10 Não vai à escola, porém muito novo para ter largado a escola & 0,0 & 0,0 & - & - & - & - & - \\
\hline 11 Largou a escola, fazendo supletivo & 0,0 & 0,0 & - & - & - & - & - \\
\hline 12 Largou a escola & 3,0 & 0,0 & - & - & - & - & - \\
\hline 13 Já se formou & 0,0 & 0,0 & - & - & - & - & - \\
\hline 14 Colocação avançada & 0,0 & 0,0 & - & - & - & - & - \\
\hline
\end{tabular}


Tabela 5 - Comparação da Escala Psicossocial para Crianças em Idade Escolar - Revisada com variáveis de controle entre famílias com filhos com THB e famílias com filhos sem transtornos psiquiátricos

\begin{tabular}{|c|c|c|c|c|c|c|c|}
\hline & \multirow[b]{2}{*}{$\begin{array}{c}\text { THB } \\
(\mathrm{n}=33) \\
\%\end{array}$} & \multirow{2}{*}{$\begin{array}{c}\text { Controle } \\
(\mathrm{n}=29) \\
\%\end{array}$} & \multicolumn{5}{|c|}{ Comparação } \\
\hline & & & Wald & Valor-p & g.l. & RC (THB) & $\begin{array}{l}\text { Limite da } \\
\text { correção de } \\
\text { Bonferroni } \\
\end{array}$ \\
\hline Tipo de Escola Atualmente & - & - & - & - & - & - & - \\
\hline 01 Repetiu o ano * & 6,1 & 0,0 & - & 0,494 & - & - & - \\
\hline 02 Sala regular * & 63,6 & 96,6 & - & 0,002 & - & 0,063 & - \\
\hline 03 Sala regular com reforço * & 18,2 & 0,0 & - & 0,026 & - & - & - \\
\hline 04 Sala especial & 0,0 & 0,0 & - & - & - & - & - \\
\hline 07 Escola especial * & 3,0 & 0,0 & - & 1,000 & - & - & - \\
\hline 08 Parcialmente internado & 0,0 & 0,0 & - & - & - & - & - \\
\hline 09 Institucionalizado & 0,0 & 0,0 & - & - & - & - & - \\
\hline 10 Não vai à escola, porém muito novo para ter largado a escola * & 3,0 & 0,0 & - & 1,000 & - & - & - \\
\hline 11 Largou a escola, fazendo supletivo & 0,0 & 0,0 & - & - & - & - & - \\
\hline 12 Largou a escola * & 12,1 & 0,0 & - & 0,116 & - & - & - \\
\hline 13 Já se formou & 0,0 & 3,4 & - & - & - & - & - \\
\hline 14 Colocação avançada & 0,0 & 0,0 & - & - & - & - & - \\
\hline Funcionamento da criança na escola & - & - & - & - & - & - & 0,025 \\
\hline A. Problemas de comportamento na escola & 81,8 & 3,4 & 13,752 & $<0,001$ & 1 & 544,11 & - \\
\hline B. Baixo desempenho acadêmico & 84,8 & 37,9 & 14,320 & $<0,001$ & 1 & 17,80 & - \\
\hline Família não intacta & 60,6 & 20,7 & 6,999 & 0,008 & 1 & 5,55 & 0,050 \\
\hline
\end{tabular}


Tabela 5 - Comparação da Escala Psicossocial para Crianças em Idade Escolar - Revisada com variáveis de controle entre famílias com filhos com THB e famílias com filhos sem transtornos psiquiátricos

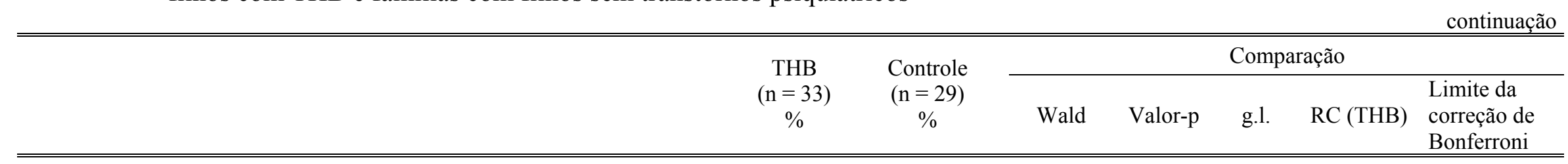

Relação Pais - Filho (a)

Boa relação entre os pais separados

Relação mãe - Filho (a)

1. Atividades conjuntas frequentes

2. Conversas diárias *

3. Sempre confia

4. Ambiente consistente em relação aos limites impostos

5. Hostilidade frequente

6. Ausência de castigo corporal

7. Tipo de castigo físico (tapa, surra, bater sem perder o controle e espancamento)

8. Pior Castigo Físico durante o último ano (tapa, surra, bater sem perder

o controle e espancamento)

9. Baixo acolhimento materno

10. Alta tensão materna *
30.8

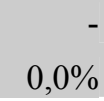

0,000

1,000

-

0,00

0,050

$\begin{array}{rrrrrr}- & - & - & - & - \\ 62,5 & 86,2 & 4,152 & 0,042 & 1 & 0,24 \\ 75,0 & 100,0 & - & 0,005 & - & - \\ 50,0 & 75,9 & 6,558 & 0,010 & 1 & 0,17 \\ 40,6 & 82,8 & 12,174 & <0,001 & 1 & 0,05 \\ 81,3 & 17,2 & 16,921 & <0,001 & 1 & 41,22 \\ 53,1 & 75,9 & 1,600 & 0,206 & 1 & 0,42 \\ 62,5 & 58,6 & 0,000 & 0,983 & 1 & 0,99 \\ 65,6 & 62,1 & 0,083 & 0,773 & 1 & 0,84 \\ 84,4 & 55,2 & 3,831 & 0,050 & 1 & 3,83 \\ 100,0 & 58,6 & - & <0,001 & - & -\end{array}$

0,005

-

continua 
Tabela 5 - Comparação da Escala Psicossocial para Crianças em Idade Escolar - Revisada com variáveis de controle entre famílias com filhos com THB e famílias com filhos sem transtornos psiquiátricos

\begin{tabular}{|c|c|c|c|c|c|c|c|}
\hline & \multirow{2}{*}{$\begin{array}{c}\text { THB } \\
(\mathrm{n}=33) \\
\%\end{array}$} & \multirow{2}{*}{$\begin{array}{c}\text { Controle } \\
(\mathrm{n}=29) \\
\%\end{array}$} & \multicolumn{5}{|c|}{ Comparação } \\
\hline & & & Wald & Valor-p & g.l. & $\mathrm{RC}(\mathrm{THB})$ & $\begin{array}{l}\text { Limite da } \\
\text { correção de } \\
\text { Bonferroni } \\
\end{array}$ \\
\hline Relação pai - Filho (a) & - & - & - & - & - & - & 0,005 \\
\hline 1. Atividades conjuntas frequentes & 36,7 & 65,4 & 6,109 & 0,013 & 1 & 0,18 & - \\
\hline 2. Conversas diárias & 36,7 & 80,8 & 9,953 & 0,002 & 1 & 0,02 & - \\
\hline 3. Sempre confia & 36,7 & 61,5 & 7,006 & 0,008 & 1 & 0,12 & - \\
\hline 4. Ambiente consistente em relação aos limites impostos & 50,0 & 73,1 & 3,858 & 0,049 & 1 & 0,25 & - \\
\hline 5. Hostilidade frequente & 43,3 & 11,5 & 5,371 & 0,020 & 1 & 7,00 & - \\
\hline 6. Ausência de castigo corporal & 80,0 & 84,6 & 0,050 & 0,823 & 1 & 0,83 & - \\
\hline $\begin{array}{l}\text { 7. Tipo de castigo físico (tapa, surra, bater sem perder o controle e } \\
\text { espancamento) }\end{array}$ & 36,7 & 30,8 & 0,028 & 0,868 & 1 & 0,90 & - \\
\hline $\begin{array}{l}\text { 8. Pior Castigo Físico durante o último ano (tapa, surra, bater sem perder } \\
\text { o controle e espancamento) }\end{array}$ & 56,7 & 34,6 & 2,051 & 0,152 & 1 & 2,60 & - \\
\hline 9. Baixo acolhimento paterno & 86,7 & 65,4 & 3,979 & 0,046 & 1 & 4,83 & - \\
\hline 10. Alta tensão paterna & 96,7 & 57,7 & 8,551 & 0,003 & 1 & 51,43 & - \\
\hline Indícios de Abuso Sexual & 36,4 & 10,3 & 5,060 & 0,024 & 1 & 6,79 & $\begin{array}{r}0,050 \\
\text { continua }\end{array}$ \\
\hline
\end{tabular}


Tabela 5 - Comparação da Escala Psicossocial para Crianças em Idade Escolar - Revisada com variáveis de controle entre famílias com filhos com THB e famílias com filhos sem transtornos psiquiátricos

\begin{tabular}{|c|c|c|c|c|c|c|c|}
\hline & \multirow{2}{*}{$\begin{array}{c}\text { THB } \\
(\mathrm{n}=33) \\
\%\end{array}$} & \multirow{2}{*}{$\begin{array}{c}\text { Controle } \\
(\mathrm{n}=29) \\
\%\end{array}$} & \multicolumn{5}{|c|}{ Comparação } \\
\hline & & & Wald & Valor-p & g.l. & $\mathrm{RC}(\mathrm{THB})$ & $\begin{array}{l}\text { Limite da } \\
\text { correção de } \\
\text { Bonferroni }\end{array}$ \\
\hline Relações com colegas & - & - & - & - & - & - & 0,006 \\
\hline 1. Muitos amigos & 21,2 & 37,9 & 2,441 & 0,118 & 1 & 0,37 & - \\
\hline 2. Possui um amigo especial & 66,7 & 89,7 & 3,180 & 0,075 & 1 & 0,24 & - \\
\hline 3. Tímido com os amigos & 48,5 & 31,0 & 4,449 & 0,035 & 1 & 4,72 & - \\
\hline 4. Possui um amigo há dois anos ou mais * & 66,7 & 100,0 & - & $<0,001$ & - & - & - \\
\hline 5. Visitas frequentes dos amigos em casa & 12,1 & 6,9 & 0,466 & 0,495 & 1 & 2,08 & - \\
\hline 6. Visitas frequentes à casa dos amigos & 12,1 & 10,3 & 0,006 & 0,937 & 1 & 0,93 & - \\
\hline 7. Provocado frequentemente pelos colegas & 72,7 & 27,6 & 7,708 & 0,005 & 1 & 5,61 & - \\
\hline 8. Boas relações entre colegas & 9,1 & 31,0 & 4,280 & 0,039 & 1 & 0,20 & - \\
\hline Relacionamento com irmãos & - & - & - & - & - & - & 0,025 \\
\hline Relacionamento adequado com os irmãos & 33,3 & 87,0 & 11,215 & 0,001 & 1 & 0,06 & - \\
\hline Boa compreensão com os irmãos e cooperação mútua * & 0,0 & 34,8 & - & 0,001 & - & - & - \\
\hline Outros relacionamentos significativos & 72,7 & 75,9 & 0,002 & 0,964 & 1 & 0,97 & 0,050 \\
\hline
\end{tabular}


Tabela 5 - Comparação da Escala Psicossocial para Crianças em Idade Escolar - Revisada com variáveis de controle entre famílias com filhos com THB e famílias com filhos sem transtornos psiquiátricos

\begin{tabular}{|c|c|c|c|c|c|c|c|}
\hline & \multirow{2}{*}{$\begin{array}{c}\text { THB } \\
(\mathrm{n}=33) \\
\%\end{array}$} & \multirow{2}{*}{$\begin{array}{c}\text { Controle } \\
(\mathrm{n}=29) \\
\%\end{array}$} & \multicolumn{5}{|c|}{ Comparação } \\
\hline & & & Wald & Valor-p & g.l. & RC (THB) & $\begin{array}{l}\text { Limite da } \\
\text { correção de } \\
\text { Bonferroni }\end{array}$ \\
\hline Relação entre os pais ou o casal & - & - & - & - & - & - & 0,004 \\
\hline Irritabilidade dentro do casal $\leq 1$ vez por mês & 31,6 & 64,0 & 3,192 & 0,074 & 1 & 0,29 & - \\
\hline Ausência de reclamação & 5,3 & 36,0 & 4,019 & 0,045 & 1 & 0,09 & - \\
\hline Nenhuma ou discussões infrequentes & 68,4 & 88,0 & 1,550 & 0,213 & 1 & 0,31 & - \\
\hline Violência física entre o casal & - & - & - & - & - & - & - \\
\hline Ausência de violência física entre o casal & 78,9 & 88,0 & 0,024 & 0,876 & 1 & 1,18 & - \\
\hline Atividades conjuntas a maior parte do tempo & 52,6 & 44,0 & 0,074 & 0,786 & 1 & 1,22 & - \\
\hline Relacionamento caloroso e afetuoso & 47,4 & 60,0 & 0,443 & 0,506 & 1 & 0,61 & - \\
\hline Conversas suficientes para a satisfação de ambos & 57,9 & 72,0 & 1,163 & 0,281 & 1 & 0,43 & - \\
\hline Os assuntos de importância são plenamente discutidos/resolvidos & 63,2 & 92,0 & 5,023 & 0,025 & 1 & 0,05 & - \\
\hline Educação Infantil & - & & - & - & - & - & - \\
\hline Sem contradições em relação a educação das crianças & 68,4 & 88,0 & 2,905 & 0,088 & 1 & 0,20 & - \\
\hline Satisfação com a divisão das atividades domésticas e outras tarefas & 52,6 & 68,0 & 3,152 & 0,076 & 1 & 0,26 & - \\
\hline Tomadas de decisão (predominantemente o marido) & 20,0 & 24,0 & 0,000 & 0,989 & 1 & 1,01 & - \\
\hline Atividades em família de algum tipo (pelo menos uma vez por semana) & 63,2 & 84,0 & 1,152 & 0,283 & 1 & 0,39 & - \\
\hline Baixo acolhimento entre o casal & 84,2 & 68,0 & 2,033 & 0,154 & 1 & 3,45 & - \\
\hline Alta tensão entre o casal & 89,5 & 80,0 & 1,226 & 0,268 & 1 & 3,20 & - \\
\hline
\end{tabular}


Tabela 5 - Comparação da Escala Psicossocial para Crianças em Idade Escolar - Revisada com variáveis de controle entre famílias com filhos com THB e famílias com filhos sem transtornos psiquiátricos

\begin{tabular}{|c|c|c|c|c|c|c|c|}
\hline & \multirow{2}{*}{$\begin{array}{c}\text { THB } \\
(\mathrm{n}=33) \\
\%\end{array}$} & \multirow{2}{*}{$\begin{array}{c}\text { Controle } \\
(\mathrm{n}=29) \\
\%\end{array}$} & \multicolumn{5}{|c|}{ Comparação } \\
\hline & & & Wald & Valor-p & g.l. & $\mathrm{RC}(\mathrm{THB})$ & $\begin{array}{l}\text { Limite da } \\
\text { correção de } \\
\text { Bonferroni }\end{array}$ \\
\hline Exposição da criança à violência familiar no último ano & - & - & - & - & - & - & \\
\hline Exposição à vilolência familiar frequente & 18,2 & 3,4 & 1,501 & 0,221 & 1 & 4,142 & 0,025 \\
\hline $\begin{array}{l}\text { Gravidade da violência familiar testemunhada pela criança (tapas, bater } \\
\text { sem perder o controle ou ambos) }\end{array}$ & 12,1 & 3,4 & 0,863 & 0,353 & 1 & 3,01 & \\
\hline
\end{tabular}

Wald: estatística de teste, g.l.: graus de liberdade, RC: razão de chances

* Teste Exato de Fisher

Os valores de probabilidade corrigidos e o número de comparações em cada domínio foram os seguintes: duas comparações e um $p \leq 0,025$, corrigido para boa saúde da mãe e do pai; oito comparações e um $p \leq 0,006$, corrigido para perinatal; quatro comparações e um $p \leq 0,013$, corrigido para como seu filho (a) era quando criança (antes do primeiro ano de vida); cinco comparações e um $\mathrm{p} \leq 0,010$, corrigido para como seu filho era antes da pré-escola; quatro comparações e um $\mathrm{p} \leq 0,013$, corrigido para como seu filho (a) era na escola primária. Foram feitas uma comparação e um $p \leq 0,050$ corrigido para excelente saúde física atual da criança/adolescente, oito comparações e um $p \leq 0,006$, corrigido para tipo de doença crônica, vinte e quatro comparações e um $\mathrm{p} \leq 0,002$, corrigido para escolaridade, duas comparações e um $\mathrm{p} \leq 0,025$, corrigido para funcionamento da criança na escola. Foram feitas uma comparação e um $\mathrm{p} \leq 0,050$ para família não intacta, uma comparação e um $\mathrm{p} \leq 0,050$ para relação pais - filho (a), dez comparações e um $\mathrm{p} \leq 0,005$, corrigido para relação mãe - filho (a), dez comparações e um $p \leq 0,005$ corrigido para relação pai - filho (a), uma comparação e um $p \leq 0,050$ para indícios de abuso sexual, oito comparações e um $p \leq 0$,006, corrigido para relações com os colegas, duas comparações e um $\mathrm{p} \leq 0,025$, corrigido para relacionamento com irmãos, uma comparação e um $\mathrm{p} \leq 0,050$ corrigido para outros relacionamentos significativos, quatorze comparações e um $\mathrm{p} \leq 0,004$ corrigido para relação entre os pais ou o casal e duas comparações e um $\mathrm{p} \leq 0,025$ corrigido para exposição da criança à violência familiar no último ano. 


\subsubsection{FES - Escala de Ambiente Familiar}

As famílias com filhos com THB apresentaram menores níveis de coesão ( $\mathrm{F}$ $=10,99$ e $\mathrm{p}=0,002)$, organização $(\mathrm{F}=9,37$ e $\mathrm{p}=0,003)$; maiores níveis de conflito $(\mathrm{F}=14,66$ e $\mathrm{p}<0,001)$ e controle $(\mathrm{F}=13,02$ e $\mathrm{p}=0,001)$, quando comparadas com as famílias com crianças e adolescentes sem transtornos psiquiátricos. Com a correção para múltiplas análises nessa escala $(p=0,05 / 10)$, adotamos $p \leq 0,005$ e os resultados permanecem significativos.

Não houve diferenças entre as famílias com filhos com THB e famílias com filhos sem transtornos psiquiátricos em relação à expressividade, independência, assertividade, interesses culturais, lazer e religião (ver Tabela 6).

Foi encontrado um efeito de idade indicando que aqueles que possuem melhores condições socioeconômicas possuem maior nível de lazer $(\mathrm{F}=8,67$ e p $=$ 0,005) (ver Tabela 7).

Com a correção para múltiplas análises, nessa escala não foi encontrado nenhum efeito significativo quando foi ajustado um modelo controlando pela idade, sexo, etnia, QI, grau de puberdade, psicose 2 grupos (psicose e não psicose), família não intacta, tipo de THB das crianças e adolescentes (I e II versus SOE), diagnóstico dos pais unilineal versus bilineal versus sem nenhum desses diagnósticos, comorbidades das crianças e adolescentes com THB (com comorbidades versus sem comorbidades, TDAH versus sem transtornos psiquiátricos; TOD + TC versus sem transtornos psiquiátricos), estados do humor mania + hipomania + misto versus depressão versus eutimia e idade do primeiro diagnóstico THB. 
Tabela 6 - Comparação da FES pelas variáveis de controle (Média e desvio-padrão) entre famílias com filhos com THB versus famílias com filhos sem transtornos psiquiátricos

\begin{tabular}{|c|c|c|c|c|c|c|c|c|c|c|c|c|}
\hline \multirow[b]{2}{*}{ Subescalas FES } & \multicolumn{3}{|c|}{ THB $(n=33)$} & \multicolumn{3}{|c|}{ Controle $(\mathrm{n}=29)$} & \multicolumn{6}{|c|}{ Comparação } \\
\hline & Média & D.P. & Min-Max & Média & D.P. & Min-Max & $\mathrm{F}$ & Valor-p & Poder & $\mathrm{TE}$ & g.l. & Escore-z \\
\hline Coesão & 47,61 & 13,80 & $18-65$ & 57,48 & 7,15 & $38-65$ & 10,99 & 0,002 & 0,902 & 0,172 & $1 / 53$ & $-1,38$ \\
\hline Expressividade & 50,18 & 11,29 & $22-71$ & 51,31 & 10,45 & $22-65$ & 0,05 & 0,826 & 0,055 & 0,001 & $1 / 53$ & $-0,11$ \\
\hline Conflito & 55,36 & 11,82 & $33-80$ & 42,34 & 9,69 & $33-65$ & 14,66 & $<0,001$ & 0,964 & 0,217 & $1 / 53$ & 1,34 \\
\hline Independência & 41,61 & 12,49 & $21-69$ & 44,45 & 10,68 & $21-61$ & 1,45 & 0,233 & 0,220 & 0,027 & $1 / 53$ & $-0,27$ \\
\hline Assertividade & 49,73 & 10,25 & $29-66$ & 52,59 & 6,98 & $35-59$ & 3,01 & 0,089 & 0,398 & 0,054 & $1 / 53$ & $-0,41$ \\
\hline Interesses culturais & 45,21 & 13,59 & $19-63$ & 52,03 & 11,03 & $30-69$ & 3,59 & 0,063 & 0,461 & 0,063 & $1 / 53$ & $-0,62$ \\
\hline Lazer & 47,09 & 11,84 & $23-69$ & 50,76 & 11,83 & $23-69$ & 1,38 & 0,246 & 0,211 & 0,025 & $1 / 53$ & $-0,31$ \\
\hline Religião & 59,36 & 8,89 & $32-71$ & 61,52 & 7,94 & $46-71$ & 2,72 & 0,105 & 0,367 & 0,049 & $1 / 53$ & $-0,27$ \\
\hline Organização & 54,36 & 9,65 & $26-69$ & 61,14 & 6,59 & $42-69$ & 9,37 & 0,003 & 0,852 & 0,150 & $1 / 53$ & $-1,03$ \\
\hline Controle & 57,12 & 6,43 & $43-70$ & 49,62 & 8,14 & $32-65$ & 13,02 & 0,001 & 0,943 & 0,197 & $1 / 53$ & 0,92 \\
\hline
\end{tabular}

D.P.: desvio-padrão, Min: mínimo, Max: máximo, F: estatística de teste, TE: tamanho de efeito (até 0,3: efeito pequeno, de 0,3 a 0,7: efeito médio, maior que 0,7: efeito grande), g.1.: graus de liberdade 
Tabela 7 - Associação entre nível socioeconômico e FES medido pelo modelo de ANCOVA

\begin{tabular}{llrrrrrr}
\hline \hline Variável & Parâmetro & Coef. (B) & F & Valor-p & Poder & TE & g.l. \\
\hline Lazer & Nível Socioeconômico & 0,289 & 8,67 & 0,005 & 0,824 & 0,141 & $1 / 53$ \\
\hline \hline
\end{tabular}

Coef.: coeficiente de regressão, F: estatística de teste, TE: tamanho de efeito (até 0,3: efeito pequeno, de 0,3 a 0,7: efeito médio, maior que 0,7: efeito grande), g.l.: graus de liberdade 


\subsubsection{Análise Discriminante}

A análise discriminante procura uma função das variáveis para classificar as crianças e adolescentes como controle (valores negativos) ou THB (valores positivos). Com isso, é possível determinar quais variáveis têm maior impacto na predição de novos casos. A Tabela 9 mostra que EE negativa tem maior peso padronizado, ou seja, tem maior poder preditivo. Como essa foi a variável que apresentou maior tamanho de efeito para distinguir os dois grupos, isso era esperado. O modelo final classificou $92,7 \%$ dos casos corretamente.

A tabela 8, a seguir, apresenta os preditores em ordem decrescente, ou seja, EE negativa é o preditor mais forte, depois EE positiva e assim por diante. Além disso, o sinal indica a direção da classificação: EE negativa tem sinal positivo, então, quanto maior, mais THB. EE positiva tem sinal negativo, então, quanto menor, mais THB. 
Tabela 8- Pesos padronizados dos preditores para classificação de famílias com crianças e adolescentes com THB obtidos pela análise discriminante

\begin{tabular}{lc}
\hline \hline Variável & $\begin{array}{c}\text { Peso } \\
\text { padronizado }\end{array}$ \\
\hline EE negativa - comportamento do filho (a) com relação à mãe * & 0,798 \\
\hline EE positiva - comportamento do filho (a) com relação à mãe* & $-0,599$ \\
\hline EE negativa - comportamento da mãe com relação ao filho (a)* & 0,449 \\
\hline Tensão Materna** & 0,381 \\
\hline EE positiva - comportamento da mãe com relação ao filho (a) * & $-0,362$ \\
\hline Conflito *** & 0,353 \\
Tensão Paterna ** & 0,326 \\
\hline Família não intacta ** & 0,316 \\
\hline Organização *** & $-0,281$ \\
Controle *** & 0,276 \\
Coesão *** & $-0,271$ \\
\hline \hline
\end{tabular}

* Inventário de Adjetivos de Emoção Expressa

** Escala Psicossocial para Crianças em Idade Escolar - Revisada

*** FES - Escala de Ambiente Familiar 


\subsubsection{Curva ROC}

A Curva ROC é utilizada para encontrar pontos de corte que separem as escalas em dois grupos. A qualidade do ponto encontrado é medida pela área sob a curva, sendo 1 o valor com discriminação perfeita e 0,5 , uma divisão não diferente do acaso. O valor-p apresentado é do teste que tem a hipótese nula de que essa área seja 0,5 e queremos saber se ela é maior do que essa quantidade. A tabela 9 organiza as escalas utilizadas em ordem decrescente de área sob a curva e os sinais após o ponto de corte indicam se a classificação com THB ocorre acima (+) ou abaixo (-) do valor indicado. Esses pontos foram escolhidos de acordo com o critério de maior soma de sensibilidade e especificidade. A ordenação foi semelhante à encontrada na Análise Discriminante, sendo as três primeiras posições iguais e pouca variação nas demais, notavelmente para EE do filho (a) em relação à mãe que se mostrou mais discriminante nessa análise. 
Tabela 9- Parâmetros da Curva ROC Receiver Operating Characteristic Característica Operativa do Receptor

\begin{tabular}{|c|c|c|c|c|c|c|}
\hline Variável & $\begin{array}{c}\text { Área sob a } \\
\text { Curva }\end{array}$ & EP & Valor-p & $\begin{array}{l}\text { Ponto } \\
\text { de corte }\end{array}$ & Sensibilidade & Especificidade \\
\hline EE negativa $^{1} *$ & 0,956 & 0,023 & $<0,001$ & 38,5 & $87,50 \%$ & $89,66 \%$ \\
\hline EE positiva $^{1 *}$ & 0,914 & 0,038 & $<0,001$ & 59,5 & $81,25 \%$ & $93,10 \%$ \\
\hline EE negativa $^{2} *$ & 0,869 & 0,047 & $<0,001$ & 29,5 & $75,00 \%$ & $82,76 \%$ \\
\hline EE positiva $^{2} *$ & 0,813 & 0,056 & $<0,001$ & 68,5 & $81,25 \%$ & $72,41 \%$ \\
\hline Conflito $* *$ & 0,792 & 0,059 & $<0,001$ & 46,5 & $78,13 \%$ & $79,31 \%$ \\
\hline Controle ** & 0,751 & 0,063 & 0,001 & 51,5 & $81,25 \%$ & $58,62 \%$ \\
\hline Organização ** & 0,744 & 0,063 & 0,001 & 60,5 & $78,13 \%$ & $58,62 \%$ \\
\hline Coesão ** & 0,720 & 0,065 & 0,003 & 48,5 & $46,88 \%$ & $89,66 \%$ \\
\hline
\end{tabular}

${ }^{1}$ Comportamento do filho (a) com relação à mãe/pai; ${ }^{2}$ Comportamento da mãe/pai com relação ao filho (a), E.P.: erro-padrão

* Inventário de Adjetivos de Emoção Expressa

** FES - Escala de Ambiente Familiar

THB se maior que ponto de corte

THB se menor que ponto de corte 
Gráfico 1- Curva ROC para variáveis em que o THB está acima do ponto de corte

Curva Roc

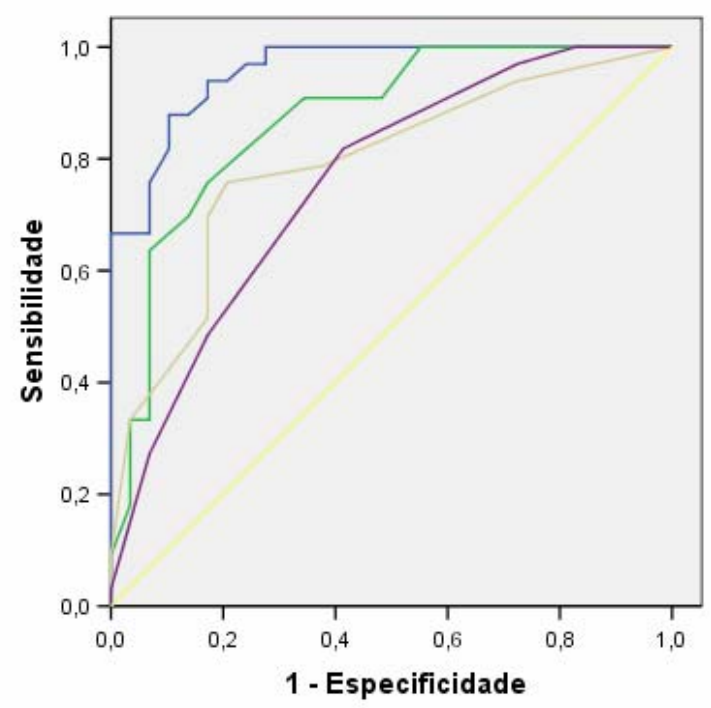

Fonte

EE Negativa Comportamento do filho (a) com

relaçăo à mãe/pai)

EE Negativa

(Comportamento da

mãe/pai com

relaçảo ao filho (a))

Conflito

Controle

Linha de referência

Gráfico 2- Curva ROC para variáveis em que o THB está abaixo do ponto de corte

Curva ROC

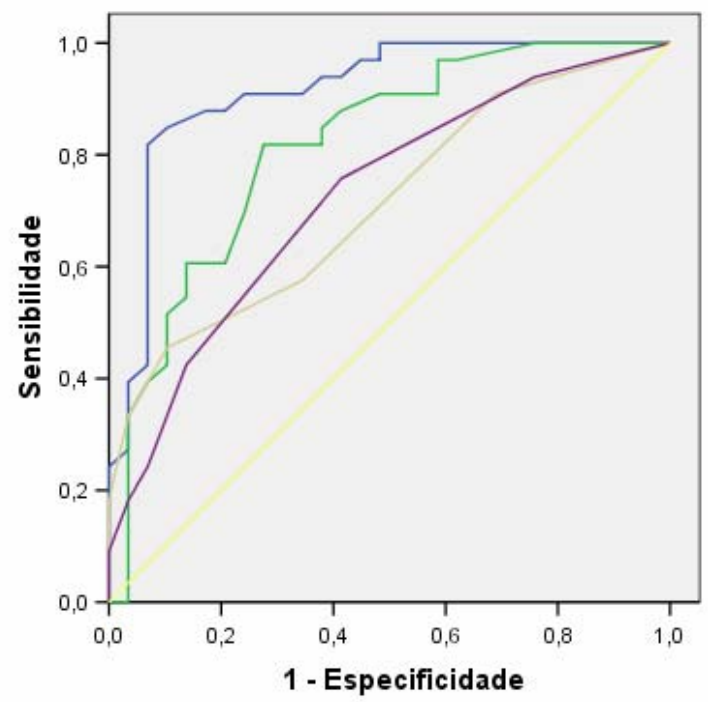

Fonte

EE Positiva

(Comportamento do

illho (a) con

relaçắo à mãe/pai)

EE Positiva

(Comportamento da

mãe/pai com

relaçấo ao filho (a))

Coesão

Organização

Linha de referência 


\section{Demais associações das escalas com as variáveis clínicas}

Nas correlações realizadas no grupo de THB e C-GAS, CDRS-R, YOUNG e CGI, apresentamos apenas as que foram mais fortes que 0,3. Em relação ao Inventário de Adjetivos de EE, quanto maior a EE positiva do comportamento do filho (a) em relação à mãe/pai menor a CDRS-R $(\mathrm{CP}=-0,460$ e $\mathrm{p}=0,008)$; e, quanto maior a EE positiva do comportamento da mãe/pai em relação ao filho (a), menor a C-GAS atual $(\mathrm{CP}=-0,383$ e $\mathrm{p}=0,031)$.

Na Escala Psicossocial para Crianças em Idade Escolar - Revisada e na FES não encontramos nenhuma correlação. 


\subsection{Características sócio-demográficas e clínicas}

As amostras de crianças e adolescentes com THB e controles sem transtornos psiquiátricos apresentaram características sócio-demográficas semelhantes, por exemplo, nível intelectual médio. As crianças e adolescentes com THB e sem transtornos psiquiátricos encontraram-se em sua maioria no nível socioeconômico B condizentes com 23\% da população brasileira, segundo a ANEP (Associação Nacional de Empresas de Pesquisa), com base no Levantamento Sócio Econômico 2000 do IBOPE (Instituto Brasileiro de Opinião Pública e Estatística).

As crianças e adolescentes com THB apresentaram-se moderadamente doentes e em diferentes episódios do humor. Onze crianças e adolescentes apresentavam sintomas de psicose, mas apenas duas crianças e adolescentes estiveram em hospitalização psiquiátrica; o tratamento psicossocial mais prevalente foi a psicoterapia individual. Em nosso estudo, 75,8\% das crianças e adolescentes com THB apresentaram comorbidades, sendo a mais prevalente o TDAH, o que está de acordo com a literatura (Faraone et al., 1997; Kowatch et al., 2000). 


\subsection{Avaliação da Família}

\subsubsection{Inventário de Adjetivos de Emoção Expressa}

Em nosso estudo, os familiares de crianças e adolescentes com THB apresentaram altos níveis de EE negativa e baixos níveis de EE positiva, quando comparadas aos familiares de crianças e adolescentes sem transtornos psiquiátricos, tanto no comportamento do filho em relação à mãe/pai, quanto no comportamento da mãe/pai em relação ao filho. Nossos achados foram concordantes com os estudos em crianças e adolescentes com THB, utilizando o inventário de Adjetivos de Emoção Expressa (Fristad et al., 1998a, 1998b, 2003; Fristad, 2006), e outras escalas de EE (Coville et al., 2008; Miklowitz et al., 2009; Sullivan; Miklowitz, 2010).

Considerando que o THB é uma doença caracterizada por extremos (mania e depressão) e por instabilidade, haveria uma maior demanda do uso de adjetivos mais intensos e em maior frequência pelos pais, principalmente os negativos (Geller et al., 2000b). Possivelmente, os pais falam estes adjetivos aos filhos na tentativa de descrever e interpretar o que seriam sintomas da doença. Os pais evidenciam esses comportamentos e sentimentos para assim inibir os que são inadequados para a criança. Contudo, a repetição destes adjetivos pode fazer com que as crianças se identifiquem com estes, modelando dessa forma seu comportamento e estabelecendo uma imagem negativa de si mesmas (Fristad et al. 2009).

A relação entre pais e filhos com THB pode ser complicada também pela dificuldade que crianças e adolescentes com THB ou em risco para THB apresentam para reconhecer emoções nos rostos de crianças e adultos (Brotman et al., 2008). 
Essas crianças são propensas a classificar de forma incorreta expressões faciais neutras como hostis e ameaçadoras (Rich et al., 2006). No ambiente familiar, isso pode se traduzir pelo uso de adjetivos negativos pelos filhos para descrever os pais, vistos como hostis. Essa teoria é reforçada pelos relatos de problemas psicossociais em pacientes com THB, mesmo durante a remissão (Bozikas et al., 2006; Rocca et al., 2009). Contudo, pesquisas sobre a estrutura familiar, com foco em EE, associada a déficits de reconhecimento de emoções, ainda não foram realizadas (Simoneau et al., 1998; Rich et al., 2006; Brotman et al., 2008).

Esse processo se torna mais disfuncional ainda à medida em que pais e familiares não conseguem fazer a distinção entre sintomas da doença e características inerentes da criança em desenvolvimento. Talvez seja exatamente por esses fatores que a diferenciação entre comportamento patológico e comportamento infantil seja um dos principais elementos de promissoras abordagens psicoterápicas (Fristad et al. 2009).

Após intervenções psicoeducacionais, em que os sintomas da doença são explicados, os familiares de crianças com THB apresentaram diminuição na EE negativa e melhora na interação familiar positiva (Fristad et al., 1998a, 1998b, 2003, 2006; 2009; Frank et al., 2000; Frank, 2005; Miklowitz, 2008).

Miklowitz et al. (2009), ao longo de 21 sessões com adolescentes e pais com alta EE, constataram uma resposta significativa, em termos de melhoria nos sintomas depressivos e de mania. EE pode englobar amplas disfunções sistêmicas na família, tais como afeto, resolução de problemas e comunicação (Miklowitz et al., 2009). Destaca-se que a comunicação, todas as maneiras pelas quais as pessoas passam 
informação, é o maior fator individual que determina os tipos de relacionamento que as pessoas têm umas com as outras (Satir, 1988).

Em nosso estudo, altos níveis de EE negativa não foram associados à presença de psicose nas crianças e nos adolescentes. A alteração da comunicação nas famílias de crianças e adolescentes com THB pode ser consequência de uma alteração primária do humor e não necessariamente da psicose. Temos a ressalva que a psicose é avaliada quanto as suas dimensões de sintomas positivos e negativos. A dimensão de desorganização, da psicose, não é devidamente considerada nas crianças e adolescentes com THB. Por exemplo, a euforia grave sem alucinações ou delírios podem se apresentar com comportamentos desorganizados, devido ao aumento da psicomotricidade (DSM-IV, 1994; Rabinowitz et al., 1998; Carlson et al., 2000; Strakowski et al., 2000; Ulloa et al., 2000; Caetano et al., 2006).

Outro achado interessante foi que quanto maior o nível socioeconômico menor o nível de EE negativa no comportamento do filho (a) em relação à mãe/pai. Provavelmente as famílias que possuem pior nível socioeconômico apresentam também um pior nível educacional e, consequentemente, pior entendimento do quadro diagnóstico das crianças e adolescentes com THB. Fatores culturais, socioeconômicos, históricos e políticos podem ser outras variáveis que influenciam as reações dos familiares em relação aos transtornos mentais (Jenkins; Karno, 1992).

Ressaltamos que nossos escores de EE positiva e negativa da mãe em relação ao filho foram maiores dos que dos estudos de Fristad et al. (1998a; 1998b; 2003) e Fristad (2006). Uma possível explicação pode ser uma diferença cultural. As culturas latino-americanas são mais comunicativas de maneira geral (Vianna et al., 2007). 


\subsubsection{Escala Psicossocial para Crianças em Idade Escolar - Revisada}

Em nosso estudo, as famílias com crianças e adolescentes com THB apresentaram baixo acolhimento materno e paterno; e alta tensão materna e paterna, dados concordantes com Geller et al. (2000b, 2002a; 2004; 2008). No entanto, acolhimento materno e paterno não foram significativos após correções para múltiplas comparações, possivelmente pelo tamanho amostral.

O THB nos filhos solicita habilidades de parentalidade muito além das rotineiramente praticadas, tais como, impor limites a comportamentos impulsivos e agressivos. O aumento da demanda por atenção e suporte por parte dos filhos pode tornar mais difícil suprir todos os cuidados. Em consequência, os pais podem sentir impotência pessoal e relacional ao lidar com essa criança, gerando sentimentos de hostilidade e irritação desses pais em relação ao filho com THB (Geller et al., 2000b). O aumento da tensão, da evitação e distanciamento, em última instância, podem levar ao baixo acolhimento e alta tensão materno/paterno.

Crianças e adolescentes com THB são muitas vezes instáveis e imprevisíveis e, portanto, pode ser muito mais difícil estabelecer uma relação mãe/pai - filho(a) que seja mais acolhedora ou menos tensa. Relacionamentos entre mãe e filho com THB iniciado na infầncia são caracterizados por menos calor, maior tensão e conflito, maior hostilidade do que entre mãe e filho sem transtornos psiquiátricos (Schenkel et al., 2008; Geller et al., 2000b).

O déficit no reconhecimento de faces, citado anteriormente, pode indicar que crianças e adolescentes com THB precisem da expressão de emoções mais intensamente para o reconhecimento delas. Para os outros que não possuem tais 
dificuldades (como familiares saudáveis), isso pode ser interpretado como indiferença, resultando na dificuldade de comunicação e relações mais frias e tensas entre pais e filhos. Além do mais, esses pais muitas vezes têm que ser mais intensos para modelar o comportamento do filho (a), pois a criança/ adolescente conseguirá discriminar melhor estímulos mais intensos.

Famílias com crianças com transtornos psiquiátricos podem estar mais desorganizadas, muitas vezes, por terem pais que também apresentam transtornos psiquiátricos. Pais com THB são frequentemente mais instáveis, irritados e agressivos. Em sendo o THB um transtorno com alta herdabilidade (Faraone et al., 2003), há uma grande probabilidade que essas famílias provenham de gerações de não parentalidade e não cuidados dos pais (Geller et al., 2000b; 2002a; 2004; 2008).

Parentalidade positiva é definida como acolhimento e escuta sensível (Compas et al.,2010). Por outro lado, a parentalidade negativa é definida como intromissão, hostilidade, negligenciamento / distanciamento (Compas et al., 2010).

Em famílias de crianças com THB, observou-se a associação entre escores parentais e depressão (Calam et al, 2012). Este estudo preliminar demonstrou que os pais com diagnóstico de THB se classificam como tendo dificuldades pessoais e dificuldades em criar seus filhos, e a maioria descreveu as crianças como tendo altos níveis de dificuldades de adaptação. A saúde mental dos pais foi associada com a parentalidade em geral (Calam et al, 2012).

O alto nível de hostilidade encontrado na escala Psicossocial para Crianças em Idade Escolar - Revisada entre mãe / pai e filho (a) também foi visto no Inventário de Adjetivos de EE. No Inventário de Adjetivos de EE, estamos 
mostrando uma dificuldade na comunicação e, na Escala Psicossocial para Crianças em Idade Escolar - Revisada, nos comportamentos.

As famílias de crianças e adolescentes com THB apresentaram níveis mais altos de família não intacta, o que foi relatado também por Geller et al. (2000b, 2002a). A taxa de divórcio no Brasil, entre casais com filhos menores de 18 anos de idade é de 31,4\% (IBGE, 2008), condizente com o alto nível de família intacta nas famílias de crianças e adolescentes sem transtornos psiquiátricos. O alto nível de família não intacta nas famílias de crianças e adolescentes com THB pode ser explicado pela presença de pais acometidos por THB ou outros transtornos do humor, que podem apresentar grandes dificuldades em manter um relacionamento estável e funcional com um parceiro. Pessoas com THB são impulsivas e com episódios de hipersexualidade, o que pode levar à falta de planejamento para formar uma família (Geller et al., 2000b). Diferentemente de outros processos de transição, esperados na vida familiar, a separação dos pais ou divórcio pode ter um potencial maior para causar desequilíbrio (Carter; McGoldrick, 1999).

Dos demais achados da Escala Psicossocial para Crianças em Idade Escolar Revisada, destacamos, em nosso estudo, a alta frequência de abuso sexual em crianças e adolescentes com THB. A história de uma infância com maus-tratos, com abuso sexual, em particular, foi significativamente mais frequente em indivíduos com THB em comparação a indivíduos com TDM, e a presença de abuso na infância pode estar associada a diversos prejuízos futuros (Hyun et al., 2000). 


\subsubsection{FES - Escala de Ambiente Familiar}

Em nosso estudo, as famílias de crianças e adolescentes com THB apresentaram baixos níveis de coesão e organização e altos níveis de conflito e controle, quando comparados às famílias de crianças e adolescentes sem transtornos psiquiátricos. Portanto, as famílias de crianças e adolescentes com THB encontramse com dificuldades na Dimensão de Relacionamento Interpessoal (coesão e conflito) e na Dimensão de Manutenção do Sistema (organização e controle) que se refere ao funcionamento interno familiar (Romero et al., 2005). Esses achados podem ser explicados pelo próprio contexto caótico e desestabilizador do diagnóstico de THB, nas crianças e adolescentes, e pelo fato de muitas vezes os pais também apresentarem transtornos de humor (Chang et al., 2001; Romero et al., 2005; Belardinelli et al., 2008).

A baixa coesão (ajuda e suporte entre os membros) nas famílias de crianças e adolescentes com THB, comparada às famílias de crianças e adolescentes sem transtornos psiquiátricos, é um achado consistente em todos os estudos envolvendo famílias com pais com THB (Chang et al., 2001; Romero et al., 2005) e com filhos com THB (Belardinelli et al., 2008). Uma maior coesão foi associada com melhor funcionamento, quando examinada a relação entre o ambiente familiar e o funcionamento global dos filhos de pais com THB (Romero et al., 2005). Uma família coesa pode influenciar positivamente o desenvolvimento cognitivo e emocional (Romero et al., 2005).

Baixos níveis de coesão e altos níveis de conflito observados nas famílias de crianças e adolescentes com THB levanta a questão se essas crianças e adolescentes 
têm prejudicado as percepções e/ou nomeação dos seus estados emocionais, ou mesmo as intenções de seus familiares e, por sua vez, se esses equívocos afetam suas escolhas de resposta (Miklowitz; Johnson; 2009).

O baixo nível de coesão e o alto nível de conflito em famílias com crianças com THB podem ser influenciados tanto pelos filhos com THB quanto pelos pais com THB. Pode haver uma bidirecionalidade entre filhos e pais acometidos. Em famílias com ao menos um dos pais com THB, comparadas aos dados normativos da população, foram encontrados menores níveis de coesão e organização e maiores níveis de conflito (Chang et al., 2001), o que também foi observado em famílias de crianças com THB (Belardinelli et al., 2008).

As famílias com menor coesão entre si podem ter maior dificuldade também em encontrar apoio e suporte em outras redes sociais. Baixo apoio social prediz maiores níveis de depressão ao longo do tempo entre as pessoas com THB (Johnson et al., 1999; Johnson, et al., 2003). Em famílias com um pai com depressão também foram relatados menor suporte, menor organização e baixa independência e integração social, e menos organização, com consequências negativas para as crianças (Billings, Moos; 1983, 1985; 1986; Esposito-Smythers et al., 2006). As crianças dessas famílias que tiveram maior apoio tiveram menos problemas de saúde (Billings; Moos; 1983; 1986).

Alto nível de conflito (expresso abertamente na família) encontrado nas famílias de crianças e adolescentes com THB versus famílias com crianças e adolescentes sem transtornos psiquiátricos reproduz os dados dos estudos de Chang et al. (2001) e Belardinelli et al. (2008). Conflitos e discórdia familiar, assim como o temperamento, personalidade e o estresse da vida, são influências importantes na 
evolução do THB, isoladamente e em interação um com o outro (Miklowitz; Johnson, 2009).

O funcionamento familiar geral inclui fatores como a coesão, harmonia e a capacidade de lidar com os problemas conflitantes. Essas características podem ter um impacto profundo sobre as experiências dos filhos e as suas trajetórias de vida, desempenhando um papel importante no desenvolvimento emocional durante a infância (Cuffe et al., 2005), bem como para o risco de transtornos do humor (Althoff, et al., 2005; Yap et al., 2007). Ter um membro da família com TDM pode representar efeitos negativos sobre o funcionamento da família (Robertson et al., 2001; Saeki et al., 2002; Goossens et al., 2008; Magliano et al., 2009). Crianças com depressão que tentaram suicídio descreveram suas famílias como mais estressantes, menos favoráveis e com menos coesão e mais conflitos do que as crianças com depressão não-suicidas (Asarnow et al., 1987). As famílias de crianças com TDM também demonstraram níveis mais altos de conflitos em relação às famílias de crianças sem transtornos psiquiátricos, sugerindo que elas expressavam sua raiva contra membros da família mais abertamente e de forma orientada para o conflito (Ogburn et al., 2010).

O baixo nível de organização nas famílias com crianças e adolescentes com THB, também observado por Chang et al. (2001), sugere dificuldade no planejamento de atividades familiares. Em famílias com menores níveis de organização e coesão, é esperada a presença de altos níveis de conflito, visto que são famílias com menos apoio e suporte familiar.

O alto nível de controle (presença de regras e procedimentos na vida familiar cotidiana) observado no presente estudo reproduz achados por Chang et al. (2001). 
Altos níveis de controle podem significar a tentativa dessas famílias de controlar seus membros, estabelecer regras para diminuir os prejuízos decorrentes dos sintomas do THB (como envolvimento excessivo em atividades prazerosas). Ressalta-se que em nosso estudo e no estudo de Chang et al. (2001), as famílias com THB apresentaram menores níveis de organização e maiores níveis de controle, o que pode sugerir possibilidade de haver uma associação entre as famílias com dificuldades em se organizar nas atividades diárias com a necessidade de presença excessiva de regras.

Em nosso estudo não houve diferenças significativas em expressividade, independência, assertividade, interesses culturais, lazer e religião entre as famílias com filhos com THB e famílias com filhos sem transtornos psiquiátricos.

Não alteração na expressividade (expressão de sentimentos) foi concordante com Chang et al. (2001) e discordante de Romero et al., (2005) e Belardinelli et al. (2008). No estudo de Romero et al. (2005), a expressividade foi muito maior no grupo controle saudável do que nos dados normativos da população americana. Isso pode explicar porque eles encontraram pontuações significativamente menores de expressividade em famílias com THB, quando comparados ao grupo saudável. No estudo de validação da FES no Brasil, os escores de expressividade foram maiores do que os americanos (Vianna et al., 2007), indicando que há diferenças socioculturais e, talvez por isso, não encontramos baixos níveis de expressividade na nossa amostra.

Não encontramos diminuição de independência (capacidade de decisão), relatada por Chang et al. (2001), quando compararam os dados das famílias com THB com dados normativos da FES nos EUA. Mas nosso achado foi concordante com Romero et al. (2005) e Belardinelli et al. (2008), que compararam o grupo com THB a grupo saudável correspondente à mesma área geográfica e cultural. 
Não alteração da assertividade (atividades orientadas para um objetivo), foi concordante com Romero et al. (2005) e Belardinelli et al. (2008), mas discordante de Chang et al. (2001), que encontraram baixos níveis nas famílias de crianças e adolescentes com ao menos um pai biológico com THB, comparados aos dados normativos da FES. A menor assertividade nas famílias brasileiras, em relação a comportamentos considerados assertivos na cultura norte-americana, pode ser decorrentes de diferenças socioculturais e talvez por isso não encotramos qualquer alteração (Vianna et al., 2007).

Nossos achados de não alteração nos interesses culturais (atividades políticas, intelectuais e culturais) são concordantes com Romero et al. (2005) mas discordantes de Chang et al. (2001), que encontraram altos níveis de interesses culturais nas famílias de crianças e adolescentes com ao menos um pai biológico com THB e os dados normativos da FES; e de Belardinelli et al. (2008) nas famílias de crianças com THB versus famílias com crianças saudáveis que encontraram baixos níveis, por sua vez.

Não alteração nos escores de lazer (atividades sociais e recreacionais), também observado em Chang et al. (2001) e Romero et al. (2005), mas não em Belardinelli et al. (2008), que encontraram baixos níveis de lazer nas famílias de crianças com THB versus famílias com crianças saudáveis. Os achados negativos dos estudos americanos podem ser devido ao nível socioeconômico bastante elevado da casuística da população envolvida e o fácil acesso a essas atividades culturais na melhor área de São Francisco (Chang et al., 2001). Em nosso estudo, quando analisamos as famílias com pais bilineal, estes apresentaram menores níveis de lazer. Também encontramos um efeito de nível social, indicando que aqueles que possuem 
melhores condições socioeconômicas possuem maior nível de lazer nas 2 amostras estudadas. Aqueles que possuem melhores condições socioeconômicas possuem maiores níveis de lazer. Segundo a pesquisa "O Observador - 2011", feita pela Cetelem, quanto maior o nível socioeconômico de uma família maiores são seus gastos com lazer. Nenhum estudo anterior relatou esse resultado (Chang et al., 2001; Romero et al., 2005; Belardinelli et al. 2008).

De maneira geral, nossos resultados são semelhantes aos de Chang et al., (2001) nas famílias de crianças e adolescentes com ao menos um pai biológico com THB e os dados normativos da FES e menos semelhantes com o estudo de Romero et al., (2005), quando compararam famílias com pelo menos um dos pais com THB e famílias com pais saudáveis, mas semelhantes aos resultados quando comparadas aos dados normativos da população dos EUA.

Tanto pela Análise Discriminante quanto pela Curva ROC, encontramos resultados semelhantes, pois tanto EE negativa e positiva do comportamento do filho em relação à mãe-foram as variáveis mais importantes. Portanto, pensamos que futuramente essas variáveis devem ser trabalhadas em uma terapia familiar. Por exemplo, seria importante abordar temas como a comunicação, separar os sintomas das características das crianças, parentalidade, resolução dos problemas (conflitos e ajuda e suporte) entre os membros família e a família como suporte.

É importante ressaltar que utilizamos duas escalas de auto-preenchimento (Inventário de Adjetivos de EE e FES) e uma entrevista semi-estruturada (Escala Psicossocial para Crianças em Idade Escolar - Revisada) e que esta última requer um treinamento importante de profissionais da área da saúde em um tempo considerável. Ou seja, tanto o Inventário de Adjetivos de EE e a FES são escalas com menores 
custos pela não necessidade de treinamento de profissionais e também mais rápidas. Contudo, essas escalas ainda precisam ser avaliadas em estudos longitudinais.

O Inventário de Adjetivos de Emoção Expressa e a Escala Psicossocial para Criança em Idade Escolar - Revisada não foram validados para o português. Vianna et al. (2007) fizeram a tradução para o português e validação da FES, e também realizaram uma comparação entre as médias da amostra estudada e as obtidas em cinco estudos internacionais (Moos e Moos, 1994; Carlson et al., 1991). As famílias brasileiras apresentaram maior pontuação nas subescalas de coesão e organização e menor pontuação na subescala de conflito quando comparadas aos cinco outros estudos avaliados (Vianna et al., 2007). Nenhuma das três escalas, Inventário de adjetivos de EE, a Escala Psicossocial para Criança em Idade Escolar - Revisada e a FES, até o presente, foram padronizadas para a população brasileira.

O tamanho de nossa amostra é uma limitação, mas fizemos um cálculo de tamanho amostral que evidenciou que o tamanho de nossa amostra era suficiente Baseado no trabalho de Belardinelli et. al. (2008), para comparar os escores da FES de famílias saudáveis com famílias com fillhos com THB, o tamanho mínimo de amostra requerido, para alcançar um poder de 95\% (considerando erro do tipo I de 5\%) foi de 26 famílias em cada grupo. Para amostra de tamanho 30 em cada grupo, o poder estimado pode chegar a 97\%. Baseado em Geller et al. (2000b), para comparar os escores da Escala Psicossocial para Crianças em Idade Escolar-Revisada de famílias saudáveis com famílias com filhos bipolares referente ao zelo (ternura, acolhimento) mútuo na relação mãe e filho, o tamanho mínimo de amostra requerido para alcançar um poder de 95\% (utilizando teste $\mathrm{t}$, considerando erro do tipo I de 5\%), seria de 53 famílias em cada grupo. Para amostra de tamanho 60 em cada 
grupo, o poder estimado pode chegar a 97\%. Em relação ao Inventário de adjetivos de emoção expressa, não existem trabalhos prévios comparando famílias com filhos bipolares com famílias saudáveis. Entretanto, supôs-se que 53 famílias em cada grupo fosse razoável para as comparações de interesse.

\subsection{A família compreendida como um sistema}

O bom funcionamento do sistema familiar é caracterizado por uma relação funcional entre os membros familiares com comunicação clara, com tolerância para as emoções negativas e estimulação das interações positivas; resolução cooperativa dos problemas; desenvolvimento compreendido como processo (equilíbrio e adaptação e desequilíbrio); padrões organizacionais flexíveis; capacidade de mudança; capacidade de conexão; respeito e limites na relação entre os subsistemas. São famílias geralmente com possibilidade de acesso a recursos sociais e econômicos (Minuchin, 1974; Walsh, 2003, 2005). Entendemos, portanto, que o bom funcionamento do sistema familiar é caracterizado por níveis adequados de $\mathrm{EE}$ negativa e EE positiva; de tensão materna e paterna; coesão e conflito.

É importante ressaltar que no presente trabalho nossa meta era de compreender nossos resultados de acordo com os construtos de cada escala. Mas também procuramos verificar se esses construtos eram semelhantes às características de bom funcionamento na visão sistêmica. De acordo com nossos resultados, podemos inferir que as famílias com crianças e adolescentes com THB apresentam características de uma família desligada, em que a relação da família se caracteriza 
por pouca comunicação, coesão diminuída entre os membros, muita tensão e conflitos e com fronteiras fechadas / rígidas (Minuchin, 1974; Minuchin; Fishman, 1990; Piszezman, 2006).

\subsubsection{Tratamento: Terapia de Família}

A terapia de família também pode ser vista como uma possibilidade importante para a redução dos níveis de ansiedade e estresse familiar, fatores esses que podem contribuir para a desestabilização do paciente. É importante destacar a dor da família ou luto dos pais diante do diagnóstico de um filho com um transtorno psiquiátrico como o THB. Mais difícil, ainda, pode ser no caso da doença ser conhecida pelos membros familiares e ter interferido no funcionamento da mesma (Kowatch; 2005).

Quando esses pais estão adjetivando os filhos estão buscando organizar, controlar e exercer o acolhimento e através da terapia eles podem se organizar de outra maneira.

A proposta de psicoterapia de família em grupos seria de grande benefício, visto que a comunicação limitada e seu posicionamento mais fechado limitam a compreensão e busca de recursos para lidar com a situação do filho. A visão sistêmica enfatiza a organização da família para se adaptar a essa dificuldade. Em um trabalho grupal, seria mais fácil eles encontrarem pessoas que vivem situações bem parecidas com as suas. No grupo também seria mais fácil ajudá-los a desenvolver melhor a comunicação, pois as dificuldades ou falas não compreendidas poderiam ser mais bem trabalhadas e elaboradas. 
A psicoeducação permite que o paciente com THB aprenda sobre os tratamentos e como reconhecer sinais e sintomas iniciais de possíveis novos episódios para que então uma intervenção mais precoce possa acontecer. Muitas vezes são os familiares que conseguem compreender e observar as primeiras mudanças nos pacientes. Klaus e Fristad (2005) sugerem que a psicoterapia psicoeducacional envolva três principais componentes: apoio, desenvolvimento de habilidades diversas relacionadas ao problema e educação. Esses três componenteschave podem ajudar os membros familiares a se tornarem melhores consumidores dos serviços de saúde mental, incluindo maior habilidade para manejar e argumentar sobre as medicações prescritas.

A psicoterapia englobaria, assim, a comunicação verbal entre mãe/pai e filho, portanto subsistema de pai/mãe e filho. Também envolveria as relações e as comunicações verbais e não verbais entre mãe e filho, pai e filho, amigos, irmãos e casal, ou seja, as relações separadamente, portanto subsistema de mãe e filho, pai e filho, amigos, irmãos e casal. Também a família como um todo, portanto, o sistema familiar.

Por ser um tratamento focado e com número de sessões definidas, a psicoterapia psicoeducacional é um tratamento que deve ser considerado em redes públicas.

Em suma, o presente estudo pode ser o primeiro estudo no Brasil que pesquisa sistematicamente e avalia, simultaneamente, a comunicação e as relações entre os membros da família e o ambiente familiar de crianças e adolescentes portadores de THB. Também talvez seja o primeiro estudo, no Brasil, que analisa essas características em famílias brasileiras com crianças e adolescentes portadores 
de THB. Nossa contribuição encontra-se na constatação de que a EE é a variável de família que melhor distingue famílias com crianças e adolescentes portadores de THB das famílias de sem transtornos psiquiátricos. 


\section{CONCLUSÕES}


No presente estudo, buscou-se avaliar a estrutura de família de crianças e adolescentes com THB, comparada à estrutura de famílias de crianças e adolescentes sem transtornos psiquiátricos, de acordo com o Inventário de Adjetivos de Emoção Expressa, com a Escala Psicossocial para Crianças em Idade Escolar - Revisada e a FES, bem como e determinar qual variável dessas escalas distinguiria melhor os dois grupos.

Famílias de crianças e adolescentes com THB comparadas às famílias de crianças e adolescentes sem transtornos psiquiátricos apresentaram:

- maior nível de EE negativa e baixo nível de EE positiva nos familiares de crianças e adolescentes com THB de acordo com o Inventário de Adjetivos de Emoção Expressa.

- menor nível de coesão e maior nível de conflito de acordo com a FES.

- Também encontramos menor organização e maior nível de controle.

- Não foi confirmada a hipótese de menor acolhimento materno e paterno após correção para múltiplas análises. Por outro lado, encontramos maior nível de tensão materna e paterna e alto nível de família não intacta, segundo a Escala Psicossocial em Idade Escolar - Revisada.

- Não foi confirmada a hipótese de que coesão seria a variável que melhor diferenciou os dois grupos. 
- EE negativa do comportamento do filho em relação à mãe; foi a variável que melhor diferenciou os dois grupos (crianças e adolescentes com THB e crianças e adolescentes sem transtornos psiquiátricos). 
8 ANEXOS 


\section{Anexo I}

\section{Inventário de Adjetivos de Emoção Expressa}

Por favor, use os seguintes adjetivos para descrever como O COMPORTAMENTO DE SEU FILHO/SUA FILHA foi COM VOCÊ NOS ÚLTIMOS TRÊS MESES.

Por favor circule a melhor reposta

NUNCA

SEMPRE

\begin{tabular}{|c|c|c|c|c|c|c|c|}
\hline 1. Aceitante/Receptivo & 1 & 2 & 3 & 4 & 5 & 6 & 7 \\
\hline 2. Ativo & 1 & 2 & 3 & 4 & 5 & 6 & 7 \\
\hline 3. Bravo & 1 & 2 & 3 & 4 & 5 & 6 & 7 \\
\hline 4. Entediado & 1 & 2 & 3 & 4 & 5 & 6 & 7 \\
\hline 5. Claro & 1 & 2 & 3 & 4 & 5 & 6 & 7 \\
\hline
\end{tabular}

Agora, por favor, use os mesmos adjetivos para descrever como O SEU PRÓPRIO COMPORTAMENTO foi PARA O SEU FILHO/SUA FILHA NOS ÚLTIMOS TRÊS MESES. Por favor circule a melhor reposta.

NUNCA

SEMPRE

\begin{tabular}{|c|c|c|c|c|c|c|c|}
\hline 11. Aceitante/Receptivo & 1 & 2 & 3 & 4 & 5 & 6 & 7 \\
\hline 12. Ativo & 1 & 2 & 3 & 4 & 5 & 6 & 7 \\
\hline 13. Bravo & 1 & 2 & 3 & 4 & 5 & 6 & 7 \\
\hline 14. Entediado & 1 & 2 & 3 & 4 & 5 & 6 & 7 \\
\hline 15. Claro & 1 & 2 & 3 & 4 & 5 & 6 & 7 \\
\hline 16. Considerável & 1 & 2 & 3 & 4 & 5 & 6 & 7 \\
\hline
\end{tabular}




\section{Anexo II - Escala de Ambiente Familiar (FES)}

\section{Questionário da Família}

\section{Family Environment Scale - Form R}

\section{Rudolf H. Moos}

Posição na família (assinale uma):

_ mãe/esposa _ pai/marido _ filho/filha _enteado/enteada outra

Por favor, responda todas as 90 questões abaixo colocadas. São questões sobre famílias. Se considerar que a frase se aplica bastante ou muito à sua família assinale com um $\mathrm{X}$ o retângulo à frente na mesma linha e embaixo do Verdadeiro. Se a frase aplica mesmo pouco ou nada à sua família assinale com um $\mathrm{X}$ na mesma linha e embaixo do Falso.

Pode às vezes ter a sensação que algumas das afirmações são verdadeiras relativamente a algum membro de sua família e falsas em relação a outros. Assinale Verdadeiro se a afirmação for verdadeira para maior parte dos membros da família. Escolha Falso se a afirmação for falsa para a maior parte dos membros da família. Se os membros da família se dividirem igualmente pelas duas opções, decida qual a impressão geral mais forte e responda de acordo com ela.

Lembre-se que gostaríamos de saber qual a sua impressão sobre a sua família. Por isso não tente adivinhar a forma como os outros membros vêem a sua família. Preencha o questionário sem ajudas. 


\begin{tabular}{|l|l|l|}
\hline & Verdadeiro & Falso \\
\hline 1.Na nossa família ajudamos e apoiamos uns aos outros & & \\
\hline $\begin{array}{l}\text { 2.Geralmente os membros da família guardam para si seus próprios } \\
\text { sentimentos }\end{array}$ & & \\
\hline 3.Brigamos muito na nossa família & & \\
\hline 4.Na nossa família não é freqüente fazermos coisas sozinhos & & \\
\hline $\begin{array}{l}\text { 5.Achamos que é importante sermos os melhores em qualquer coisa que } \\
\text { fazemos }\end{array}$ & & \\
\hline 6.Falamos de temas políticos e sociais com freqüência & & \\
\hline 7.Passamos a maior parte dos fins de semana de feriados em casa & & \\
\hline $\begin{array}{l}\text { 8.Os membros da nossa família vão com regularidade aos cultos ou à } \\
\text { formação religiosa }\end{array}$ & & \\
\hline 9.As atividades da nossa família são cuidadosamente planejadas & & \\
\hline 10.Os membros na nossa família raramente recebem ordens & & \\
\hline $\begin{array}{l}\text { 11.Muitas vezes temos a impressão de que só estamos em casa para "passar o } \\
\text { tempo" }\end{array}$ & & \\
\hline 12.Em casa podemos dizer o que queremos & & \\
\hline 13.Os membros da família raramente se zangam abertamente & & \\
\hline 14.Em nossa família somos fortemente encorajados a ser independentes & & \\
\hline 15.Para nossa família é muito importante triunfar na vida & & \\
\hline 16.Raramente assistimos a conferências, a peças de teatros ou a concertos. & & \\
\hline 17.É freqüente os amigos aparecerem para jantar ou para uma visita. & & \\
\hline 18.Na nossa família não fazemos orações & & \\
\hline 19.Somos geralmente muito arrumados e limpos & & \\
\hline 20.Na nossa família há muito poucas regras para se cumprir & & \\
\hline 21.Todos nos esforçamos muito no que fazemos em casa & & \\
\hline
\end{tabular}


Anexo III - Termo de Consentimento Livre e Esclarecido

HOSPITAL DAS CLÍNICAS DA FACULDADE DE MEDICINA DA UNIVERSIDADE DE SÃO PAULO - HCFMUSP

TERMO DE CONSENTIMENTO LIVRE E ESCLARECIDO

DADOS DE IDENTIFICAÇÃO DO SUJEITO DA PESQUISA OU RESPONSÁVEL LEGAL

1..NOME:

DOCUMENTO DE IDENTIDADE $\mathrm{N}^{\mathrm{*}}$ : SEXO : .M $\square \mathrm{F} \square$

DATA NASCIMENTO:

ENDEREÇO

BAIRRO:

$\mathrm{N}^{\mathrm{o}}$ APTO

CEP: CIDADE

TELEFONE: DDD

..)

2.RESPONSÁVEL LEGAL

NATUREZA (grau de parentesco, tutor, curador etc.)

DOCUMENTO DE IDENTIDADE : SEXO: $\mathrm{M} \square \mathrm{F} \square$

DATA NASCIMENTO.: .....................

ENDEREÇO:

BAIRRO:

$\mathrm{N}^{\mathrm{o}}$ APTO:

CEP. $\quad$ TELEFONE: DDD (

CIDADE

TELEFONE: DDD (...........................

\section{DADOS SOBRE A PESQUISA}

1. TÍTULO DO PROTOCOLO DE PESQUISA: Avaliação da Estrutura Familiar com criança portadora de Transtorno Bipolar.

2. CARGO/FUNÇÃO: Professor Associado da FMUSP

INSCRIÇÃO CONSELHO REGIONAL N ${ }^{\circ} 57815$

UNIDADE DO HCFMUSP: Departamento de Psiquiatria

3. AVALIAÇÃO DO RISCO DA PESQUISA:

$\begin{array}{ll}\text { RISCO MÍNIMOX } & \text { RISCO MÉDIO } \\ \text { RISCO BAIXO } & \text { RISCO MAIOR }\end{array}$

4.DURAÇÃO DA PESQUISA : Dois Anos

\section{HOSPITAL DAS CLÍNICAS DA FACULDADE DE MEDICINA DA UNIVERSIDADE DE SÃO PAULO-HCFMUSP}

1. Desenho e objetivos do estudo: essas informações estão sendo fornecidas para sua participação voluntária neste estudo, que pretende estudar a estrutura da família brasileira utilizando as seguintes escalas: FES, a Escala Psicossocial para Crianças em Idade Escolar - Revisada e o Inventário de 
Adjetivos de Emoção Expressa em crianças e adolescentes apresentando THB comparado a famílias de crianças e adolescentes saudáveis.

2. Procedimentos que serão utilizados e propósitos: Gostaríamos que você respondesse a uma sériede perguntas sobre como você tem se sentido, e sobre coisas que podem ter ocorrido com você recentemente. Também queremos entrevistar seus pais ou responsáveis para perguntar como você tem se sentido e comportado. Para participar deste estudo você precisa ter entre 6 anos e 17 anos e onze meses. O médico que lhe atenderá para o diagnóstico fará o encaminhamento para a psicóloga, caso você concorde em realizar as escalas. Sua participação será em sessão individual. O tempo estimado para a conclusão destas tarefas é de aproximadamente duas horas.

3. Desconfortos e riscos esperados: Não existe nenhum risco em relação à realização das escalas, mas um possível desconforto é o cansaço que, pode acontecer antes de você concluir todas as atividades; se isto ocorrer você poderá fazer um intervalo.

4. Benefícios que poderão ser obtidos: De imediato não existem benefícios diretamente ligados a você, mas os dados obtidos nesta pesquisa possibilitarão um maior conhecimento a respeito do que ocorre com a estrutura da família com pacientes que sofrem com este transtorno. Estes dados irão favorecer, posteriormente, o planejamento e a elaboração de indicações terapêuticas, com a finalidade de reduzir ou adaptar o impacto que estes prejuízos podem ocasionar na vida cotidiana e na adaptação social.

5. Garantia de acesso: em qualquer etapa do estudo, você terá acesso aos profissionais responsáveis pela pesquisa para esclarecimento de eventuais dúvidas.

O principal investigador é a Dra. Sheila C. Caetano que pode ser encontrado no endereço Rua Ovídio Pires de Campos, S/N - $3^{\circ}$ andar - tel: 2661-7928. Ou Edmir Cavalcanti Gurgel Pini Nader PROMAN/PROTHUIA - IPq- HC - FM USP Tel: 2661-7928.

Se você tiver alguma consideração ou dúvida sobre a ética da pesquisa, entre em contato com o Comitê de Ética em Pesquisa (CEP) - Rua Ovídio Pires de Campos, 225 - $5^{\circ}$ andar - tel: 2661-6442 ramais 16, 17, 18 ou 20, FAX: 2661-6442 ramal 26 - E-mail: cappesq@hcnet.usp.br

6. É garantida a liberdade da retirada de consentimento a qualquer momento e deixar de participar do estudo, sem qualquer prejuízo à continuidade de seu tratamento na Instituição;

7. Direito de confidencialidade - As informações obtidas serão analisadas em conjunto com outros pacientes, não sendo divulgado a identificação de nenhum paciente; 
8. Direito de ser mantido atualizado sobre os resultados parciais das pesquisas, quando em estudos abertos, ou de resultados que sejam do conhecimento dos pesquisadores;

9. Despesas e compensações: não há despesas pessoais para o participante em qualquer fase do estudo, incluindo exames e consultas. Também não há compensação financeira relacionada à sua participação. Se existir qualquer despesa adicional, ela será absorvida pelo orçamento da pesquisa.

Acredito ter sido suficientemente informado a respeito das informações que li ou que foram lidas para mim, descrevendo o estudo "Avaliação da Estrutura da Família com Transtorno Bipolar”

Eu discuti com a Dra. Sheila C. Caetano sobre a minha decisão em participar nesse estudo. Ficaram claros para mim quais são os propósitos do estudo, os procedimentos a serem realizados, seus desconfortos e riscos, as garantias de confidencialidade e de esclarecimentos permanentes. Ficou claro também que minha participação é isenta de despesas e que tenho garantia do acesso a tratamento hospitalar quando necessário. Concordo voluntariamente em participar deste estudo e poderei retirar o meu consentimento a qualquer momento, antes ou durante o mesmo, sem penalidades ou prejuízo ou perda de qualquer benefício que eu possa ter adquirido, ou no meu atendimento neste Serviço.

Assinatura do paciente/representante legal

Data

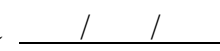

Assinatura da testemunha

Data

para casos de pacientes menores de 18 anos, analfabetos, semi-analfabetos ou portadores de deficiência auditiva ou visual.

(Somente para o responsável do projeto)

Declaro que obtive de forma apropriada e voluntária o Consentimento Livre e Esclarecido deste paciente ou representante legal para a participação neste estudo.

Assinatura do responsável pelo estudo Data $1 / 1$




\section{REFERÊNCIAS}


Althoff RR, Faraone SV, Rettew DC, Morley CP, Hudziak JJ. Family, twin, adoption, and molecular genetic studies of juvenile bipolar disorder. Bipolar Disord. 2005;7(6): 598-609.

Arthur D, Nursing Research Group. The validity and reliability of the measurement of the concept 'expressed emotion' in the family members and nurses of Hong Kong patients with schizophrenia. Int J Ment Health Nurs. 2002;11(3):192-198.

Asarnow JR, Carlson GA, Guthrie D. Coping strategies, self-perceptions, hopelessness, and perceived family environments in depressed and suicidal children. J Consult Clin Psychol. 1987; 55(3): 361-366.

Barbosa G, Dias M, Gaião A, Lorenzo W. Escala para avaliação de depressão em crianças - revisada (CDRS-R): uma análise exploratória. Infanto - Rev Neuropsiq Inf Adol. 1997;5(1):15-18.

Barrowclough C, Johnston M, Tarrier N. Attributions, expressed emotion, and patient relapse: An attributional model of relatives' response to schizophrenic illness. Behavior Therapy. 1994;25:67-88.

Belardinelli C, Hatch JP, Olvera RL, Fonseca M, Caetano SC, Nicoletti M, Pliszka S, Soares JC. Family environment patterns in families with bipolar children. J Affect Disord. 2008;107(1-3):299-305.

Bhangoo RK, Dell ML, Towbin KE, Myers FS, Lowe CH, Pine DS, Leibenluft E. Clinical correlates of episodicity in juvenile mania. $J$ Child Adolesc Psychopharmacol. 2003;13(4):507-514. 
Biederman J, Faraone S, Wozniak J, Mick E, Kwon A, Aleardi M. Further evidence of unique developmental phenotypic correlates of pediatric bipolar disorder: findings from a large sample of clinically referred preadolescent children assessed over the last 7 years. J Affect Disord. 2004a;82 Suppl 1:S45-58.

Biederman J, Mick E, Faraone SV, Wozniak J. Pediatric bipolar disorder or disruptive behavior disorder? Primary Psychiatry. 2004b;11(9):36-41.

Billings AG, Moos RH. Children of parents with unipolar depression: a controlled 1year follow-up. J Abnorm Child Psychol. 1986;14(1):149-66.

Billings AG, Moos RH. Comparisons of children of depressed and nondepressed parents: a social-environmental perspective. J Abnorm Child Psychol 1983; 11(4): 463-85.

Billings AG, Moos RH. Psychosocial processes of remission in unipolar depression: comparing depressed patients with matched community controls. J Consult Clin Psychol. 1985;53(3): 314-25.

Birmaher B. Longitudinal course of pediatric bipolar disorder. Am J Psychiatry. 2007;164(4): 537-539.

Birmaher B, Axelson D, Monk K, Kalas C, Goldstein B, Hickey MB, Obreja M, Ehmann M, Iyengar S, Shamseddeen W, Kupfer D, Brent D. Lifetime psychiatric disorders in school-aged offspring of parents with bipolar disorder: the Pittsburgh Bipolar Offspring Study. Arch Gen Psychiatry. 2009;66(3):287-296.

Birmaher B, Axelson D, Strober M, Gill MK, Valeri S, Chiappetta L, Ryan N, Leonard H, Hunt J, Iyengar S, Keller M. Clinical course of children and adolescents with bipolar spectrum disorders. Arch Gen Psychiatry. 2006;63(2):175-183. 
Bozikas VP, Tonia T, Fokas K, Karavatos A, Kosmidis MH. Impaired emotion processing in remitted patients with bipolar disorder. J Affect Disord. 2006;91(1):536.

Brasil HHA. Desenvolvimento da versão brasileira da K-SADS-PL (Schedule for Affective Disorders and Schizophrenia for School Aged Children Present and Lifetime Version) e estudo de suas propriedades psicométricas [Tese de Doutorado]. São Paulo: Universidade Federal de São Paulo; 2003.

Brewin CR, MacCarthy B, Duda K, Vaughn CE. Attribution and expressed emotion in the relatives of patients with schizophrenia. J Abnorm Psychol. 1991;100(4):546554.

Brotman MA, Guyer AE, Lawson ES, Horsey SE, Rich BA, Dickstein DP, Pine DS, Leibnluft E. Facial emotion labeling deficits in children and adolescents at risk for bipolar disorder. Am J Psychiatry. 2008;165(3):385-9.

Brown GW. Experiences of discharged chronic schizophrenic patients in various types of living groups. Milbank Mem Fund Q. 1959; 37(2):105-31.

Brown GW, Birley JLT, Wing JK. Influence of family life on the course of schizophrenic disorders: a replication. Br J Psychiatry. 1972; 121(562):241-58.

Brown GW, Rutter M. The Measurement of family activities and relationships: a methodological study. Human Relations. 1966: 19:241-263.

Bruscagin C. Terapia familiar sistêmica. Revista Psicoterapias - Mente e Cérebro. 2010;4:37-65.

Butzlaff RL, Hooley JM. Expressed emotion and psychiatric relapse. A metaanalysis. Arch Gen Psychiatry. 1998;55(6):547-552. 
Caetano SC, Olvera RL, Hunter K, Hatch JP, Najt P, Bowden C, Pliszka S, Soares JC. Association of psychosis with suicidality in pediatric bipolar I, II and bipolar NOS patients. J Affetc Disord. 2006;91(1):33-7.

Calam R, Jones S, Sanders MR, Dempsey R, Sadhnani V. Parenting and the emotional and behavioural adjustment of young children in families with a parent with bipolar disorder. Behav Cogn Psychother. 2012; Mar 14:1-13.

Capra F. O ponto de Mutação. Cap. 9. São Paulo: Cultrix; 1982.

Carlson CI, Cooper CR, Spradling VY. Developmental implications of shared versus distinct perceptions of the family in early adolescence. New Dir Child Dev. 1991;51:13-31.

Carlson GA, Bromet EJ, Sievers S. Phenomenology and outcome of subjects with early- and adult-onset psychotic mania. Am J Psychiatry. 2000;157(2), 213-19.

Carlson GA, Kelly KL. Manic symptoms in psychiatrically hospitalized children what do they mean? J Affect Disord. 1998;51(2):123-35.

Carter B, McGoldrick M. The expanded family life cycle ed. Needham Heights, MA: Allyn and Bacon, 1999.

Cerveny CM. A Família como modelo - Desconstruindo a Patologia. São Paulo: Editorial Psy II; 1994.

Chang KD, Blasey C, Ketter TA, Steiner H. Family environment of children and adolescents with bipolar parents. Bipolar Disord. 2001;3(2):73-78.

Chang K, Steiner H, Ketter T. Studies of offspring of parents with bipolar disorder. Am J Med Genet C Semin Med Genet. 2003;123C(1):26-35. 
Chengappa KN, Kupfer DJ, Frank E, Houck PR, Grochocinski VJ, Cluss PA, Stapf DA. Relationship of birth cohort and early age at onset of illness in a bipolar disorder case registry. Am J Psychiatr. 2003;160(9):1636-1642.

Children's Personal Data Inventor. ECDEU Assessment battery for psychopharmacology. NIMH. 1973.

Children's Symptom History. ECDEU Assessment battery for psychopharmacology. NIMH. 1973.

Coddington RD. Significance of life events as etiologic factors in the diseases of children. II. A study of a normal population. J Psychosom Res. 1972a; 16(3):205-13.

Coddington RD. The significance of life events as etiologic factors in the diseases of children. I. A survey of professional workers. J Psychosom Res. 1972b; 16(1):7-18.

Compas BE, Champion JE, Forehand R, Cole DA, Reeslund KL, Fear J, Hardcastle EJ, Keller G, Rakow A, Garai E, Merchant MJ, Roberts L. Coping and parenting: Mediators of 12-month of a family group cognitive-behavioral preventive intervention with families of depressed parents. $J$ Consult Clin Psychol. 2010;78(5):623-34.

Coville AL, Miklowitz DJ, Taylor DO, Low KG. Correlates of high expressed emotion attitudes among parents of bipolar adolescents. J Clin Psychol. 2008;64(4): 438-449.

Cuffe SP, McKeown RE, Addy CL, Garrison CZ. Family and psychosocial risk factors in a longitudinal epidemiological study of adolescents. J Am Acad Child Adolesc Psychiatry. 2005; 44(2): 121-9.

Cunha JA. Psicodiagnóstico - V. Porto Alegre: ArtMed; 2002. 
DSM-IV-Tr-Tm. Manual Diagnóstico e Estatístico de Transtornos Mentais. Porto Alegre: Artmed; 1994.

Epstein NB, Baldwin LM, Bishop DS. The McMaster Family Assessment Device. $J$ Marital Fam Ther. 1983;9:171-180.

Esposito-Smythers C, Birmaher B, Valeri S, Chiappetta L, Hunt J, Ryan N, Axelson D, Strober M, Leonard H, Sindelar H, Keller M. Child comorbidity, maternal mood disorder, and perceptions of family functioning among bipolar youth. J Am Acad Child Adolesc Psychiatry. 2006; 45(8):955-64.

Faraone S, Glatt S, Tsuang M. The genetics of pediatric-onset bipolar disorder. Biol Psychiatry. 2003;53(11):970-7.

Faraone SV, Biederman J, Wozniak J, Mundy E, Mennin D, O’Donnell D. Is comorbidity with ADHD a marker for juvenile-onset mania? J Am Acad Child Adolesc Psychiatry. 1997;36(8):1046-1055.

Fleitlich B, Goodman R. Prevalence of Child and Adolescent Psychiatric Disorders in Southeast Brazil. J Am Acad Child Adolesc Psychiatry, 2004;43 (6): 727-734.

Frank E. Treating bipolar disorder: A clinician's guide to interpersonal and social rhythm therapy. NewYork: Guilford Publications; 2005.

Frank E, Swartz HA, Kupfer DJ. Interpersonal and social rhythm therapy: managing the chaos of bipolar disorder. Biol Psychiatry. 2000;48(6):593-604.

Friedmann MS, Goldstein MJ. Relatives' awareness of their own expressed emotion as measured by a self-report adjective checklist. Fam Process. 1993;32(4): 459-471.

Fristad MA. Psychoeducational treatment for school-aged children with bipolar disorder. Dev Psychopathol. 2006;18:1289-1306. 
Fristad MA, Arnett MM, Gavazzi SM. The impact of psychoeducational workshops on families of mood-disordered children. Fam Ther 1998a;25(3):151-159.

Fristad MA, Gavazzi SM, Soldano KW. Multi-family psychoeducation groups for childhood mood disorders: Program description \& preliminary efficacy data. Contemporary Family Therapy, 1998b;20(3):385-402.

Fristad MA, Goldberg-Arnold JS, Gavazzi SM. Multi-family psychoeducation groups (MFPG) in the treatment of children with mood disorders. J Marital Fam Ther. 2003;29(4):491-504.

Fristad M, Verducci J, Walters K, Matthew E, Young MA. Impact of multifamily psychoeducational psychotherapy in treating children aged 8 to 12 years with mood disorders. Arch Gen Psychiatry. 2009;66(9):1013-1021.

Geller B, Bolhofner K, Craney JL, Williams M, DelBello MP, Gundersen K. Psychosocial functioning in a prepubertal and early adolescent bipolar disorder phenotype. J Am Acad Child Adolesc Psychiatry. 2000b;39(12):1543-1548.

Geller B, Craney JL, Bolhofner K, Nickelsburg MJ, Williams M, Zimerman B. Twoyear prospective follow-up of children with a prepubertal and early adolescent bipolar disorder phenotype. Am J Psychiatry. 2002a;159(6):927-933.

Geller B, Tillman R, Bolhofner K, Zimerman B. Child bipolar I disorder: prospective continuity with adult bipolar I disorder; characteristics of second and third episodes; predictors of 8-year outcome. Arch Gen Psychiatry. 2008;65(10):1125-1133.

Geller B, Tillman R, Craney JL, Bolhofner K. Four year prospective outcome and natural history of mania in children with a prepubertal and early adolescent bipolar disorder phenotype. Arch Gen Psychiatry. 2004;61(5):459-467. 
Geller B, Zimerman B, Williams M, Bolhofner K, Craney JL, Delbello MP, Soutullo CA. Diagnostic characteristics of 93 cases of a prepubertal and early adolescent bipolar disorder phenotype by gender, puberty and comorbid attention deficit hyperactivity disorder. J Child Adolesc Psychopharmacol. 2000a;10(3):157-64.

Geller B, Zimerman B, Williams M, DelBello MP, Bolhofner K, Craney JL, Frazier J, Beringer L, Nickelsburg MJ. DSM-IV mania symptoms in a prepubertal and early adolescent bipolar disorder phenotype compared to attention-deficit hyperactive and normal controls. J Child Adolesc Psychopharmacol. 2002c;12(1):11-25.

Geller B, Zimerman B, Williams M, Delbello MP, Frazier J, Beringer L. Phenomenology of prepubertal and early adolescent bipolar disorder: examples of elated mood, grandiose behaviors, decreased need for sleep, racing thoughts and hypersexuality. J Child Adolesc Psychopharmacol. 2002b;12(1): 3-9.

Goldstein TR, Birmaher B, Axelson D, Ryan ND, Strober MA, Gill MK, Valeri S, Chiappetta L, Leonard H, Hunt J, Bridge JA, Brent DA, Keller M. History of suicide attempts in pediatric bipolar disorder: Factors associated with increased risk. Bipolar Disord. 2005;7(6):525-535.

Goossens PJ, Van Wijngaarden B, Knoppert-van der Klein EA, Van Achterberg T. Family caregiving in bipolar disorder: caregiver consequences, caregiver coping styles, and caregiver distress. Int J Soc Psychiatry. 2008; 54(4): 303-16.

Guy W. In NCDEU Assessment Manual for Psychopharmacology. Rockville, MD: NIMH; 1976.

Hollingshead AB. Four Factor Index of Social Status. Yale: Yale University, Working paper, 1976.

Honig A, Hofman A, Hilwig M, Noorthoorn E, Ponds R. Psychoeducation and expressed emotion in bipolar disorder, preliminary findings. Psychiatry Res. $1995 ; 56(3): 299-301$. 
Honig A, Hofman A, Rozendaal N, Dingemans P. Psycho-education in bipolar disorder: Effect on expressed emotion. Psychiatry Res. 1997;72(1):17-22.

Hooley J, Gotlib I. A diathesis-stress conceptualization of expressed emotion and clinical outcome. Journal of Applied and Preventive Psychology. 2000;9:135-151.

Hooley J, Phil D. Expressed Emotion and Locus of Control. Journal of Nervous \& Mental Disease. 1998;186(6):374-378.

Hua LL, Wilens TE, Martelon M, Wong P, Wozniak J, Biederman J. Psychosocial functioning, familiality, and psychiatric comorbidity in bipolar youth with and without psychotic features. J Clin Psychiatry. 2011; 72(3):397-405.

Hyun M, Friedman SD, Dunner DL. Relationship of childhood physical and sexual abuse to adult bipolar disorder. Bipolar Disord. 2000 Jun;2(2):131-5.

Jannuzzi P, Baeninger R. Qualificação socioeconômica de demográfica das classes da escala ABIPEME. Revista de Administração, São Paulo. 1996;31(3):82-90.

Jenkins JH, Karno M. The meaning of expressed emotion: Theoretical issues raised by cross-cultural research. Am J Psychiatry. 1992; 149(1), 9-21.

Johnson L, Lundstrom O, Aberg-Wistedt A, Mathe AA. Social support in bipolar disorder: its relevance to remission and relapse. Bipolar Disord. 2003;5(2):129-37.

Johnson SL, Winett CA, Meyer B, Greenhouse WJ, Miller I. Social support and the course of bipolar disorder. J Abnorm Psychology. 1999;108(4):558-66.

Kaufman J, Birmaher B, Brent D, Rao U, Flynn C, Moreci P, et al: Schedule for affectivedisorders and schizophrenia for schoolage children-present and lifetime version (KSADS-PL): initial reliability and validity data. J Am Acad Child Adolesc Psychiatry 1997; 36 (7): 980-988. 
Kavanagh D, O’Halloran P, Manicavasagar V, Clark D, Piatkowska D, Tennant C, Rosen A. The Family Attitude Scale: reliability and validity of a new scale for measuring the emotional climate of families. Psychiatry Res. 1997;70(3):185-195.

Kim EY, Miklowitz DJ. Expressed emotion as a predictor of outcome among bipolar patients undergoing family therapy. J Affect Disord. 2004;82(3):343-352.

Klaus N, Fristad MA. Family psychoeducation as a valuable adjunctive intervention for children with bipolar disorder. Directions in Psychiatry. 2005, 25(19): 217-230.

Kowatch RA, Fristad M, Birmaher B, Wagner KD, Findlind RL, Hellander M, Child Psychiatric Workgroup on Bipolar Disorder. Treatment guidelines for children and adolescents with bipolar disorder. J Am Acad Child Adolesc Psychiatry. 2005;44(3): 213-35.

Kowatch RA, Suppes T, Carmody TJ, Bucci JP, Hume JH, Kromelis M, Emslie GJ, Weinberg WA, Rush AJ. Effect size of lithium, divalproex sodium, and carbamazepina in children and adolescent with bipolar disorder. J Am Acad Child Adolesc Psychiatry. 2000;39(6):713-720.

Kuipers L. Expressed emotion: a review. Br J Soc Clin Psychol. 1979;18(2):237-43.

Leff J, Berkowitz R, Shavit N, Strachan A, Glass I, Vaughn C. A trial of family therapy versus a relative group for schizophrenia. Br J Psychiatry. 1989;154, 58-66.

Leff J, Vaughn C. The role of maintenance therapy and relatives' expressed emotion in relapse of schizophrenia: a 2-year follow up. Br J Psychiatry. 1981;139: 102-104.

Leff J, Wig NN, Ghosh A, Bedi H, Menon DK, Kuipers L, Ernberg G, Day R, Sartorius N, Jablensky A. Expressed emotion and schizophrenia in north India. III. Influence of relatives' expressed emotion on the course of illness in Chandigarh. $\mathrm{Br} J$ Psychiatry. 1987;151:166-173. 
Leibenluft E, Charney DS, Towbin KE, Bhangoo RK, Pine DS. Defining clinical phenotypes of juvenile mania. Am J Psychiatry. 2003;160(3):430-437.

Lewinsohn PM, Klein DN, Seeley JR. Bipolar disorders in a community sample of older adolescents: prevalence, phenomenology, comorbidity, and course. J Am Acad Child Adolosc Psychiatry. 1995;34(4):454-463.

Lewinsohn PM, Seeley JR, Klein DN. Bipolar disorder during adolescence. Acta Psychiatr Scand. 2003;418(Suppl.):47-50.

Lish JD, Dime-Meenan S, Whybrow PC, Price RA, Hirschfeld RM. The National Depressive and Manic-Depressive Association (DMDA) survey of bipolar members. J Affect Disord. 1994;31(4):281-294.

Magaña AB, Goldstein JM, Karno M, Miklowitz DJ, Jenkins J, Falloon IR. A brief method for assessing expressed emotion in relatives of psychiatric patients. Psychiatry Res. 1986;17(3):203-212.

Magliano L, Orrico A, Fiorillo A, Del Vecchio H, Castiello G, Malangone C, et al. Family burden in bipolar disorders: results from the Italian Mood Disorders Study (IMDS). Epidemiol Psichiatr Soc. 2009; 18(2): 137-46.

Marom S, Munitz H, Jones PB, Weizman A, Hermesh H. Expressed emotion: relevance to rehospitalization in schizophrenia over 7 years. Schizophr Bull. 2005;31(3):751-758.

Merikangas KR, Jin R, He JP, Kessler RC, Lee S, Sampson NA, Viana MC, Andrade LH, Hu C, Karam EG, Ladea M, Medina-Mora ME, Ono Y, Posada-Villa J, Sagar R, Wells JE, Zarkov Z. Prevalence and correlates of bipolar spectrum disorder in the world mental health survey initiative. Arch Gen Psychiatry. 2011;68(3):241-51.

Miklowitz DJ. Bipolar disorder: a family-focused treatment approach. Vol. 2. New York, NY: Guilford Press; 2008. 
Miklowitz DJ, Axelson DA, George EL, Taylor DO, Schneck CD, Sullivan AE, Dickinson LM, Birmaher B. Expressed emotion moderates the effects of familyfocused treatment for bipolar adolescents. J Am Acad Child Adolesc Psychiatry. 2009;48(6):643-651.

Miklowitz DJ, Johnson SL. Social and familial factors in the course of bipolar disorder: basic processes and relevant interventions Clin Psychol. (New York). 2009; 16(2): 281-96.

Miklowitz D, Goldstein MJ. Bipolar Disorder: A Family-Focused Treatment Approach. New York: Guilford; 1997.

Miklowitz DJ, Goldstein MJ, Doane JA, Nuechterlein KH, Strachan AM, Snyder KS, Magaña-Amato A. Is expressed emotion an index of a transactional process? I. Parents' affective style. Fam Process, 1989; 28(2):153-67.

Miklowitz DJ, Goldstein MJ, Nuechterlein KH, Snyder KS, Mintz J. Family factors and the course of bipolar affective disorder. Arch Gen Psychiatry. 1988;45(3):225231.

Miklowitz DJ, Simoneau TL, George EL, Richards JA, Kalbag A, Sachs-Ericsson N, Suddath R. Family-focused treatment of bipolar disorder: 1 - year effects of a psychoeducational program in conjunction with pharmacotherapy. Biol Psychiatry. 2000;48(6):582-592.

Mino Y, Shinodera S, Inoue S, Fujita H, Tanaka S, Kanazawa S. Expressed emotion of families and the course of mood disorders: A cohort study in Japan. J Affect Disord. 2001;63(1-3):43-49.

Minuchin S. Família: Funcionamento e tratamento. Porto Alegre: Artes Médicas, 1974. 
Minuchin S, Rosman B, Baker L. Psychosomatic Families. Harvard University Press, 1978.

Minuchin S, Fishman CH. Técnicas de Terapia Familiar. Porto Alegre: Artes Médicas, 1990

Montagna PK. Emoções expressas no ambiente familiar e evolução da esquizofrenia [Dissertação de mestrado]. São Paulo: Faculdade de Medicina, Universidade de São Paulo, 1981.

Moss RH. Conceptual and empirical approaches to developing family-based assessment procedures: Resolving the case of the Family Environment Scale. Fam Process. 1990;29(2):199-208.

Moos R. The Social Climate Scales: A user's guide. $3^{\text {rd }}$ ed. Menlo Park, CA: Mind Garden; 2003.

Moos RH, Moos BS. Family Environment Scale Manual and Sampler Set: Development, Applications and Research. Fourth Edition. Palo Alto, California: Center for Health Care Evaluation Department of Psychiatry and Behavioral Sciences Stanford University School of Medicine; 1974, 1994, 2002, 2009.

Moos RH, Moos BS. Family Environment Scale Manual and Sampler Set: Development, Applications and Research. Fourth Edition. Palo Alto, California: Center for Health Care Evaluation Department of Psychiatry and Behavioral Sciences Stanford University School of Medicine; 2009.

Moos RH, Moos BS. Family Environment Scale Manual, Third Edition. Palo Alto, CA: Consulting Psychologists Press, Inc; 1994. p. 96.

Moos RH, Moos BS. Family Environment Scale Manual. $3^{\text {rd }}$ ed. Palo Alto, CA: Mind Garden; 2002. 
Moos RH, Moos BS. Manual for the Family Environment Scale. Palo Alto, CA: Consulting Psychologists Press; 1974.

Ogburn KM, Sanches M, Williamson DE, Caetano SC, Olvera RL, Pliszka S, Hatch JP, Soares JC. Family Environment and Pediatric Major Depressive Disorder. Psychopathology. 2010 Jul 28;43(5):312-318.

Olson DH, Russell CS, Sprenkle DH. Circumplex model of marital and family systems: VI. Theoretical update. Fam Process. 1983;22(1):69-83.

Olson DH, Tiesel J. FACES II: Linear scoring and interpretation. Available from: Life Innovations, Family Inventories Project, P. O. Box 190, Minneapolis, MN 55440-0190; 1991.

Pavuluri MN, Graczyk PA, Henry DB, Carbray JA, Heidenreich J, Miklowitz DJ. Child- and family-focused cognitive-behavioral therapy for pediatric bipolar disorder: development and preliminary results. J Am Acad Child Adolesc Psychiatry. 2004;43(5):528-37.

Petersen AC, Crockett L, Richards M, Boxer A. A self-report measure of pubertal status: reliability, validity, and initial norms. J Youth Adolescence, 1988;17:117-33.

Pipher M. The shelter of each other: rebuilding our families. New York: Ballantine; 1997.

Piszezman ML. Família e estrutura: a abordagem estrutural e a terapia de família. In: Cerveny CMO. Família e... São Paulo: Casa do Psicólogo; 2006.

Poznanski EO, Freeman LN, Mokros HB. Children's depression rating scale revised. Psychopharmacol Bull. 1985; 21: 979-989.

Puig-Antich J, Lukens E. The psychosocial schedule for school-age children (ages 616). New York: State Psychiatric Institute (unpublished); 1978. 
Puig-Antich J, Lukens E, Brent D. Psychosocial Schedule for School Age ChildrenRevised in 1986 and 1987. Pittsburgh, PA: Western Psychiatric Institute and Clinic; 1986.

Rabinowitz J, Bromet EJ, Lavelle J, Carlson G, Kovasznay B, Schwartz JE. Prevalence and severity of substance use disorders and onset of psychosis in firstadmission psychotic patients. Psychol Med. 1998;28(6):1411-19.

Rich BA, Vinton DT, Roberson-Nay R, Hommer RE, Berghorst LH, McClure EB, Fromm SJ, Pine DS, Leibenluft E. Limbic hyperactivation during processing of neutral facial expressions in children with bipolar disorder. Proc Natl Acad Sci USA. 2006;103(23):8900-5.

Robertson HA, Kutcher SP, Bird D, Grasswick L. Impact of early onset bipolar disorder on family functioning: adolescents' perceptions of family dynamics, communication, and problems. J Affect Disord. 2001; 66(1):25-37.

Rocca CC, van den Heuvel E, Caetano SC, Lafer B. Facial emotion recognition in bipolar disorder: a critical review. Rev Bras Psiquiatr. 2009;31(2):171-80.

Romero S, Delbello MP, Soutullo CA, Stanford K, Strakowski SM. Family environment in families with versus families without parental bipolar disorder: a preliminary comparison study. Bipolar Disord. 2005;7(6):617-622.

Roosa MW, Beals J. Measurement issues in family assessment: the case of the Family Environment Scale. Fam Process. 1990; 29(2):191-8.

Rutter M, Brown GW. Reliability and validity of measures of family life and relationships in families containing apsychiatric patient. Soc Psychiat. 1966:1:38-53.

Saeki T, Asukai N, Miyake Y, Miguchi M, Yamawaki S. Characteristics of family functioning in patients with endogenous monopolar depression. Hiroshima J Med Sci. 2002; 51(2): 55-62. 
Satir V. The new people making. Mountain View, CA: Science and Behavior books, Inc., 1988.

Scazufca M. Avaliação de emoção expressa (EE) em familiares de pacientes psicóticos. Rev Psiq Clin. 1998; 25(6) Edição Especial: 368-373.

Schenkel L, West AE, Harral EM, Patel NB, Pavuluri MN. Parent-child interactions in pediatric bipolar disorder. J Clin Psychol. 2008;64(4): 422-437.

Shaffer D, Gould MS, Brasic J, Ambrosini P, Fisher P, Bird H, Aluwahlia S. A Children's Global Assessment Scale (CGAS). Arch Gen Psychiatry. 1983;40(11): $1228-1231$.

Simoneau TL, Miklowitz DJ, Saleem R. Expressed emotion and interactional patterns in the families of bipolar patients. J Abnorm Psychol. 1998;107(3):497-507.

Sluzki CE. Process, structure and world views in family therapy: toward and integration of systemic models in family therapy. Fam Process. 1983;22(4):469-476.

Strakowski SM, Williams JR, Sax KW, Fleck DE, DelBello MP, Bourne ML. Is impaired outcome following a first manic episode due to mood-incongruent psychosis? J. Affect. Disord. 2000;61(1-2): 87-94.

Sullivan AE, Miklowitz DJ. Family functioning among adolescents with bipolar disorder. J Fam Psychol. 2010;24(1):60-67.

Tarrier N, Barrowclough C, Vaughn CE, Bamrah JS, Porceddu K, Watts S, Freeman H. The community management of schizophrenia: A controlled trial of a behavioural intervention to reduce relapse. Br J Psychiatry. 1988;153:532-542.

Tillman R, Geller B. Definitions of rapid, ultrarapid, and ultradian cycling and of episode duration in pediatric and adult bipolar disorders: a proposal to distinguish episodes from cycles. J Child Adolesc Psychopharmacol. 2003;13(3):267-271. 
Tohen M, Frank E, Bowden CL, Colom F, Ghaemi SN, Yatham LN, et al. The International Society for Bipolar Disorder (ISBD) Task Force report on the nomenclature of course and outcome in bipolar disorders. Bipolar Disord. 2009; $11(5): 453-73$

Ulloa RE, Birmaher B, Axelson D, Williamson DE, Brent DA, Ryan ND, Bridge J, Baugher M. Psychosis in a pediatric mood and anxiety disorders clinic: phenomenology and correlates. J Am Acad Child Adolesc Psychiatry. 2000;39(3): $337-45$.

Vasconcellos MJ. Pensamento Sistêmico - O Novo Paradigma da Ciência. São Paulo: Papirus; 2002.

Vaughn C. Patterns of emotional response in the families of schizophrenic patients. In: Goldstein M, Hand I, Hahlweg K (eds). Treatment of Schizophrenia. New York: Springer-Verlag, 1986.

Vaughn C, Leff J. The measurement of expressed emotion in the families of psychiatric patients. Br J Soc Clin Psychol. 1976;15(2):157-165.

Vianna VP, Silva EA, Souza-Formigoni ML. Portuguese version of the Family Environment Scale: aplication and validation. Rev Saúde Pública. 2007;41(3):419426.

Vilela J, Loureiro S. Escala de Avaliação de Mania de Young - Estudo das qualidades psicométricas da versão brasileira. Therapeutics. 1999;24:433-43.

Walsh F. (org) Normal Family Processes: Growing Diversity and Complexity. $3^{\text {rd }}$ ed. New York: The Guilford Press; 2003.

Walsh F. Fortalecendo a Resiliência Familiar. São Paulo: Editora Roca; 2005. 
Watzlwick P, Beavin B, Jackson D. Pragmática da Comunicação Humana. São Paulo: Cultrix; 1973.

Weisman A, López SR, Karno M, Jenkins J. An attributional analysis of expressed emotion in Mexican-American families with schizophrenia. J Abnorm Psychol. 1993; 102(4):601-606.

Weisman AG, Nuechterlein KH, Goldstein MJ, Snyder KS. Controllability perceptions and reactions to symptoms of schizophrenia: a within-family comparison of relatives with high and low expressed emotion. J Abnorm Psychol. 2000;109(1): 167-171.

Weisman AG, Nuechterlein KH, Goldstein MJ, Snyder KS. Expressed emotion, attributions, and schizophrenia symptom dimensions. J Abnorm Psychol. 1998; 107(2):355-359.

Wendel JS, Miklowitz DJ, Richards JA, George EL. Expressed emotion and attributions in the relatives of bipolar patients: An analysis of problem-solving interactions. J Abnorm Psychol. 2000;109(4):792-796.

Wechsler D. Wechsler Abbreviated Scale of Intelligence (WASI). San Antonio: The Psychological Corporation / Harcourt Brace \& Company; 1999.

Wozniak J, Faraone SV, Mick E, Monuteaux M, Coville A, Biederman J. A controlled family study of children with DSM-IV bipolar-I disorder and psychiatric co-morbidity. Psychol Med. 2010;40(7):1079-88.

Yan LJ, Hammen C, Cohen AN, Daley SE, Henry RM. Expressed emotion versus relationship quality variables in the prediction of recurrence in bipolar patients. $J$ Affect Disord. 2004;83(2-3):199-206. 
Yap MB, Allen NB, Sheeber L. Using an emotion regulation framework to understand the role of temperament and family processes in risk for adolescent depressive disorders. Clin Child Fam Psychol Rev. 2007;10(2):180-96.

Young RC, Biggs JT, Ziegler VE, Meyer DA. A rating scale for mania: reliability, validity and sensitivity. Br J Psychiatry. 1978;133:429-35.

\section{Documentos eletrônicos:}

ANEP - Associação Nacional de Empresas de Pesquisa - Dados com base no Levantamento Sócio Econômico - 2000 - IBOPE acessado em: 01/05/2011. http://www.datavale-sp.com.br/CCEB.pdf

http://www.scribd.com/doc/53208537/Criterio-de-Classificacao-Economica-Brasil$\underline{\text { ABEP-2010 }}$

Site $\quad$ Cetelem $\quad-\quad$ acessado em: 01/05/2011. http://www.cetelem.com.br/portal/Sobre_Cetelem/Observador.shtml

Site UOL - Fonte IBGE: Taxa de divórcio tem leve queda Evolução do número de divórcios no Brasil acessado em: 19/12/2010. http://noticias.uol.com.br/cotidiano/2010/11/12/em-2009-para-cada-cincocasamentos-houve-um-divorcio-no-brasil-revelaibge.jhtmhttp://noticias.uol.com.br/cotidiano/2010/11/12/em-2009-para-cada-cincocasamentos-houve-um-divorcio-no-brasil-revela-ibge.jhtm 